\title{
WestVirginiaUniversity
}

THE RESEARCH REPOSITORY @ WVU

Graduate Theses, Dissertations, and Problem Reports

2006

\section{Relationship between damper resistance and damper insertion depth}

Ranjit Jangam

West Virginia University

Follow this and additional works at: https://researchrepository.wvu.edu/etd

\section{Recommended Citation}

Jangam, Ranjit, "Relationship between damper resistance and damper insertion depth" (2006). Graduate Theses, Dissertations, and Problem Reports. 4235.

https://researchrepository.wvu.edu/etd/4235

This Thesis is protected by copyright and/or related rights. It has been brought to you by the The Research Repository @ WVU with permission from the rights-holder(s). You are free to use this Thesis in any way that is permitted by the copyright and related rights legislation that applies to your use. For other uses you must obtain permission from the rights-holder(s) directly, unless additional rights are indicated by a Creative Commons license in the record and/ or on the work itself. This Thesis has been accepted for inclusion in WVU Graduate Theses, Dissertations, and Problem Reports collection by an authorized administrator of The Research Repository @ WVU. For more information, please contact researchrepository@mail.wvu.edu. 


\title{
Relationship between Damper Resistance and Damper Insertion Depth
}

\author{
Ranjit Jangam \\ Thesis Submitted to the \\ College of Engineering and Mineral Resources at \\ West Virginia University \\ in partial fulfillment of the requirements \\ for the degree of \\ Master of Science \\ in \\ Industrial Engineering \\ Steven Guffey Ph.D., Chair \\ Robert Creese Ph.D. \\ Kenneth Means Ph.D. \\ Department of Industrial Engineering \\ Morgantown, West Virginia \\ 2006
}

Keywords: Slide-Gate Dampers, Relation between Damper Resistance and Damper Insertion Depth, Damper Edge, Duct Diameter, Airflow Levels, Velocity Pressure, Static Pressure, Total Pressure 


\section{Abstract \\ Relationship between Damper Resistance and Damper Insertion Depth}

\section{Ranjit Jangam}

Experiments were performed to determine a predictive model for sliding gate damper resistance $\left(\mathrm{X}_{\text {damper }}\right)$. Independent variables included eight ratios of insertion depth (I) to duct diameter (D), two different values of $\mathrm{D}$, four different levels of air velocity, two damper orientations, and two damper edges (Concave/Straight). Analysis of $\log \left(\mathrm{X}_{\text {damper }}\right)$ values showed a highly linear relationship with I/D and high statistical significance $(\mathrm{p}<0.05)$ for all independent variables and for most two-way interactions. Nearly the entire regression model $\left(R^{2}=0.985\right)$ was explained by $I / D$, so all but $I / D$ and Edge were dropped from the final model: $Y_{\log (\text { Xdanper })}=-1.434+0.089 *(E d g e)+4.30 *\left(\frac{I}{D}\right)\left(\mathrm{R}^{2}\right.$ $=0.978)$. The resulting predictive model: $X_{\text {damper }}=0.037^{*} 10^{\left(0.089^{*}(E d g e)+4.3 * \frac{I}{D}\right)}$. However error for untransformed $X_{\text {damper }}$ increased sharply with increasing (I/D) and percent errors were as high as $125 \%$ across all values of (I/D). Hence the predictive models are useful for only initial rough adjustment and should be followed by final trial and error adjustment to goal air flow. 


\section{Acknowledgements}

The author wishes to thank the following for their support: Nordfab for donating the ductwork, the graduate committee members for their advice and input and James Dalton for machining the concave edge of the damper to a straight edge. 


\section{Table of Contents}

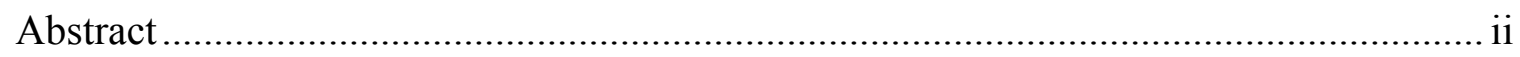

Acknowledgements.............................................................................................ii

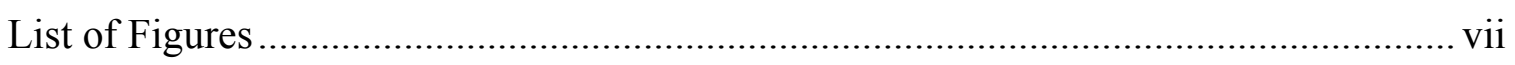

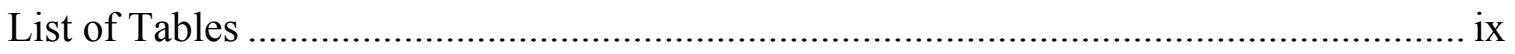

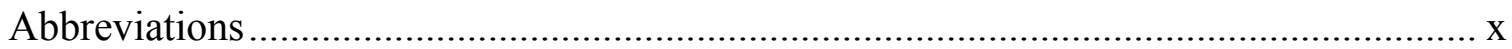

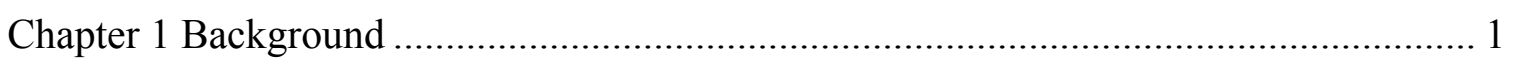

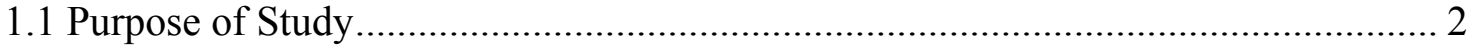

1.2 Characteristics of Slide-Gate Dampers............................................................. 3

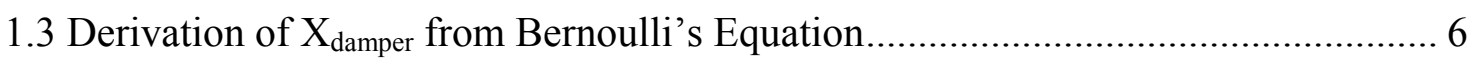

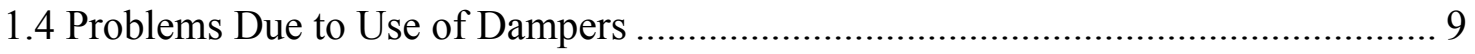

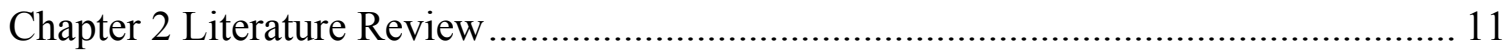

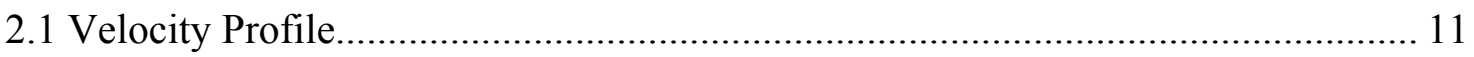

2.2 Published Damper Resistance Values .................................................................. 12

Chapter 3 Apparatus ………………………………………................................. 18

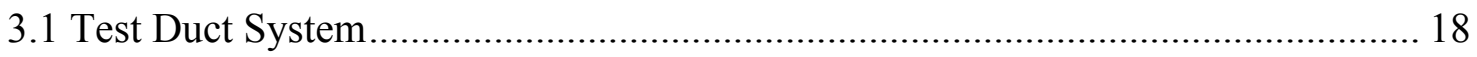

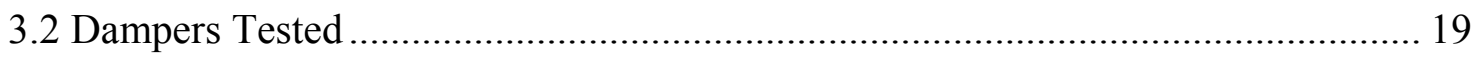

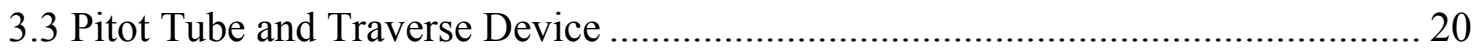

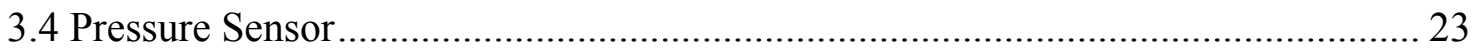

3.5 Devices to Measure Environmental Conditions ...................................................... 24

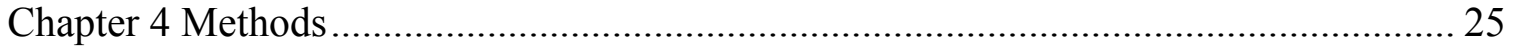

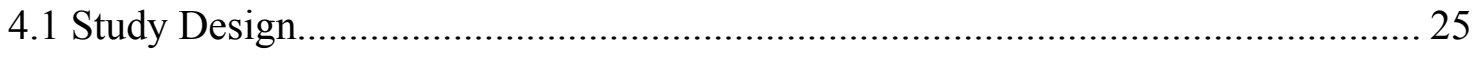

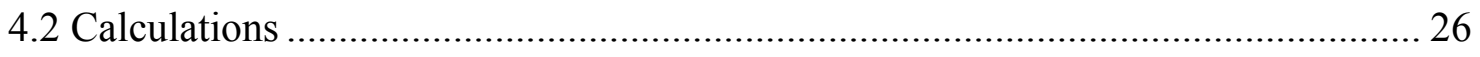

4.2.1 Density Factor Calculation........................................................................... 26

4.2.2 Average Velocity Calculation ........................................................................ 27

4.2.3 Average Velocity Pressure Calculation........................................................... 28

4.2.4 Total Pressure ( $\Delta \mathrm{TP})$ Calculation................................................................ 28

4.2.5 Damper Resistance $\left(\mathrm{X}_{\text {damper }}\right)$ Calculation......................................................... 28

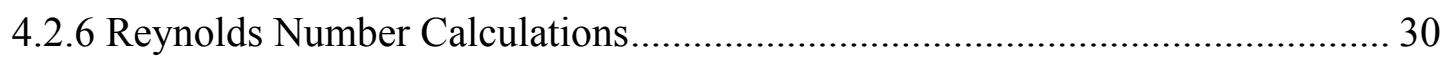


4.2.7 Pipe Factor Calculations............................................................................... 30

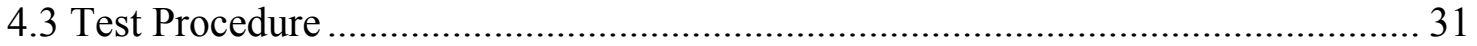

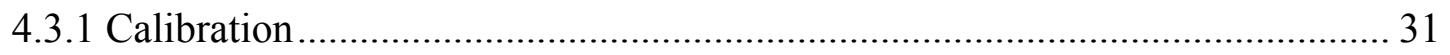

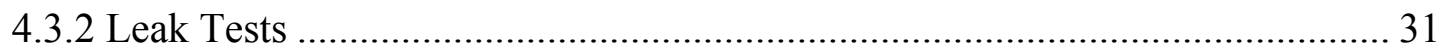

4.3.3 Preparation for Data Collection.................................................................... 32

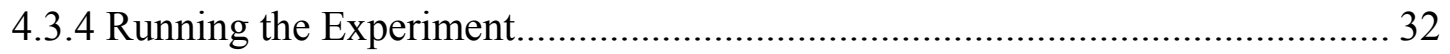

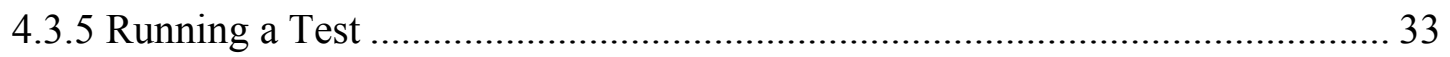

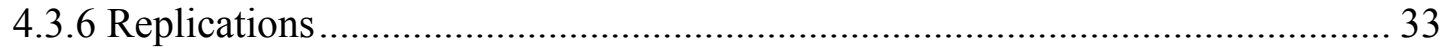

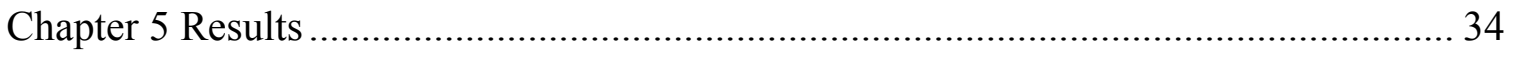

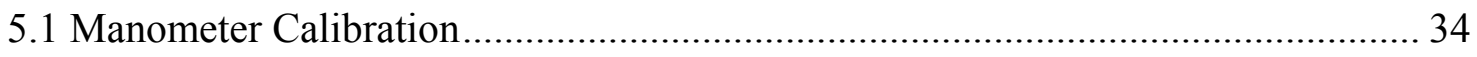

5.2 Characteristics of Velocity Measurements ................................................................ 35

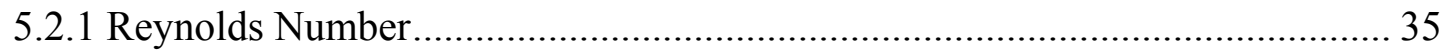

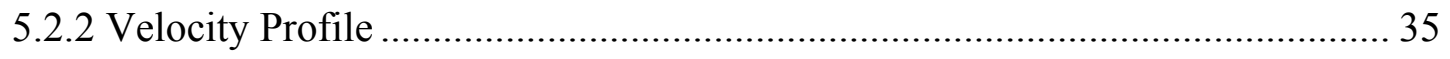

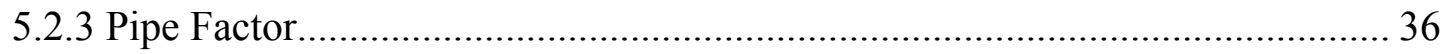

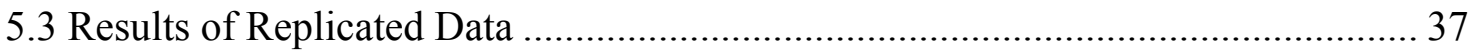

5.4 Results of Relationship between $\mathrm{X}_{\text {damper }}$ and Relative Insertion Depth (I/D) - For

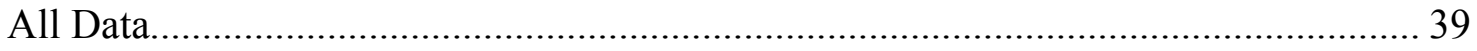

5.5 Effect of (I/D) and remaining Independent Variables on $\log \left(\mathrm{X}_{\text {damper }}\right) \ldots \ldots \ldots \ldots \ldots \ldots . . . . .41$

5.5.1 Effect of (I/D) and Damper Edges (Edge) on Log $\left(\mathrm{X}_{\text {damper }}\right)$............................ 42

5.5.2 Effect of (I/D) and Air Flow Levels (VP $\left.\mathrm{VL}_{\text {Clopen }}\right)$ on Log $\left(\mathrm{X}_{\text {damper }}\right)$..................... 43

5.5.3 Effect of (I/D) and Damper Orientation (Orient) on Log $\left(\mathrm{X}_{\text {damper }}\right)$................... 44

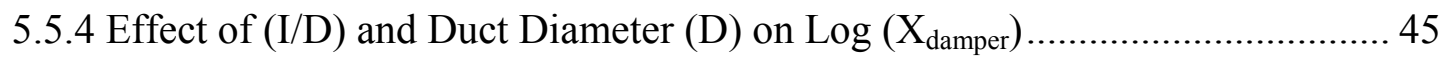

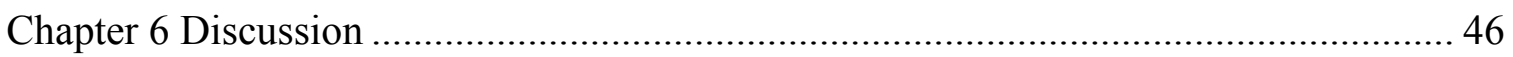

6.1 Normality of Residuals for Log-transformed Data.................................................. 46

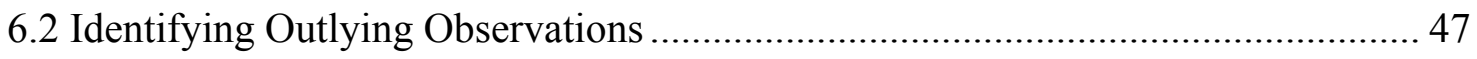

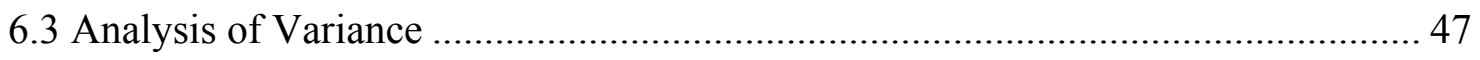

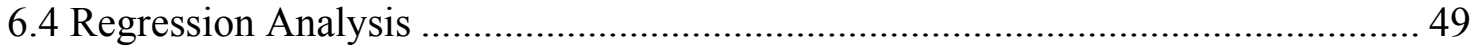

6.4 Reduced Regression Analysis Based on $\mathrm{R}^{2}$..................................................... 50

6.5 Non Log-Transformed Predictive Models........................................................... 54

6.5.1 Predictive Models for $\mathrm{X}_{\text {damper }}$........................................................................ 54

6.5.2 Complete Regression Model ............................................................................ 55 


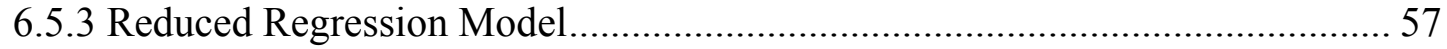

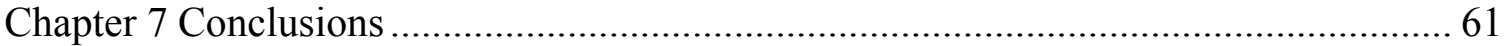

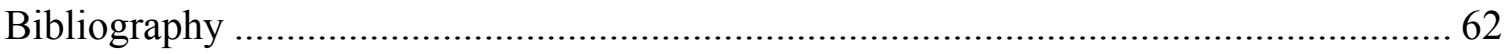

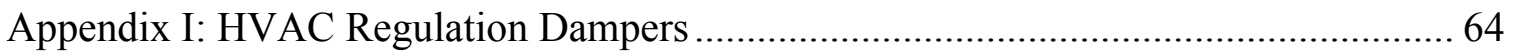

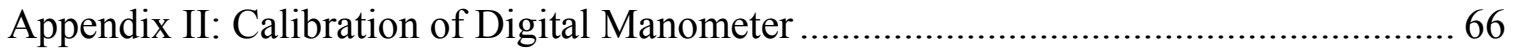

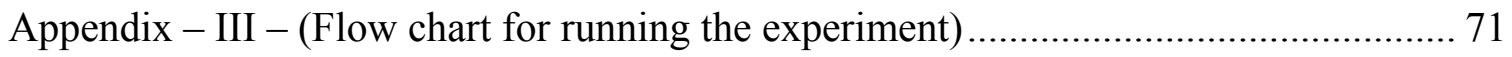

Appendix - IV - Replication Combinations..................................................... 72

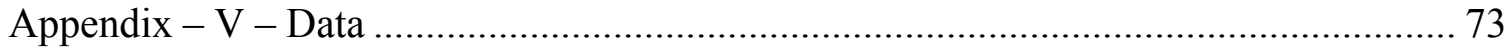




\section{List of Figures}

Figure 1 - Slide gate damper similar to those used in this study (Guffey, 2005)............. 4

Figure 2 - Flow around a slide gate damper (Guffey, 2005) ..................................... 5

Figure 3 - Different leading edges of sliding gate dampers ..................................... 6

Figure 4 - Laminar flow and turbulent flow velocity profile ..................................... 11

Figure 5 - Change in resistance with damper insertion depth (Guffey, 1999) ................ 12

Figure 6 - Graph of Idelchik (1972) Table Values....................................................... 14

Figure 7 - Log $\left(X_{\text {damper }}\right)$ V/S Insertion Depth/Duct Diameter (Idelchik, 1972) .............. 15

Figure 8 - Influence of face velocity on $C_{o}$ (Robert Van Becelaere 2005) ..................... 16

Figure 9 - Variation of $C_{o}$ with opposed blade damper (Robert Van Becelaere 2005)... 16

Figure 10- Variation of $C_{o}$ with parallel blade damper (Robert Van Becelaere 2005).... 17

Figure 12 - Duct system used for the study......................................................... 19

Figure 13 - Slide gate damper (Model No. 3241) used in the study .............................. 20

Figure 14 - Pitot tube sketch - similar to the one used in the study .............................. 20

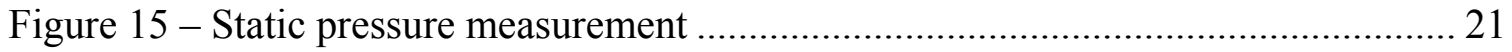

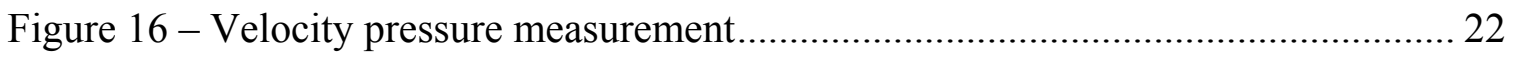

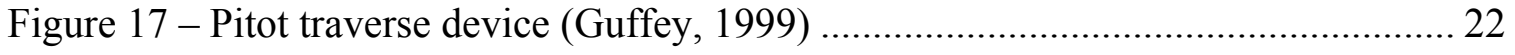

Figure 18 - Digital Manometer (Model 8702) ........................................................... 23

Figure 19 - Hook Gaze (Dwyer Instruments - Model No. 1425) ................................. 23

Figure 20 - Exhaust Ventilation System in Ventilation and Exposure Assessment

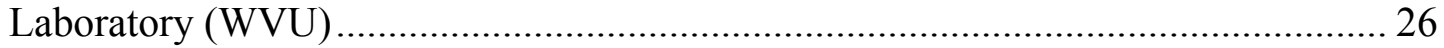

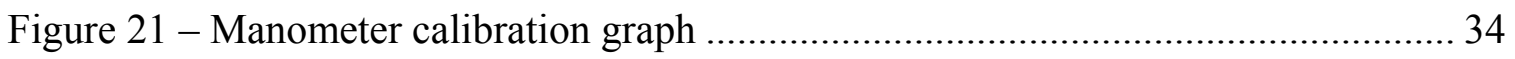

Figure 22 - Velocity Profile for $\mathrm{D}=4.85$ ", $\mathrm{VP}_{\mathrm{CLopen}}=2.103$ ” of w.g., Side 1 and Concave

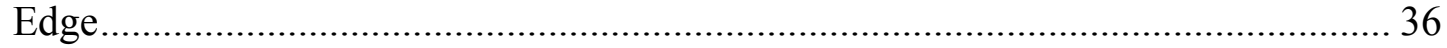

Figure $24-\mathrm{X}_{\text {damper }} \mathrm{V} / \mathrm{S}$ (I/D) for original and replicated data.................................. 38

Figure $25-\log \left(\mathrm{X}_{\text {damper }}\right) \mathrm{V} / \mathrm{S}(\mathrm{I} / \mathrm{D})$ for original and replicated data............................. 39

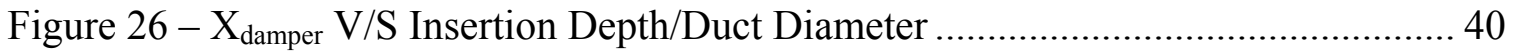

Figure 27 - Log $\left(\mathrm{X}_{\text {damper }}\right) \mathrm{V} / \mathrm{S}$ Insertion Depth/Duct Diameter ..................................... 41

Figure 28 - Log cell means for damper edges...................................................... 42 


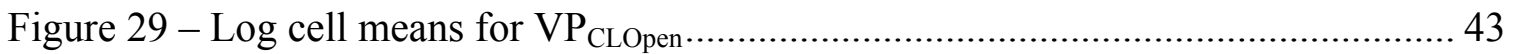

Figure 30 - Log cell means for damper orientation...................................................... 44

Figure 31 - Log cell means for duct diameter ............................................................. 45

Figure 32 - Normal Probability Plot for $X_{\text {damper }}$........................................................... 46

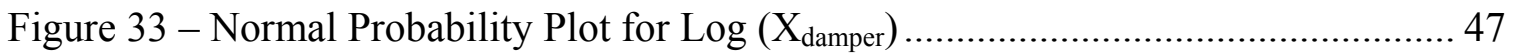

Figure 34 - Predicted Log $\left(\mathrm{X}_{\text {damper }}\right) \mathrm{V} / \mathrm{S}$ Observed $\log \left(\mathrm{X}_{\text {damper }}\right)$.................................. 50

Figure 35 - Predicted Log $\left(\mathrm{X}_{\text {damper }}\right) \mathrm{V} / \mathrm{S}$ Observed Log $\left(\mathrm{X}_{\text {damper }}\right)$ (Reduced Model) ....... 52

Figure 36 - Observed and Predicted $\left(\mathrm{X}_{\text {damper }}\right) \mathrm{V} / \mathrm{S}$ (I/D) (Complete Model) ................... 55

Figure 37 - Residuals $\left(\mathrm{X}_{\text {damper }}\right) \mathrm{V} / \mathrm{S}$ (I/D) (Complete Model) ......................................... 56

Figure 38 - Residuals $\left(\mathrm{X}_{\text {damper }}\right) \mathrm{V} / \mathrm{S}$ Predicted $\left(\mathrm{X}_{\text {damper }}\right)($ Complete Model $)$.................... 56

Figure 39 - Percent Error $\left(\mathrm{X}_{\text {damper }}\right) \mathrm{V} / \mathrm{S}(\mathrm{I} / \mathrm{D})($ Complete Model $)$.................................... 57

Figure 40 - Observed and Predicted $\left(\mathrm{X}_{\text {damper }}\right) \mathrm{V} / \mathrm{S}$ (I/D) (Reduced Model) ...................... 58

Figure 41 - Residuals $\left(X_{\text {damper }}\right)$ V/S Predicted $\left(X_{\text {damper }}\right)$ (Reduced Model $)$...................... 58

Figure 42-Residuals $\left(\mathrm{X}_{\text {damper }}\right) \mathrm{V} / \mathrm{S}(\mathrm{I} / \mathrm{D})$ (Reduced Model)............................................ 59

Figure 43 - Percent Error $\left(\mathrm{X}_{\text {damper }}\right) \mathrm{V} / \mathrm{S}$ (I/D) (Reduced Model) ....................................... 59

Figure 44 - Percent Error in Airflow V/S (I/D) (Reduced Model).................................. 60

Figure 45 - Back draft Damper and Outlet Control Damper............................................ 64

Figure 46 - Parallel Blade and Opposed Blade Outlet Dampers........................................ 65

Figure 47 - Nested Inlet Vane Damper and External Inlet Vane Damper ........................ 65 


\section{List of Tables}

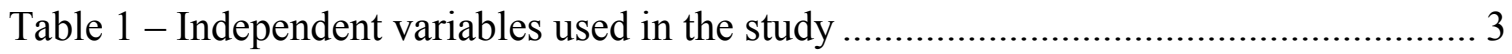

Table 2 - Damper insertion depth for 4.85" and 3.85" duct diameters ........................... 3

Table 3 - Recommended damper resistance values (Idelchik, 1972)........................... 13

Table 4: - Analysis of Variance with all Independent Variables .................................. 48

Table 5: - Analysis of Variance with Significant Independent Variables ...................... 49

Table 6: - $\mathrm{R}^{2}$ Analysis for Reduced Regression Model .............................................. 51 


\section{Abbreviations}

\begin{tabular}{|c|c|}
\hline $\mathrm{A}_{\text {open }}$ & Open area of the duct \\
\hline$A_{\text {total }}$ & Total area of the duct \\
\hline $\mathrm{C}_{\mathrm{o}}$ & Local loss coefficient \\
\hline $\mathrm{D}$ & Diameter of duct \\
\hline $\mathrm{df}$ & Density Factor \\
\hline Edge & Damper Edge \\
\hline $\mathrm{F}$ & Damper Resistance (Bernoulli) \\
\hline $\mathrm{I}$ & Insertion depth \\
\hline$(\mathrm{I} / \mathrm{D})$ & Insertion Depth/Duct Diameter (Relative Insertion Depth) \\
\hline Orient & Damper Orientation \\
\hline $\mathrm{P}$ & Pressure \\
\hline $\mathrm{P}_{\mathrm{bar}}$ & Barometric Pressure \\
\hline $\mathrm{PF}$ & Pipe Factor \\
\hline $\mathrm{P}_{\text {std. }}$ & Standard atmospheric pressure \\
\hline Q & Air Flow \\
\hline Re. & Reynolds Number \\
\hline $\mathrm{SP}_{\text {end }}$ & Static Pressure at the end of the duct \\
\hline $\mathrm{SP}_{\mathrm{h}}$ & Hood Static Pressure \\
\hline $\mathrm{T}$ & Temperature \\
\hline $\mathrm{TP}_{\text {loss }}$ & Total Pressure Loss \\
\hline $\mathrm{T}_{\text {std. }}$ & Standard atmospheric temperature \\
\hline $\mathrm{V}$ & Velocity of air in duct \\
\hline $\mathrm{V}_{\mathrm{CL}}$ & Centerline Velocity \\
\hline $\mathrm{V}_{\mathrm{avg}}$ & Average Velocity \\
\hline VP & Velocity Pressure \\
\hline $\mathrm{VP}_{\mathrm{avg}}$ & Average Velocity Pressure \\
\hline $\mathrm{VP}_{\text {CLopen }}$ & Air flow level \\
\hline
\end{tabular}




$\begin{array}{ll}\mathrm{X}_{\mathrm{br}} & \text { Branch Resistance } \\ \mathrm{X}_{\text {damper }} & \text { Damper Resistance } \\ \mathrm{X}_{\text {endwithdamper }} & \text { Damper Resistance with damper partially inserted } \\ \mathrm{X}_{\text {elbow }} & \text { Elbow Resistance } \\ \mathrm{X}_{\text {Friction }} & \text { Resistance due to friction } \\ \mathrm{X}_{\text {hood }} & \text { Hood Resistance } \\ \mathrm{X}_{\text {endwithoutdamper }} & \text { Damper resistance with damper fully open } \\ \Delta \mathrm{TP} & \text { Change in Total Pressure } \\ \rho & \text { Density } \\ v & \text { Viscosity of air }\end{array}$




\section{Chapter 1 Background}

Dampers are ventilation devices that can be used to adjust the airflows through the branches in a duct system. Dampers have been used in ventilation systems for at least fifty years (Geiger). SMACNA (1993) defines a damper as a device that varies the volume of air passing through an air outlet, air inlet, or duct. Dampers reduce the airflow to a given branch by adding to its resistance to flow. Increasing resistance of a branch duct reduces the flows to that branch and increases flows in all other branches (Guffey, 1993). Withdrawing the dampers has the reverse effect. According to Robert Van Becelaere (2005), an ideal damper is one which produces no resistance to airflow when wide open and can provide substantial resistance to the system upon partial closure. By proper adjustment of all dampers in a system, the user can force the airflows through the different branches to achieve a desired distribution of airflows.

There are different designs of adjustable dampers that can be used in exhaust ventilation systems including butterfly dampers, splitter dampers and shutter dampers (Haines, 1988). Butterfly dampers are used in branches and resemble flue dampers found in residential chimneys. Butterfly dampers swivel about an axis to block airflow either completely or partially. If the axis of the butterfly dampers is perpendicular to the duct then the resistance is maximum and if it is aligned to the duct then there is minimal resistance. Splitter dampers are used in "Y" shaped junctions to block airflow from one branch, but their use is discouraged in favor of dampers in each branch. Shutter dampers are commonly used for control of smoke, fire, and hot gases at points where ductwork passes through one wall into another area(Geiger).

The most common dampers used for contaminant control ventilation are slide-gate dampers. Slide-gate dampers are preferred in exhaust ventilation because of their ease of adjustment. Butterfly dampers are more likely to promote plugging and also vibrate at high velocities unless rigidly constructed. As demonstrated by Crowder and Loudermilk (1982) and by Idelchik (1972), as the damper insertion depth increases, damper resistance 
$\left(\mathrm{X}_{\text {damper }}\right)$ also increases. However the mathematical relationship between damper insertion depth and $X_{\text {damper }}$ to which this increase takes place has not been shown. Further it is not clear to what design of dampers their results apply. This study investigates slide gate damper resistance.

\subsection{Purpose of Study}

The study determines the relationship between damper resistance and damper insertion depth for slide gate dampers. The study will analyze the following statistical model.

Statistical model:

$$
\begin{aligned}
& \log \left(\mathrm{X}_{\text {damper-ijklm }}\right)=\mathrm{C}_{0}+\mathrm{C}_{1} *(\mathrm{I})_{\mathrm{i}}+\mathrm{C}_{2} *(1 / \mathrm{D})_{\mathrm{j}}+\mathrm{C}_{3} *\left(\mathrm{VP}_{\mathrm{CLopen}}\right)_{\mathrm{k}}+\mathrm{C}_{4} *(\text { Edge })_{1}+ \\
& \mathrm{C}_{5} *(\text { Orient })_{\mathrm{m}}+\mathrm{e}_{\mathrm{ijklm}} \\
& \text { Where } \mathrm{C}_{0}, \mathrm{C}_{1}, \mathrm{C}_{2}, \mathrm{C}_{3}, \mathrm{C}_{4}, \mathrm{C}_{5}=\text { Constants, } \\
& \mathrm{e}=\text { Residual error, } \\
& \mathrm{Edge}=\text { Damper edge } \\
& \mathrm{VP}_{\mathrm{CLopen}}=\text { Open level of airflow (inches of w.g. }) \\
& \text { Orient }=\text { Damper Orientation } \\
& \mathrm{I}=\text { Insertion depth (inches) }, \\
& \mathrm{D}=\text { Duct diameter (inches) }
\end{aligned}
$$

Where $\mathrm{i}=1,2,3,4,5,6,7,8 ; \mathrm{j}=1,2 ; \mathrm{k}=1,2,3,4 ; 1=1,2$; and $\mathrm{m}=1,2$;

Damper insertion depth (I), airflow level ( $\left.\mathrm{VP}_{\mathrm{CLopen}}\right)$, duct diameter (D), damper orientation (Orient) and edge of the damper (Edge) are the independent variables considered for this study. The levels for each are shown in Table 1. Two levels of diameter ( 3.85 and 4.85 inches) have been used for the study as the fan used to provide the airflow in the study has capacity to pull air for duct diameters up to 4.85 inches. Two edges (straight and concave) have been considered as they are used in the industry. Orientation has been used as a variable to see if the side of the test damper has any significance on $\mathrm{X}_{\text {damper }}$. Both 4.85 " and 3.85" diameter duct damper slides were inserted to eight insertion depths, including having the damper in fully open position. The eight 
damper insertion depths were obtained on the assumption that the damper resistance is proportional to the log insertion depth. If that is true, then the insertion depths will be evenly spaced in a logarithm (I/D) relationship. The damper insertion depths for both the duct diameters are shown in Table 2.

Table 1 - Independent variables used in the study

\begin{tabular}{|c|c|c|c|c|c|}
\hline \multirow{2}{*}{ Number } & \multirow{2}{*}{ Independent Variables } & \multicolumn{4}{|c|}{ Levels } \\
\cline { 3 - 6 } & & Level 1 & Level 2 & Level 3 & Level 4 \\
\hline 1 & Duct Diameter & $3.85^{\prime \prime}$ & $4.85^{\prime \prime}$ & - & - \\
\hline 2 & Damper Edge & Concave & Straight & - & - \\
\hline 3 & $V_{\text {CLopen }}$ Level of Air Flow & $2.103 "$ of w.g. & 1.01 " of w.g. & 0.51 " of w.g. & $0.255^{\prime \prime}$ of w.g. \\
\hline 4 & Damper Orientation & Side 1 & Side 2 & - & - \\
\hline 5 & Insertion Depth & \multicolumn{6}{|c|}{ Eight Insertion depths including the damper fully open position } \\
\hline
\end{tabular}

Table 2 - Damper insertion depth for 4.85” and 3.85” duct diameters

\begin{tabular}{|c|c|c|c|}
\hline \multirow{2}{*}{ Number } & \multicolumn{2}{|c|}{ Insertion Depth (inch) } & \multirow{2}{*}{ (I/D) \% } \\
\cline { 2 - 3 } & $\mathbf{4 . 8 5}$ " duct & $\mathbf{3 . 8 5}$ " duct & \\
\hline 1 & 0 & 0 & 0 \\
\hline 2 & 0.65 & 0.5 & 13 \\
\hline 3 & 0.85 & 0.7 & 18 \\
\hline 4 & 1.2 & 0.9 & 24 \\
\hline 5 & 1.5 & 1.2 & 32 \\
\hline 6 & 2.3 & 1.8 & 47 \\
\hline 7 & 3.1 & 2.5 & 63 \\
\hline 8 & 4.1 & 3.2 & 84 \\
\hline
\end{tabular}

\subsection{Characteristics of Slide-Gate Dampers}

In a slide-gate damper (see Figure 1), the slide is inserted perpendicular to the flow. As the air flows around the slide, it separates from the duct downstream of the slide. The slide-gate, also called "blast-gate or cut-off" damper, is completely out of the air stream when open, yet effectively seals the branch when shut (Haines, 1988). The region where 
the air separates from the duct downstream of the slide when the slide is inserted in to the duct is called the "separation region".

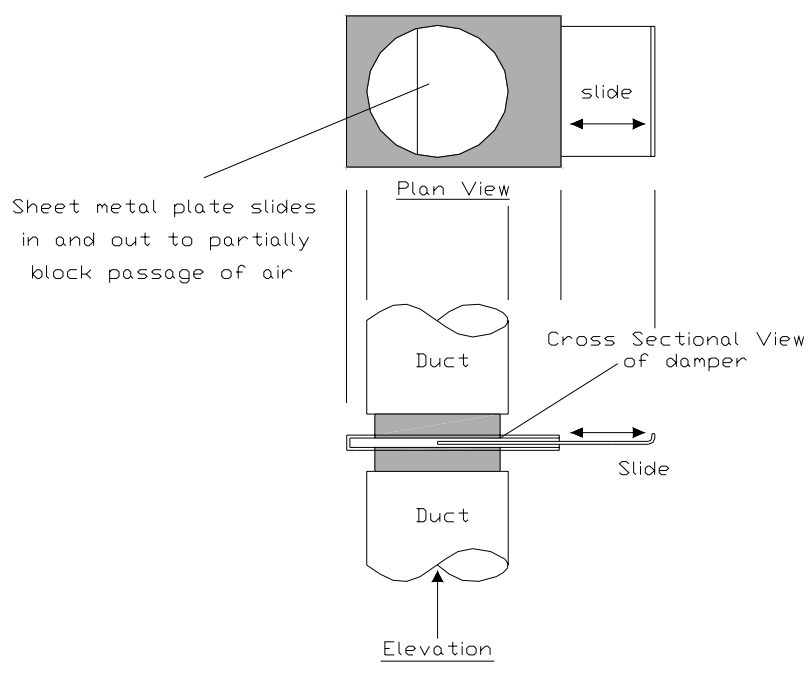

Figure 1 - Slide gate damper similar to those used in this study (Guffey, 2005)

There are energy losses in the separation region as air flows around the slide of a slide gate damper (see Figure 2). Slide gate edge sharpness (blunt or sharp), the velocity pressure (VP) of the airflow upstream of the damper, the shape of the edge of the damper (convex edge, straight edge or concave edge), and the fraction of the duct cross-section blocked by the damper (I/D - insertion depth/duct diameter) affect the energy losses in the separation region. In addition, energy losses in the separation region may be affected by upstream and downstream disturbances (e.g. elbows, hood connections, etc) (Guffey, 2005). These energy changes produce static pressure changes downstream of the damper.

Damper resistance is calculated as the difference between the resistance with and without the damper. The resistance of the damper $\left(\mathrm{X}_{\text {damper }}\right)$ can be defined as the ratio of the change in total pressure (TP) across the damper divided by the upstream velocity pressure. Since it is difficult to measure resistance across a damper accurately it is calculated in the following manner: 


$$
X_{\text {damper }}=\left(\frac{V P_{2}+S P_{2}}{V P_{2}}\right)-\left(\frac{V P_{1}+S P_{1}}{V P_{1}}\right)
$$

Where $1=$ without damper inserted

$2=$ with damper inserted to some amount

$S P=$ Static pressure measured downstream of damper

$V P=$ Average velocity pressure

Equation 1 can further be simplified to:

$X_{\text {damper }}=X_{\text {endwithdamper }}-X_{\text {endwithoutdamper }}$

Where $X_{\text {endwithoutdamper }}=$ damper resistance value with damper fully open

$X_{\text {endwithdamper }}=$ damper resistance with damper partially inserted in the duct

Figure 2 - Flow around a slide gate damper (Guffey, 2005)

Required values of $\mathrm{X}_{\text {damper }}$ on the same system for different branches typically range from

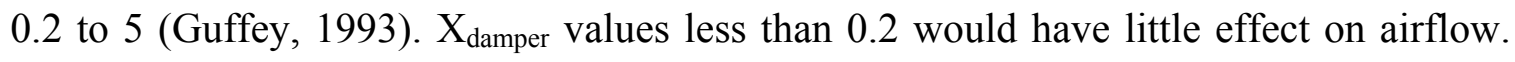
For a duct that has a diameter much larger than needed, the value of $\mathrm{X}_{\text {damper }}$ could reach 100 or even more (Guffey, 2005).

It is likely that slide gate dampers for different geometries of the edge of the slide have very different $X_{\text {damper }}$ values for a given insertion depth. There are many possible 
geometries for the leading edge of the gate of the damper but the two major ones are straight line and curved (convex/concave) (see Figure 3). A concave shape of the edge prevents complete blockage of flow in the duct, which is sometimes desirable.

The sharpness of the leading edge is another factor. As is known by analogy to orifice plates used for airflow measurement, the sharper the leading edge of the damper, the greater the value of $X_{\text {damper }}$ at a given insertion depth (Guffey, 2005).

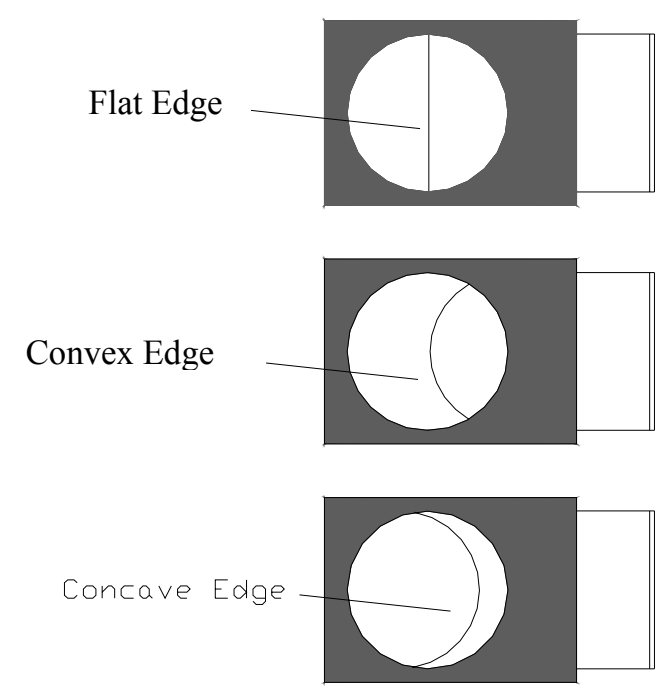

\section{Figure 3 - Different leading edges of sliding gate dampers}

Abrasive wear of a previously sharp edge of a damper can reduce the resistance of the damper at a given insertion depth. It is also possible for the damper resistance to vary due to accumulation of contaminants on the slide or just upstream or downstream of the slide. Accumulation of contaminants on the downstream side would substantially reduce the resistance. On the other hand any accumulation that extends beyond the reach of the gate could increase the resistance.

\subsection{Derivation of $X_{\text {damper }}$ from Bernoulli's Equation}

Damper resistance can be derived from Bernoulli's equation in the following manner; Bernoulli's equation is stated as: 


$$
\mathrm{SP}_{1}+\mathrm{VP}_{1}+\mathrm{P}_{\mathrm{bar} 1}=\mathrm{SP}_{2}+\mathrm{VP}_{2}+\mathrm{P}_{\mathrm{bar} 2}
$$

Where $S P=$ Static pressure measured downstream of damper

$$
\begin{aligned}
V P & =\text { Velocity pressure } \\
\mathrm{P}_{\text {bar }} & =\text { Barometric pressure } \\
1 & =\text { Inlet condition } \\
2 & =\text { Outlet condition }
\end{aligned}
$$

Assuming $\mathrm{P}_{\mathrm{bar} 1}=\mathrm{P}_{\mathrm{bar} 2}$

$$
\begin{aligned}
& \mathrm{SP}_{1}+\mathrm{VP}_{1}=\mathrm{SP}_{2}+\mathrm{VP}_{2} \\
& \mathrm{TP}_{1}=\mathrm{TP}_{2}
\end{aligned}
$$

Where $\mathrm{TP}=$ Total pressure $=\mathrm{SP}+\mathrm{VP}$

This relationship is incorrect for turbulent conditions of ventilation system ducts since it assumes zero energy losses. It has been extended by adding a 'lost pressure' term.

$$
\mathrm{TP}_{\text {loss }}=\mathrm{TP}_{1}-\mathrm{TP}_{2}
$$

Where $\mathrm{TP}_{\text {loss }}=$ Total pressure loss

It has been shown that for many components

$$
\mathrm{TP}_{\text {loss }}=\mathrm{F} * \mathrm{VP}_{1}
$$

Where $\mathrm{F}=$ Damper resistance

$$
\text { Thus } F=\frac{T P_{1}-T P_{2}}{V P_{1}}
$$

However that Kludged correction is not correct from energy per time point of view.

$$
\text { Energy }_{1}=\text { Energy }_{2}+\text { Energy Loss }
$$

For ventilation systems, changes in $\mathrm{P}_{\mathrm{bar}}$ are trivial,

$$
\text { Energy }=Q * \mathrm{TP}
$$

Where $\mathrm{Q}=$ Air flow

Hence from Equation 6 and 7,

$$
\mathrm{Q}_{1} * \mathrm{TP}_{1}=\mathrm{Q}_{2} * \mathrm{TP}_{2}+\text { Energy Loss }
$$




$$
\text { Energy Loss }=\mathrm{Q}_{1} * \mathrm{TP}_{1}-\mathrm{Q}_{2} * \mathrm{TP}_{2}
$$

Experimentally it has been demonstrated that for serial flow (Guffey, 1993)

$$
\text { Energy Loss } \approx \mathrm{X} * \mathrm{Q} * \mathrm{VP}
$$

Where $\mathrm{X}=$ Damper resistance

Hence from Equation (8) and Equation (9)

$$
X=\frac{Q_{1} * T P_{1}-Q_{2} * T P_{2}}{Q_{1} * V P_{1}}
$$

Since changes in pressure are generally small fractions of $\mathrm{P}_{\mathrm{bar}}$,

Then $\rho_{1}=\rho_{2}$, thus $\mathrm{Q}_{1}=\mathrm{Q}_{2}$

Hence Equation 10 can be further simplified to,

$$
X=\frac{T P_{1}-T P_{2}}{V P_{1}}
$$

This is the basis of predicted pressures in ventilation and hydraulic systems.

A more robust relationship can be defined using energy relationships. Energy equation is as follows:

$$
\begin{aligned}
& \text { Energy } \operatorname{Loss}_{\mathrm{A}+\mathrm{B}}=\text { Energy } \operatorname{Loss}_{\mathrm{A}}+\text { Energy } \operatorname{Loss}_{\mathrm{B}} \\
& \text { Then } \mathrm{X}_{\mathrm{A}+\mathrm{B}}=\mathrm{X}_{\mathrm{A}}+\mathrm{X}_{\mathrm{B}} \\
& \text { Where } \mathrm{X}=\text { damper resistance }
\end{aligned}
$$

In this case,

$$
\mathrm{X}_{\mathrm{br}+\text { damper }}=\mathrm{X}_{\mathrm{br}}+\mathrm{X}_{\text {damper }}
$$

Where $\mathrm{X}_{\mathrm{br}+\text { damper }}=$ Total resistance

$$
\begin{aligned}
& X_{b r}=\text { Branch resistance } \\
& X_{\text {damper }}=\text { Damper resistance }
\end{aligned}
$$

Hence from Equation 14,

$$
\begin{aligned}
& X_{\text {damper }}=X_{b r}+\text { damper } \\
& -X_{b r} \\
& X_{\text {damper }}=X_{\text {endwithdamper }}-X_{\text {endwithoutdamper }}
\end{aligned}
$$


Where $X_{\text {endwithoutdamper }}=$ damper resistance with damper fully open

$X_{\text {endwithdamper }}=$ damper resistance with damper partially inserted in the duct

$\mathrm{X}_{\text {endwithdamper }}$ can be further simplified to,

$$
\begin{aligned}
\mathrm{X}_{\text {endwithdamper }} & =\mathrm{X}_{\text {hood }}+\mathrm{X}_{\text {elbow }}+\mathrm{X}_{\text {Friction }}+\mathrm{X}_{\text {damper }} \\
\text { Where } \mathrm{X}_{\text {hood }} & =\text { Hood resistance }=0.2(\mathrm{ACGIH}, 1997) \\
\mathrm{X}_{\text {elbow }} & =\text { Elbow resistance }=0.93(\mathrm{ACGIH}, 1997) \\
\mathrm{X}_{\text {Friction }} & =\text { Resistance due to friction } \\
\mathrm{X}_{\text {damper }} & =\text { damper resistance }
\end{aligned}
$$

$\mathrm{X}_{\text {Friction }}$ is a function of velocity because TP is proportional to $\mathrm{V}^{1.9}$ instead of $\mathrm{V}^{2}$ (Guffey) Hence,

$$
X_{\text {Friction } 1}=X_{\text {Friction } 2} *\left(\frac{V_{2}}{V_{1}}\right)^{0.1}
$$

Statistically in terms of velocity pressure, Equation 17 can be written as,

$$
X_{\text {Friction } 1}=X_{\text {Friction } 2} *\left(\frac{V P_{2}}{V P_{1}}\right)^{0.05}
$$

\subsection{Problems Due to Use of Dampers}

There are many problems associated with the use of dampers. Dampers increase the total resistance of the duct system. Fan airflow output decreases with increasing resistance. Therefore increasing the damper insertion depth reduces the airflow from the fan and increases the pressure produced by the fan. High resistances may require an increase in fan speed, which increases the operating costs of fan. Fan efficiency also may be affected if the fan was not selected with the additional resistance in mind (Guffey, 2005).

If the dampers are used both to achieve required distribution and to reduce airflow, the pressure required at the fan can be substantial. However this is true only if the fan speed is unnecessarily high. If dampers are employed only to produce the desired distribution 
and the fan is adjusted properly, the pressure requirement for the system will be nearly always lower than without the dampers (Guffey, 1993).

The friction between the slide and the damper should not be too high or too low for easy slide movement. Also the duct with the slide gate damper should be supported rigidly to avoid the duct movement when pulling on the slide especially if there is high friction between the slide and the damper.

Dampers should be cleaned regularly as sticky or stringy contaminants can be caught on the slide of the damper. Plugging might likely occur due to rags, pieces of paper and other material that are sucked in to the duct by the fan. Flammable materials caught on a damper could create a fire hazard. Hence care should be taken to avoid flammable materials.

The location of damper on a duct is also important for proper operation of the system. The damper should never be located near elbows and other disturbances that may influence the pressure drop. Dampers can become sources for material build up if not located properly. 


\section{Chapter 2 Literature Review}

Despite a diligent search for articles on damper resistance and damper insertion depths very little was found in the literature on the relationship of $\mathrm{X}_{\text {damper }}$ to insertion depth of dampers. Four articles (Guffey, 1999; Idelchik, 1972; Crowder and Loudermilk, 1982; and Robert Van Becelaere, 2005) did cover damper resistance versus damper insertion depths, but there is no mention of any relationship between the two parameters. In addition to the four articles there are some publications that discuss issues relevant to investigation of damper resistances.

\subsection{Velocity Profile}

In research involving pressure and flow measurements it is important to have suitable measurement conditions. If the velocity profile is symmetric it is very likely that measured conditions are good.

The drag developed at the surface of the duct retards the airflow the most at the skin and lesser amounts as the distance from the surface increases. For air flowing undisturbed in a long straight duct, the velocity of air in the duct will vary from zero at microscopic distance from the duct to a maximum at the centerline of the duct. A turbulent flow develops a flattened parabolic velocity contour (see Figure 4), whereas a laminar flow develops a parabolic velocity contour far downstream flow (Guffey). At velocities typical of ventilation systems, the average velocity equals $90 \%$ of the centerline velocity at seven duct diameters from an upstream disturbance (Guffey). Velocity profile for the data collected will be drawn to check whether the data collected is in accordance with the literature mentioned above.
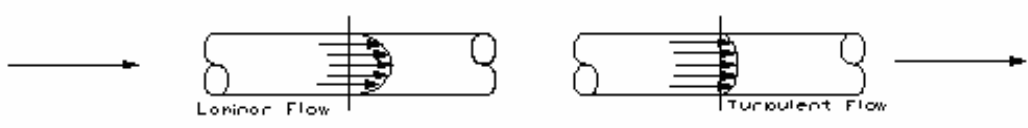

Figure 4 - Laminar flow and turbulent flow velocity profile 


\subsection{Published Damper Resistance Values}

Guffey (1999) found that values of damper resistance changed with different damper insertion depth for different branches but did not describe the mathematical relationship between damper insertion depth and $\mathrm{X}_{\text {damper. }}$. However Guffey demonstrated that values of damper resistance for a particular branch $\left(\mathrm{X}_{\mathrm{br}}\right)$ with a given damper insertion depth remained nearly constant as airflow velocities were doubled and as other branch dampers were adjusted.

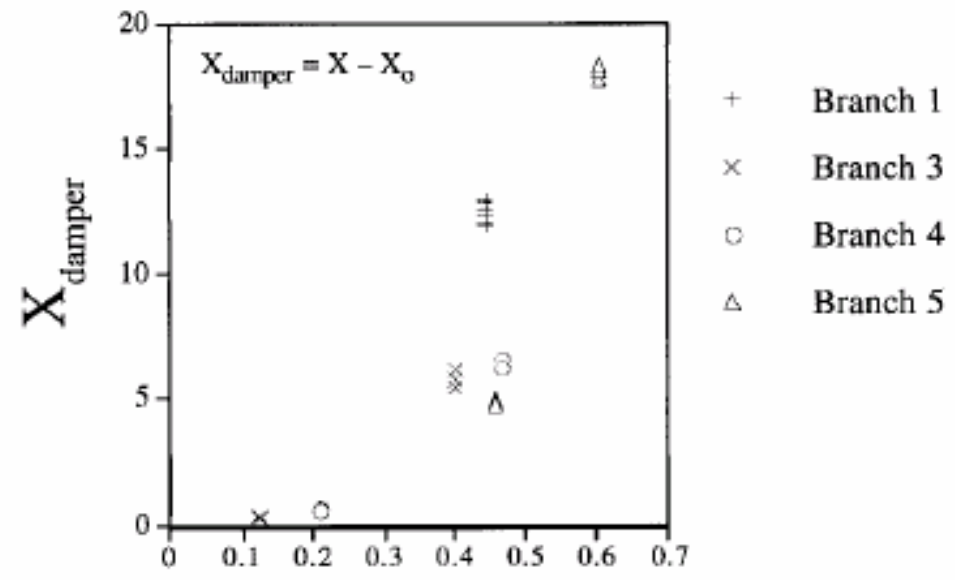

InsertionDepth/Diameter

Figure 5 - Change in resistance with damper insertion depth (Guffey, 1999)

According to Guffey (1999) the change in the value of $\mathrm{X}_{\text {damper }}$ for a branch increased steadily as the damper insertion depth was increased (see Figure 5). The values of the damper resistance increased steadily for all the branches as shown Figure 5. The values of $\mathrm{X}_{\text {damper }}$ for the different dampers did not follow a smooth curve with increasing relative insertion depths. A possible reason might be due to the damper being inserted partially even when the damper handle was pulled to its most open position. Also there was little scatter in the data points (see Figure 5) which indicates that there is no relationship between damper resistance and airflow level. 
Guffey concluded that the values of damper resistance was independent of airflow change in the branch, whether the change was caused by overall system airflow (i.e., changing fan speed) or the adjustment of the damper in another branch. This suggests that level of airflow should not be an important factor in the proposed study.

The graph of damper insertion depth and the damper resistance for all the branches except branch number 1 (see Figure 5) is similar to the graph (see Figure 6) obtained by Idelchik (1972). One reason for a different pattern for branch number 1 in Figure 5 could be the damper slide being inserted in to the duct to some extent even though the damper was in fully open position.

Idelchik (1972) provided a table of recommended values for a damper (see Table 3), but there was no explanation to how the values were produced and no description of the dampers and measuring conditions. Plotting the values showed a highly non-linear relationship (see Figure 6).

Table 3 - Recommended damper resistance values (Idelchik, 1972)

\begin{tabular}{|c|c|}
\hline (I/D) & $\mathbf{X}_{\text {damper }}$ \\
\hline 0.1 & 0 \\
\hline 0.2 & 0 \\
\hline 0.3 & 1 \\
\hline 0.4 & 2 \\
\hline 0.5 & 3 \\
\hline 0.6 & 6 \\
\hline 0.7 & 11 \\
\hline 0.8 & 37 \\
\hline
\end{tabular}




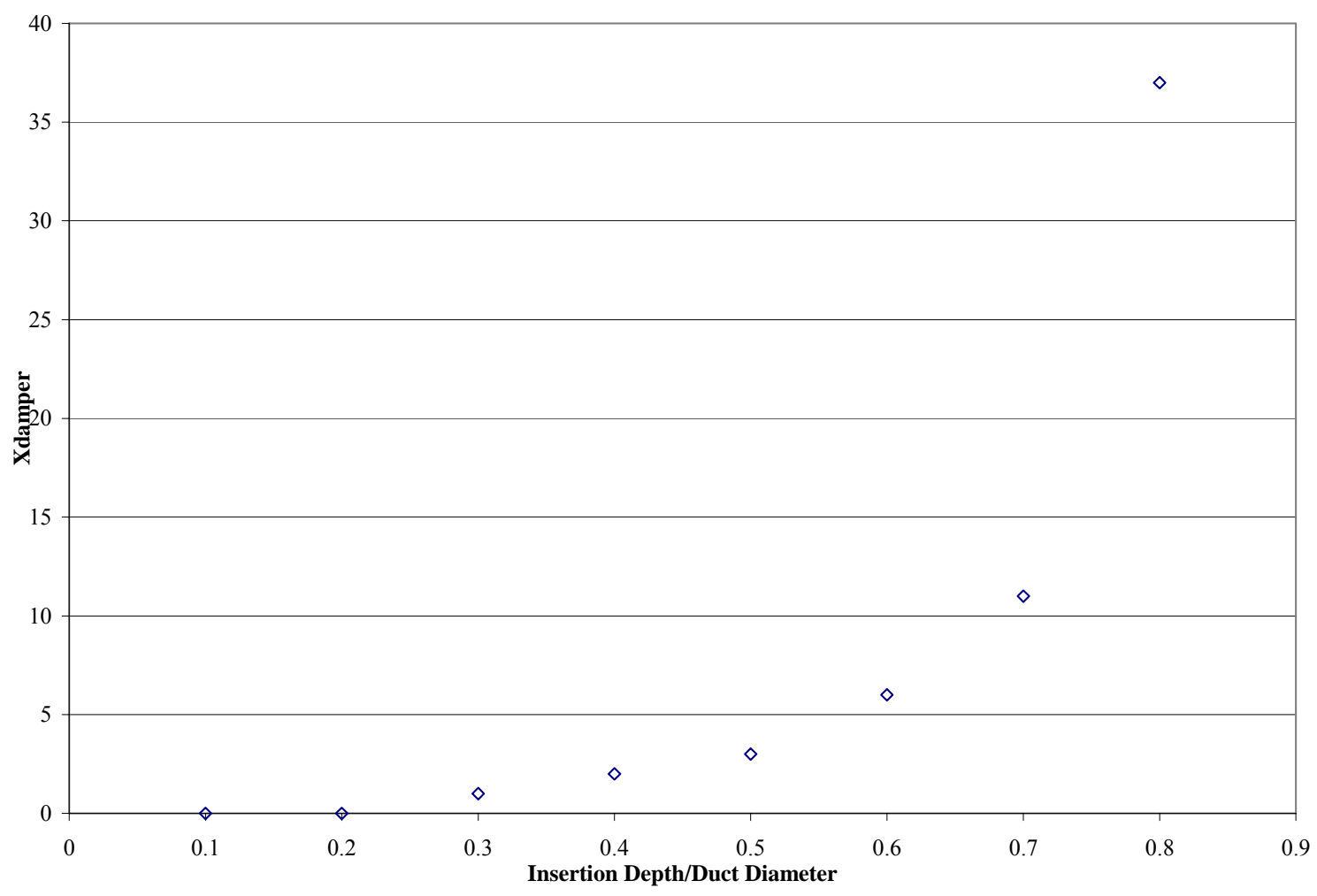

Figure 6 - Graph of Idelchik (1972) Table Values

Log transforming the values will not completely linearize them (see Figure 7). The resistance increases much more than linearly because: 1) as the damper insertion depth increases, the opening of the airflow through the duct becomes progressively smaller, increasing the air velocity past the edge of the slide (Guffey, 2005), and 2) the region of separation becomes larger (see Figure 2). 


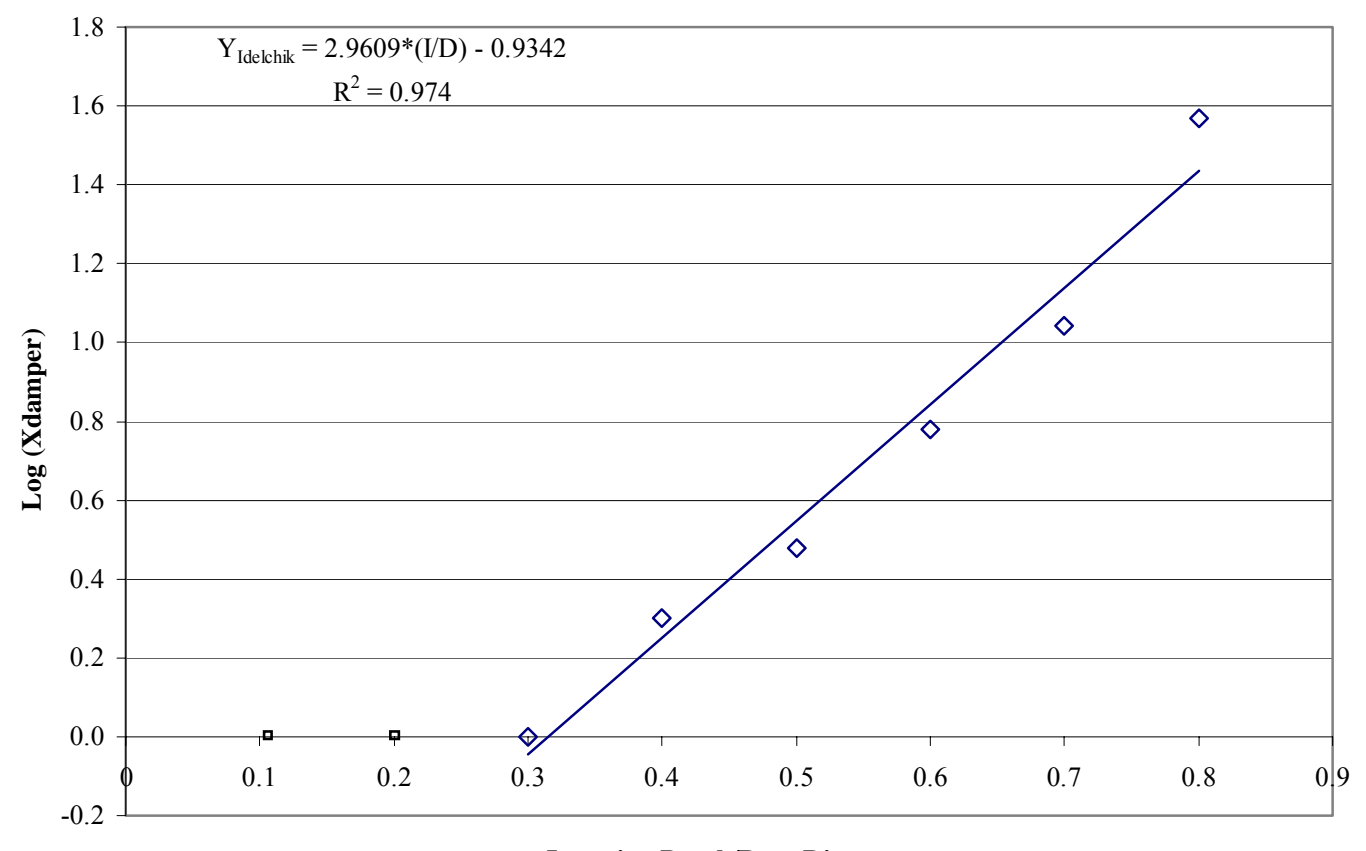

Insertion Depth/Duct Diameter

Figure 7 - $\log \left(X_{\text {damper }}\right)$ V/S Insertion Depth/Duct Diameter (Idelchik, 1972)

Different dampers may follow different curves based on damper blade design (straight or curved). It can be see that the $X_{\text {damper }}$ (see Figure 6) changes little until the damper is more than one third closed. At insertions greater than three quarters of the diameter, the change in the damper resistance is very high. Crowder and Loudermilk (1982) published a table of insertion depths to achieve different pressures at a given velocity but did not show mathematical equation and did not describe the design.

Robert Van Becelaere (2005) demonstrated the effects of type of damper, blade movement, manufacturer, installation, approach velocity, and total system pressure drop on parallel and opposed blade dampers. Resistance to flow was caused by the damper blades, the frame members, and also by the operating linkage. Damper blade positions were expressed in number of degrees from the closed position. The damper blade position was varied by varying the damper louver by 10-degree increments from closed to 90 degrees (open) in the test.

However from figure (see Figure 8), with face velocity as the parameter, it could be seen that the face velocity does have some influence on the loss coefficient at smaller 
openings. This disagrees with Guffey (1999) as mentioned earlier. The possible reason might be the manner in which the slide gate dampers and parallel and opposed blade dampers operate is different. However the proposed study can determine whether the air flow velocity does have or does not have an effect on the damper resistance.

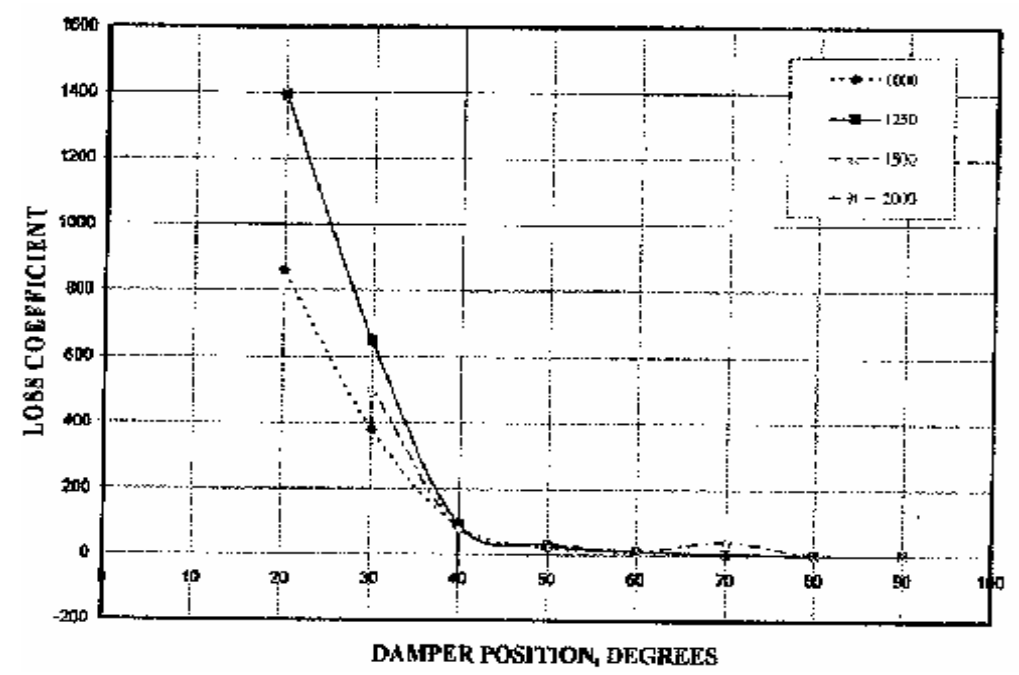

Figure 8 - Influence of face velocity on $C_{o}$ (Robert Van Becelaere 2005)

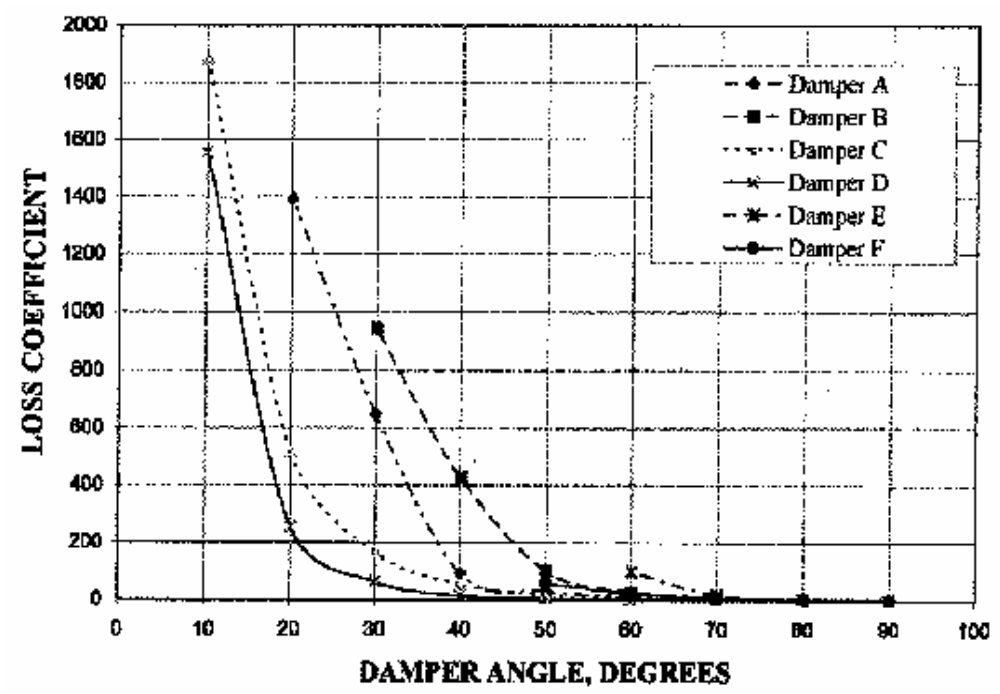

Figure 9 - Variation of $C_{o}$ with opposed blade damper (Robert Van Becelaere 2005) 


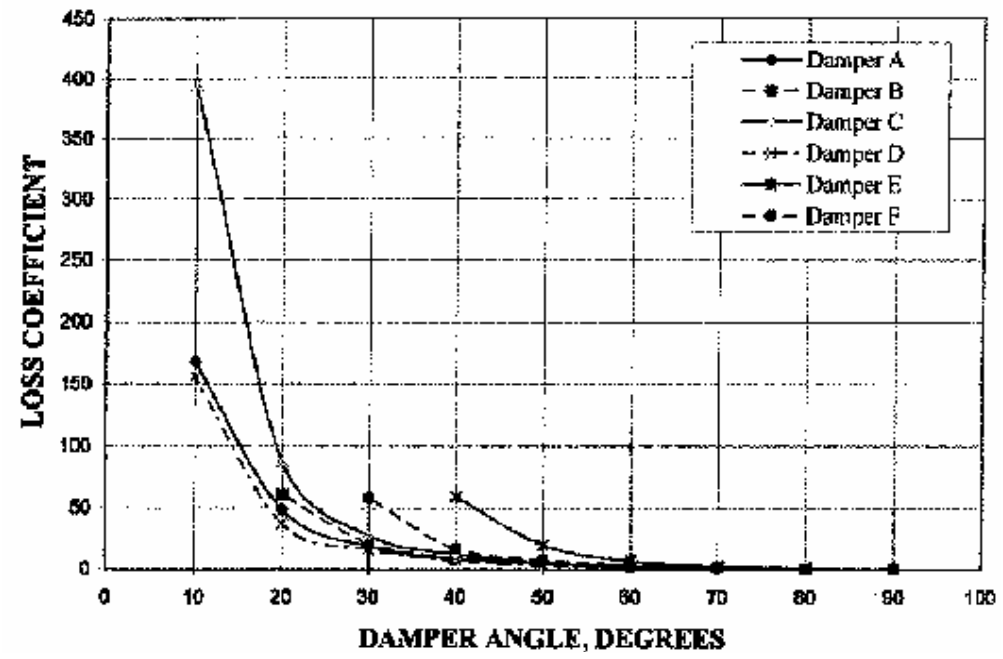

Figure 10- Variation of $C_{o}$ with parallel blade damper (Robert Van Becelaere 2005)

From the above two graphs (see Figure 9 and Figure 10) it can be seen that the system performs differently with different dampers, although Becelaere did not determine a mathematical relationship between the loss coefficient and blade position. 


\section{Chapter 3 Apparatus}

The study was performed in the West Virginia University Ventilation and Exposure Assessment Laboratory on the experimental exhaust ventilation system located in the laboratory. An Aerovent Fan (No. 315B1-SWCB-3435-3 Type SWCB Ser. 8708562-001) provided the airflow.

\subsection{Test Duct System}

A schematic of the test system is shown in Figure 11. It was assembled from 5' lengths of straight ducts (Model No. 3201) and a two $90^{\circ}$ elbow (Model No. 3211). They were manufactured and donated by Nordfab (Thomasville, N.C.).

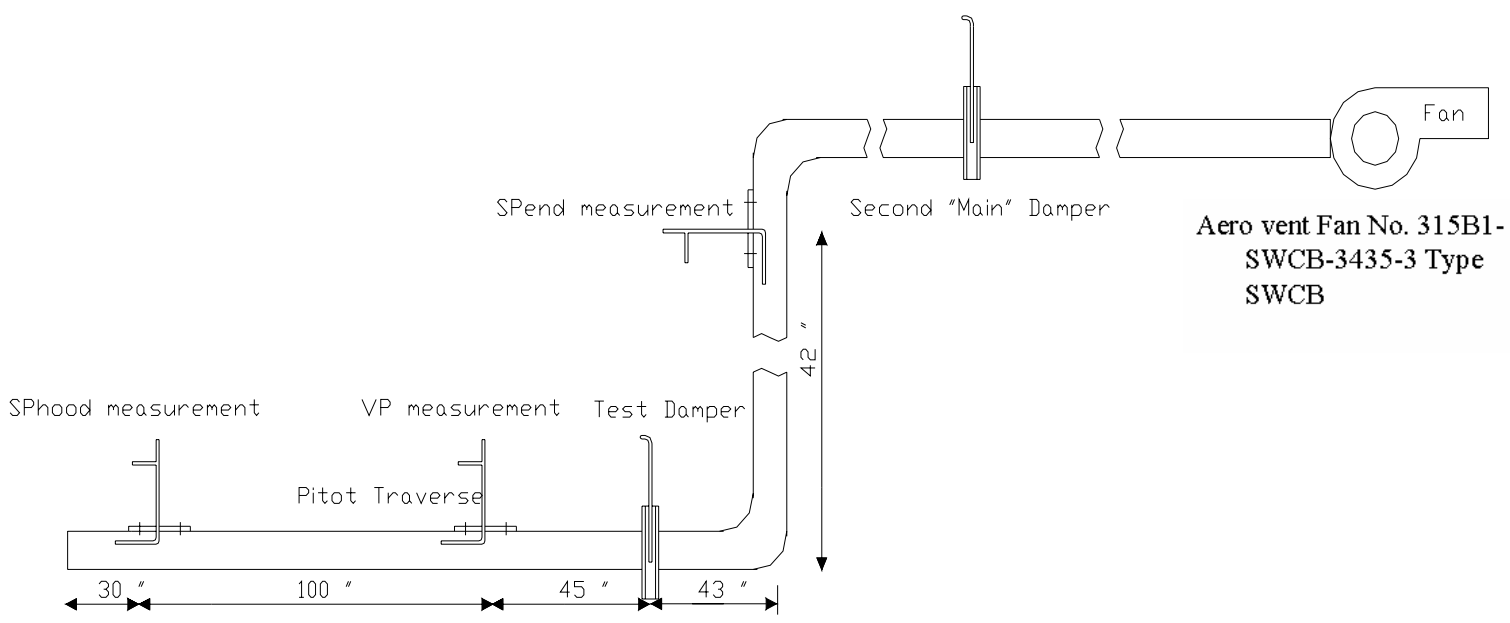

Fig 11 - Schematic of test duct system

The elbow was stamped from 20 - gauge sheet metal in a smooth, full $90^{\circ}$ turn. The 5 , duct sections were clamped to other duct sections using a clamp manufactured by Nordfab. 
Before testing, the sliding gate damper and the elbow were caulked to eliminate air leakage. Ducts were supported at 2 feet intervals using duct tape and nylon strings (see Figure 12). Two duct diameters were tested, 4.85 " and $3.85 "$ ".

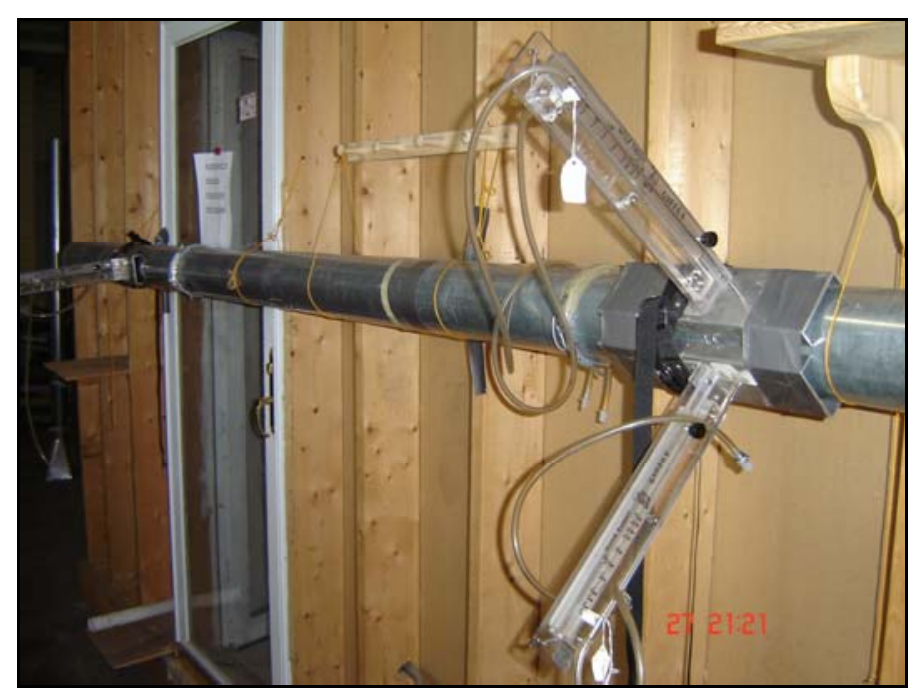

Figure 12 - Duct system used for the study

\subsection{Dampers Tested}

Two sealed slide-gate dampers (Model No. 3241 - see Figure 13) were used for the study. One was used to fit a 4.85 " diameter duct and the other to fit a 3.85 " duct diameter. Two damper edges for each duct diameter were used, one was straight edge and the other was concave edge. Duct tape was used to seal the joints of dampers. Insertion depths were measured (see Figure 13) from the displacement of the handle from the fully open position of the damper. The sliding gate damper was marked with eight insertion depths, including the fully open position (see Table 2). The damper is symmetric on both sides, and the difference in manufacturing is so subtle that it is practically impossible for a practitioner to see the gasket on side 2. Hence orientation of damper was also considered as a variable to see if there is any difference in damper orientation. 

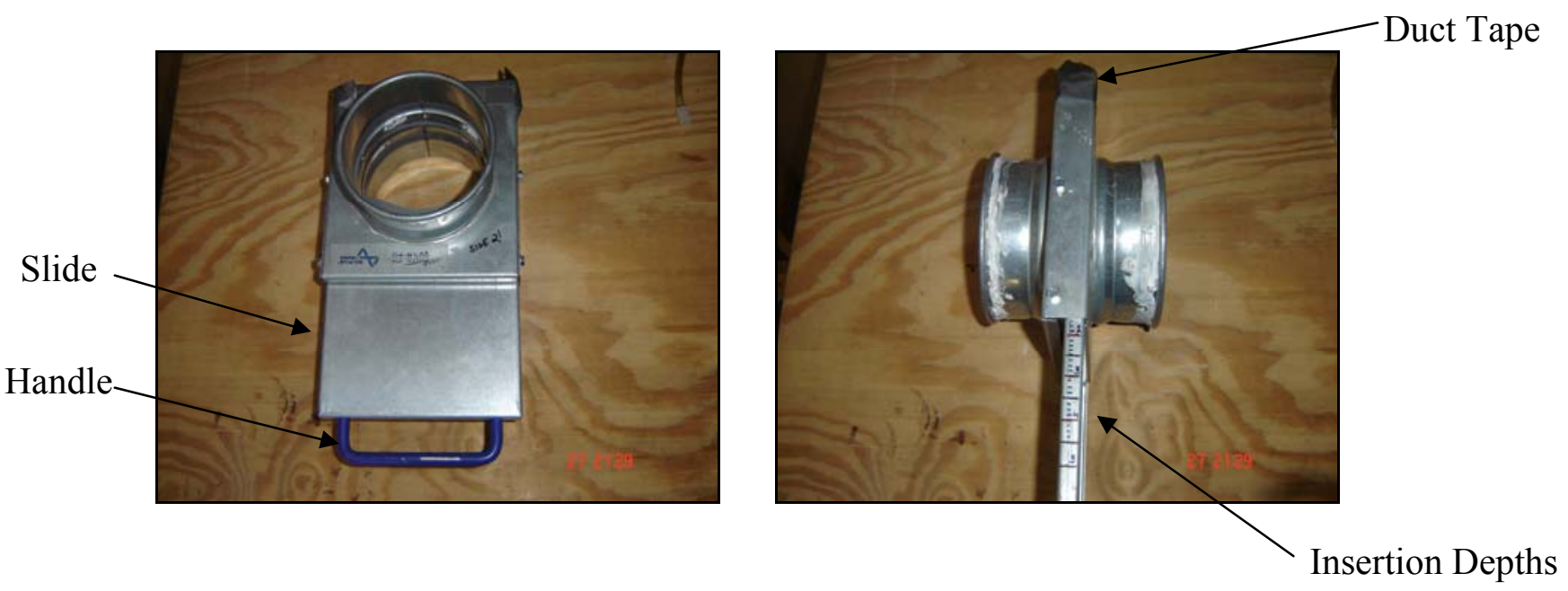

Figure 13 - Slide gate damper (Model No. 3241) used in the study

\subsection{Pitot Tube and Traverse Device}

Standard Pitot tubes (see Figure 14) were used to obtain the $\mathrm{SP}_{\text {hood }}$, and $\mathrm{SP}_{\text {end }}$ as well as 10-point log linear Pitot traverses. A TSI manometer (Model: 8702) was used to measure the (average flow velocity) velocity pressures and static pressures.

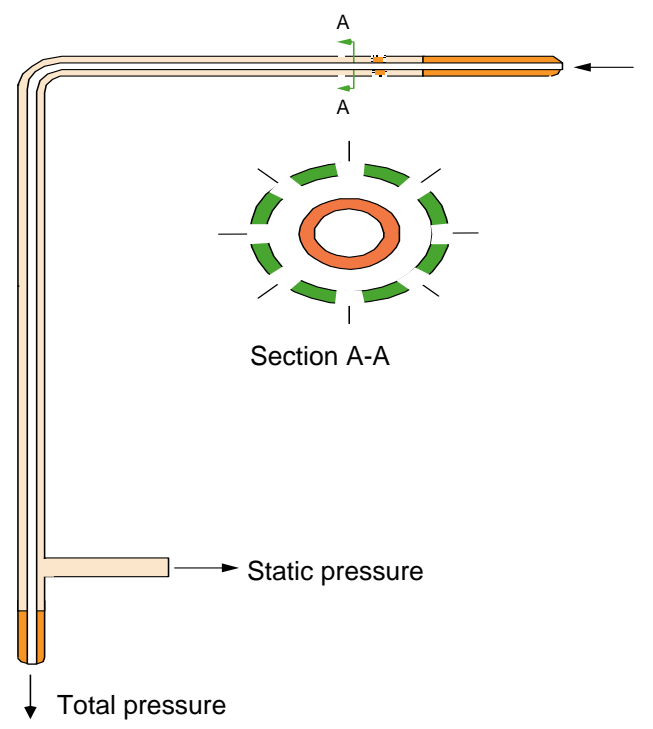

Figure 14 - Pitot tube sketch - similar to the one used in the study 
The static pressure (see Figure 15) is measured by connecting the manometer to the static pressure leg. The velocity pressure can be measured by (see Figure 16) connecting the manometer to both the legs of the Pitot tube. Pitot tubes were connected to the pressure sensor using Tygon ${ }^{\circledR}$ plastic tubing of the digital manometer. All static pressures were measured at duct centerlines.

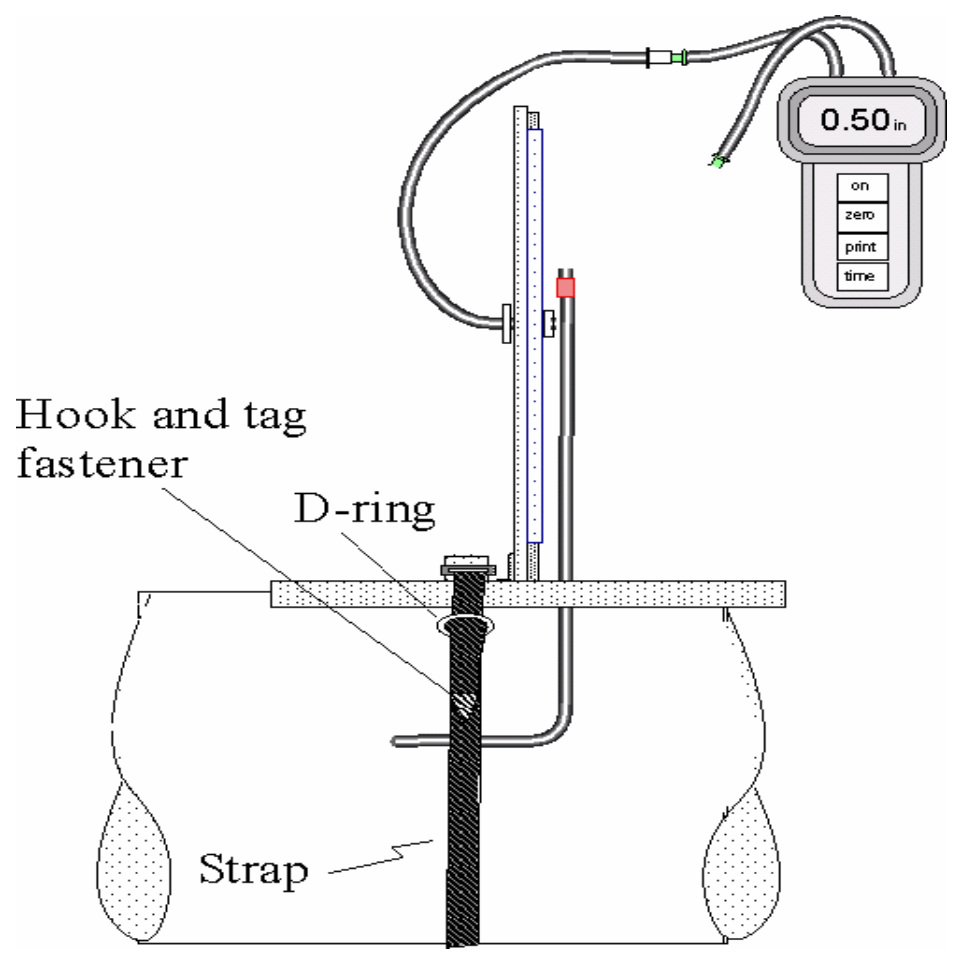

Figure 15 - Static pressure measurement

Custom-made devices (Guffey, 1990) were used to hold each Pitot tube in place (see Figure 17). Each traverse device was attached to the duct using an adjustable strap looped through a D - ring and held in place with tag straps and duct tapes.

The hood static pressures were measured seven duct diameters downstream from the start of the straight duct and the end static pressure was measured nine duct diameters downstream from the $90^{\circ}$ elbow. Velocity pressures were measured twenty-six duct diameters from the beginning of the duct opening to allow the air stream to stabilize. According to Guffey and Booth (1999), two perpendicular Pitot traverses can be taken as close as three duct diameters from disturbances with acceptable $(\leq 5 \%)$ deviations from 
measurements. In the study Pitot traverses have been taken more than seven duct diameters from disturbances.

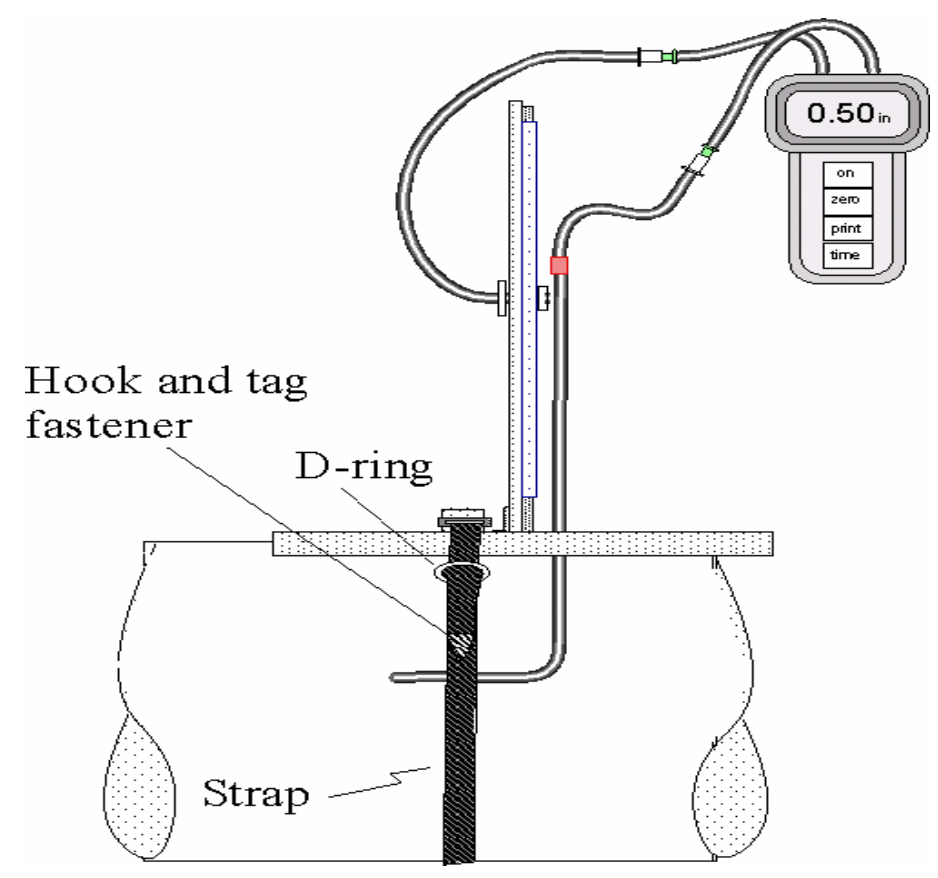

Figure 16 - Velocity pressure measurement

Also Industrial Ventilation (1998) recommends that Pitot traverses be taken at least seven duct diameters of distance downstream from disturbances.

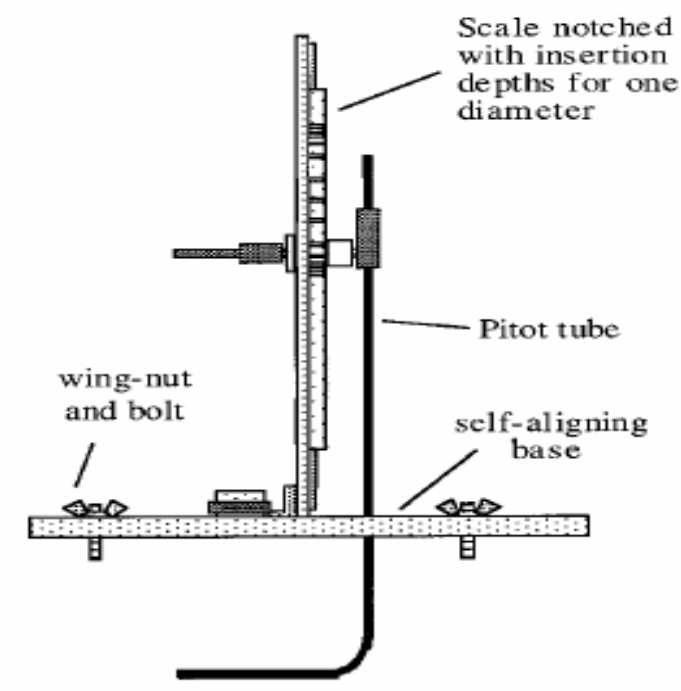

Figure 17 - Pitot traverse device (Guffey, 1999) 


\subsection{Pressure Sensor}

A TSI DP-Calc digital manometer (Model: 8702 - see Figure 18) was used to measure the hood static pressure, end static pressure, and velocity pressures. The digital manometer was calibrated using a Dwyer Instruments Inc. No. 1425 Hook gage (see Figure 19).

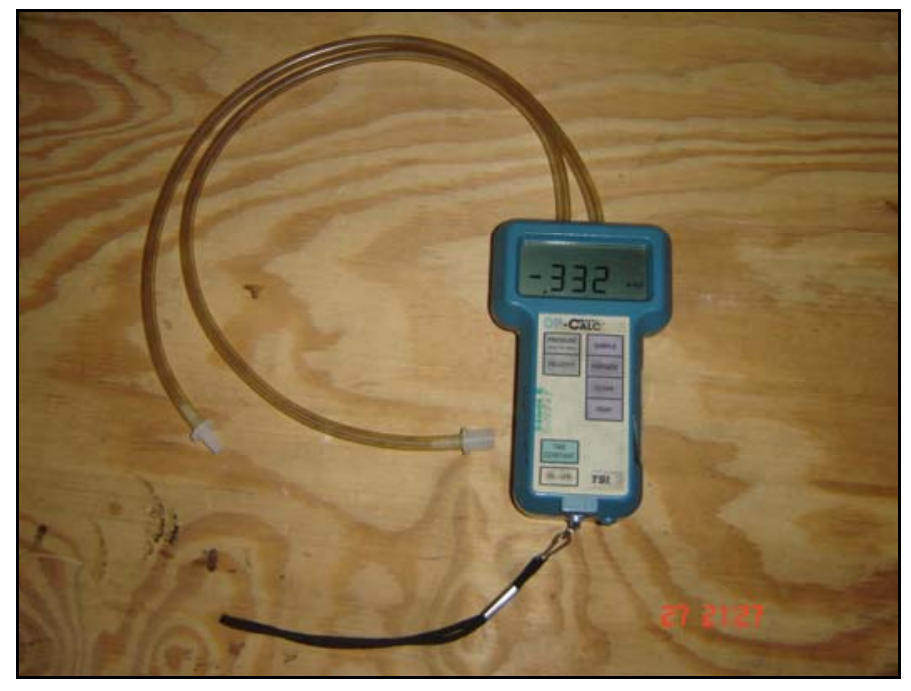

Figure 18 - Digital Manometer (Model 8702)

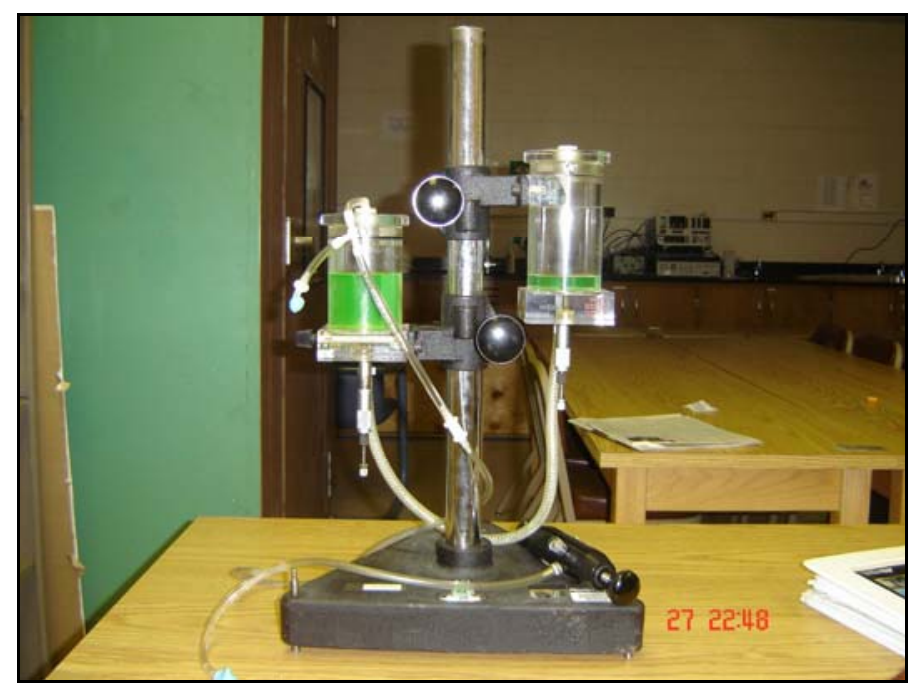

Figure 19 - Hook Gaze (Dwyer Instruments - Model No. 1425) 


\subsection{Devices to Measure Environmental Conditions}

Environmental conditions, such as temperature and pressure, were measured during the study in the laboratory every time the data was collected. The temperature in the laboratory was measured using a calibrated dry bulb thermometer and the barometric pressure was measured using a standard laboratory barometer inside the laboratory. The duct temperature was measured with a calibrated digital thermometer. The later was always within three degrees of room temperature. 


\section{Chapter 4 Methods}

This study determines the relationship between the damper resistance and damper insertion depth. This section includes study design, parameter calculations, and the test procedure followed by the author.

\subsection{Study Design}

Insertion depth, duct diameter, airflow velocity, damper orientation and damper edge were considered as variables in the study to determine the relationship between the damper insertion depth and damper resistance. For every test run, values of $\mathrm{SP}_{\text {end, }} \mathrm{SP}_{\text {hood, }}$ and 20 velocity pressure readings along with the centerline velocity pressure readings were measured using the digital manometer and Pitot tubes.

This study is a factorial design with the following variables:

Dependant variables: $\mathrm{X}_{\text {damper }}$

Independent variables: Insertion depth (I), duct diameter (D), damper edge

(Edge), damper orientation (Orient) and level of airflow ( $\left.\mathrm{VP}_{\mathrm{CLopen}}\right)$

Levels of Independent variables are shown in Table 1 and Table 2.

It was not feasible to adjust the fan in the laboratory to vary airflow velocity. Instead the level of airflow ( $\mathrm{VP}_{\text {CLopen }}$ ) was changed by adjusting a second ("Main") damper (see Figure 20) that was well downstream of the test damper. This was achieved by setting the system centerline velocity at four different ranges shown in Table 1 with the damper in open position. Velocity pressure readings for different insertion depths were measured for each of the main damper settings. 


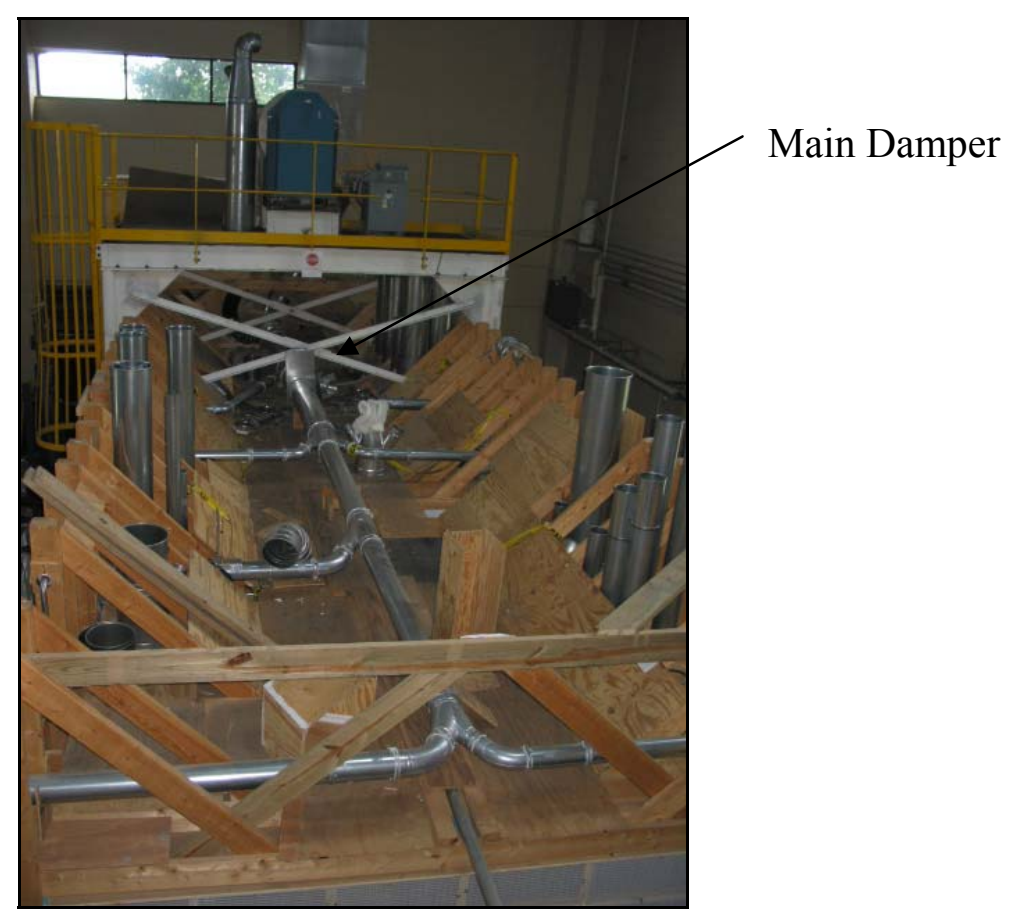

Figure 20 - Exhaust Ventilation System in Ventilation and Exposure Assessment Laboratory (WVU)

\subsection{Calculations}

This section shows the formulae and the order in which the different parameters are calculated, required for analysis of the data collected by the author.

\subsubsection{Density Factor Calculation}

Density factor is defined as the ratio of actual density to standard density. Density factor can be expressed in terms of component density for the effects of pressure, temperature and humidity on air density as shown below; 


$$
d f=\left(\frac{P_{b a r}+S P_{d u c t}}{P_{s t d}}\right) *\left(\frac{T_{s t d}}{T_{a c t}}\right)
$$

Where $P_{s t d}=407$ 'w.g. or $760 \mathrm{mmHG}$ or $101 \mathrm{kPa}$ or 29.92 " of $\mathrm{Hg}$

$$
\begin{aligned}
T_{\text {std }} & =530 \mathrm{R} \text { or } 294.3 \mathrm{~K}\left(70^{0} \mathrm{~F} \text { or } 21^{0} \mathrm{C}\right) \\
T_{\text {act. }} & =\left(460 \mathrm{R}+\mathrm{T}_{\mathrm{F}}\right) \text { or }\left(273+\mathrm{T}_{\mathrm{C}}\right) \\
d f & =\text { Density factor }
\end{aligned}
$$

\subsubsection{Average Velocity Calculation}

Air velocity can be computed from observed velocity pressures if the air density is known or can be determined using density factor (Guffey). For velocity at a single point, $\mathrm{i}$

$$
\begin{gathered}
V_{i}=1096 \sqrt{\frac{V P_{i}}{\rho}} \\
V i=4005 \sqrt{\frac{V P_{i}}{d f}}
\end{gathered}
$$

Where $V_{i}=$ velocity in fpm at a single location $\mathrm{i}(\mathrm{i}=1,2,3 \ldots 20)$

$$
\begin{aligned}
V P_{i}= & \text { Velocity pressure in inches of water gauze measured at a single } \\
& \text { location i } \\
\rho= & \text { Density of air in } \mathrm{lb} / \mathrm{ft}^{3} \\
d f= & \text { density factor }
\end{aligned}
$$

Although a point velocity can be computed from a point velocity pressure, the average velocity cannot be computed from each individual velocity pressure. Instead the average velocity is computed by calculating individual velocity from individual velocity pressure measurements and then taking the average of all the velocities as shown below.

$$
V_{\text {avg. }}=\frac{1}{n} \sum_{i=1}^{n} V_{i}
$$

Where $n=$ number of samples taken across a section

$$
V_{i}=\text { Point velocity at } \mathrm{i}(\mathrm{i}=1,2 \ldots 20)
$$




\subsubsection{Average Velocity Pressure Calculation}

Average velocity pressure is calculated from average velocity, which is equivalent to;

$$
V P_{\text {avg. }}=\left(\frac{\sum_{i=1}^{i=20} \sqrt{V P_{i}}}{20}\right)^{2}
$$

Where $V P_{\text {avg. }}=$ Average velocity pressure

This method used to calculate the average velocity pressure is mathematically identical to computing it from the density and the mean velocity (Guffey, 1999). Note that the centerline velocity pressure is not included in the calculation of average velocity pressure.

\subsubsection{Total Pressure ( $\Delta \mathrm{TP})$ Calculation}

The change in total pressure is calculated as;

$$
\Delta T P=S P_{\text {end }}+V P_{\text {avg }}
$$

Where $V P_{\text {avg. }}=$ Average velocity pressure calculated excluding the centerline Velocity pressure reading $S P_{\text {end }}=$ Static pressure at the end of the branch

\subsubsection{Damper Resistance $\left(\mathrm{X}_{\text {damper}}\right)$ Calculation}

Damper resistance is calculated as the difference between the resistance with and without the damper. The resistance of the damper $\left(\mathrm{X}_{\text {damper }}\right)$ can be defined as the ratio of the change in total pressure (TP) across the damper divided by the upstream velocity pressure. Since it is difficult to measure resistance across a damper accurately it is calculated in the following manner:

$$
X_{\text {damper }}=\left(\frac{V P_{2}+S P_{2}}{V P_{2}}\right)-\left(\frac{V P_{1}+S P_{1}}{V P_{1}}\right)
$$

Where $1=$ without damper inserted

$2=$ with damper inserted to some amount 


$$
\begin{aligned}
S P & =\text { Static pressure measured downstream of damper } \\
V P & =\text { Average velocity pressure }
\end{aligned}
$$

Equation 25 can further be simplified to:

$$
X_{\text {damper }}=X_{\text {endwithdamper }}-X_{\text {endwithoutdamper }}
$$

Where $X_{\text {endwithoutdamper }}=$ damper resistance value with damper fully open

$X_{\text {endwithdamper }}=$ damper resistance with damper partially inserted in the duct

$\mathrm{X}_{\text {endwithdamper }}$ can be further simplified to,

$$
\begin{aligned}
X_{\text {endwithdamper }} & =X_{\text {hood }}+X_{\text {elbow }}+X_{\text {Friction }}+X_{\text {damper }} \\
\text { Where } X_{\text {hood }} & =\text { Hood resistance }=0.2(\mathrm{ACGIH}, 1997) \\
X_{\text {elbow }} & =\text { Elbow resistance }=0.93(\mathrm{ACGIH}, 1997) \\
X_{\text {Friction }} & =\text { Resistance due to friction } \\
X_{\text {damper }} & =\text { damper resistance } \\
\text { Where } X_{\text {Friction }} & =X_{\text {Hood }}-X_{\text {Ellow }}-\left[1-\left(\left(\frac{V P_{\text {Avg. }}}{V P_{\text {Clopen }}}\right)^{0.5}\right)^{0.1}\right]
\end{aligned}
$$

Errors in shifts in airflow are determined in the following manner. Consider two branches ' $a$ ' and ' $b$ ' with damper in branch a.

$$
\begin{aligned}
\frac{Q_{b}}{Q_{a}} \alpha\left(\frac{1+X_{\text {enda }}+X_{\text {damper }}}{1+X_{\text {enda }}}\right)^{0.5} \\
\text { Where } \mathrm{Q}_{\mathrm{b}}=\text { Airflow in branch } \mathrm{b} \\
\mathrm{Q}_{\mathrm{a}}=\text { Airflow in branch } \mathrm{a} \\
\mathrm{X}_{\text {enda }}=\text { End damper resistance } \\
\mathrm{X}_{\text {damper }}=\text { Damper resistance }
\end{aligned}
$$

Percent error can be calculated in the following manner:

$$
\frac{\left(\frac{Q_{a}}{Q_{b}}\right)}{\left(\frac{Q_{b t}}{Q_{a t}}\right)} \alpha\left(\frac{1+X_{\text {enda }}+X_{\text {damper }}+\text { Error }}{1+X_{\text {enda }}+X_{\text {damper }}}\right)^{0.5}
$$




$$
\begin{gathered}
\text { Where } \mathrm{Q}_{\mathrm{bt}}=\text { Target airflow in branch } \mathrm{b} \\
\mathrm{Q}_{\mathrm{at}}=\text { Target airflow in branch a } \\
\text { Typically } \mathrm{X}_{\text {end }}=2
\end{gathered}
$$

Substituting $\mathrm{X}_{\text {end }}$ value in Equation 28,

$$
\text { Error }=\left(\frac{3+X_{\text {damper }}+(1+\text { Error } \%)}{3+X_{\text {damper }}}\right)^{0.5}-1
$$

\subsubsection{Reynolds Number Calculations}

Reynolds Number is used to determine the type of flow. Based on the value of Reynolds Number, flow may be laminar or turbulent. Reynolds Number is defined as the ratio of inertial force to viscous force. It is calculated as;

$$
\operatorname{Re}=\frac{\rho * V * d}{v}
$$

Where $\mathrm{Re}=$ Reynolds Number, dimensionless,

$$
\begin{aligned}
\rho & =\text { Density of medium } \mathrm{lbs} / \mathrm{ft}^{3}, \\
V & =\text { Velocity in } \mathrm{ft} / \mathrm{min} . \\
\mathrm{d} & =\text { Diameter of duct in inches, } \\
\mathrm{v} & =\text { Viscosity of air in lbs-min. } / \mathrm{ft}^{2},
\end{aligned}
$$

Reynolds number has been calculated in this study to determine whether the flow is laminar or turbulent. The results for the Reynolds number have been included in the results section.

\subsubsection{Pipe Factor Calculations}

Pipe factor (PF) is defined as the ratio of the average velocity to the centerline velocity. There is a rule of thumb that the pipe factor is typically 0.90 (Guffey). Thus the average velocity will equal $90 \%$ or some other fixed percentage of the centerline velocity. 


$$
P F=\frac{V_{\text {avg }}}{V_{C L}}
$$

Where $\mathrm{PF}=$ Pipe factor,

$\mathrm{V}_{\text {avg. }}=$ Average velocity in $\mathrm{ft} / \mathrm{min}$.

$\mathrm{V}_{\mathrm{cl}}=$ Centerline Velocity in $\mathrm{ft} / \mathrm{min}$. (from data collected)

\subsection{Test Procedure}

The test procedure included calibration (see Appendix II); steps taken prior to measurements, and steps taken during measurements.

\subsubsection{Calibration}

The digital manometer was calibrated against Dwyer hook gauge using about 20 calibration points over the range of interest. The manometer was calibrated to record positive readings. A small hand pump supplied positive pressures for these calibrations, connected through the plastic static pressure manifold to the digital manometer. The manometer was checked against water levels at 2/5, 3/5, 4/5, 1, 1 2/5, $13 / 5,1$ 4/5, 2, 2 $3 / 5,3,34 / 5,4,42 / 5,5,6,7,8,9,10,11$ and 12 inches of water gauge to cover the range of pressure readings during measurement of the ventilation system (see Appendix for calibration data).

\subsubsection{Leak Tests}

Before any experiments were conducted, the duct inlet was all capped and the fan was left running to detect the presence of any leaks in the duct connections, the damper insertion and elbow connections. The white powder smoke tube was sprayed around the duct connections, elbow connections and around the sliding gate damper to detect any flow in to the ducts, seams or joints in the ductwork. Flexible caulking and duct tape were used to seal the leaks present. Duct tape was also taped around the sliding gate damper to avoid any leak through the damper slide. 


\subsubsection{Preparation for Data Collection}

The laboratory temperature and barometric pressure were measured every time before the experiments were conducted and data measured. When measuring the static pressure, the manometer time constant was set to 5 seconds and while measuring the velocity pressure reading, the manometer time constant was set to 1 second since 20 velocity pressure readings were measured for every damper insertion depth. The digital manometer was switched on for a half hour before measurements to allow the manometer to stabilize before it was used to take measurements.

\subsubsection{Running the Experiment}

The following steps were followed to run the entire experiment to determine the relationship between damper insertion depth and damper resistance (see Appendix III for flowchart).

\section{Steps:}

1. Calibrate TSI digital manometer.

2. Select duct diameter (D) randomly.

3. Select damper edge (Concave/Straight) randomly.

4. Select damper orientation (Side 1/Side 2) randomly.

5. Set the system to one of the four airflow levels $\left(\mathrm{VP}_{\mathrm{CLopen}}\right)$ randomly.

6. Measure the velocity pressures and static pressures at one of the eight insertion depths randomly.

7. Repeat step 6 until all eight insertion depths are tested

8. Repeat steps $5-7$ for each of the remaining three $\mathrm{VP}_{\text {CLopen }}$ levels.

9. Repeat steps $4-7$ for the second damper orientation (reverse the side of damper).

10. Repeat steps $3-7$ for the second damper edge.

11. Repeat steps $2-7$ for the second duct diameter.

12. Replicate steps $1-11$ to check the consistency in the data measured. 


\subsubsection{Running a Test}

The following procedure was followed every time for running a test in the study for one diameter duct system, one damper edge, one air flow level and one damper insertion depth.

\section{Steps:}

1. Measure static pressure readings at the hood face, and at the end of the duct

2. Measure velocity pressure readings across the two 10-point log linear Pitot traverses

3. Calculate average velocity pressure, total pressure and damper resistance.

\subsubsection{Replications}

Replications were taken only for certain set of conditions (see Appendix IV). Idelchik (1972) found an exponential relationship between $X_{\text {damper }}$ and insertion depth. A plot of his table values with $\log \left(\mathrm{X}_{\text {damper }}\right)$ versus insertion depth (see Figure 6) produced a linear relationship over most of the range.

If log-transformed values of $\mathrm{X}_{\text {damper }}$ are linear with insertion depth then error can be determined from the derivations from a straight line and replications are not required greatly reducing time and effort required to conduct the study. However in case the relationship between $\mathrm{X}_{\text {damper }}$ and insertion depth proved non linear the remaining subset of data was replicated. 


\section{Chapter 5 Results}

The following results have been obtained from the data collection.

\subsection{Manometer Calibration}

Statistical regression of the manometer readings and the hook gauge readings produced a linear predictive equation (see Figure 21) used to compute pressures from manometer readings. $R^{2}$ values were typically 0.997 or better.

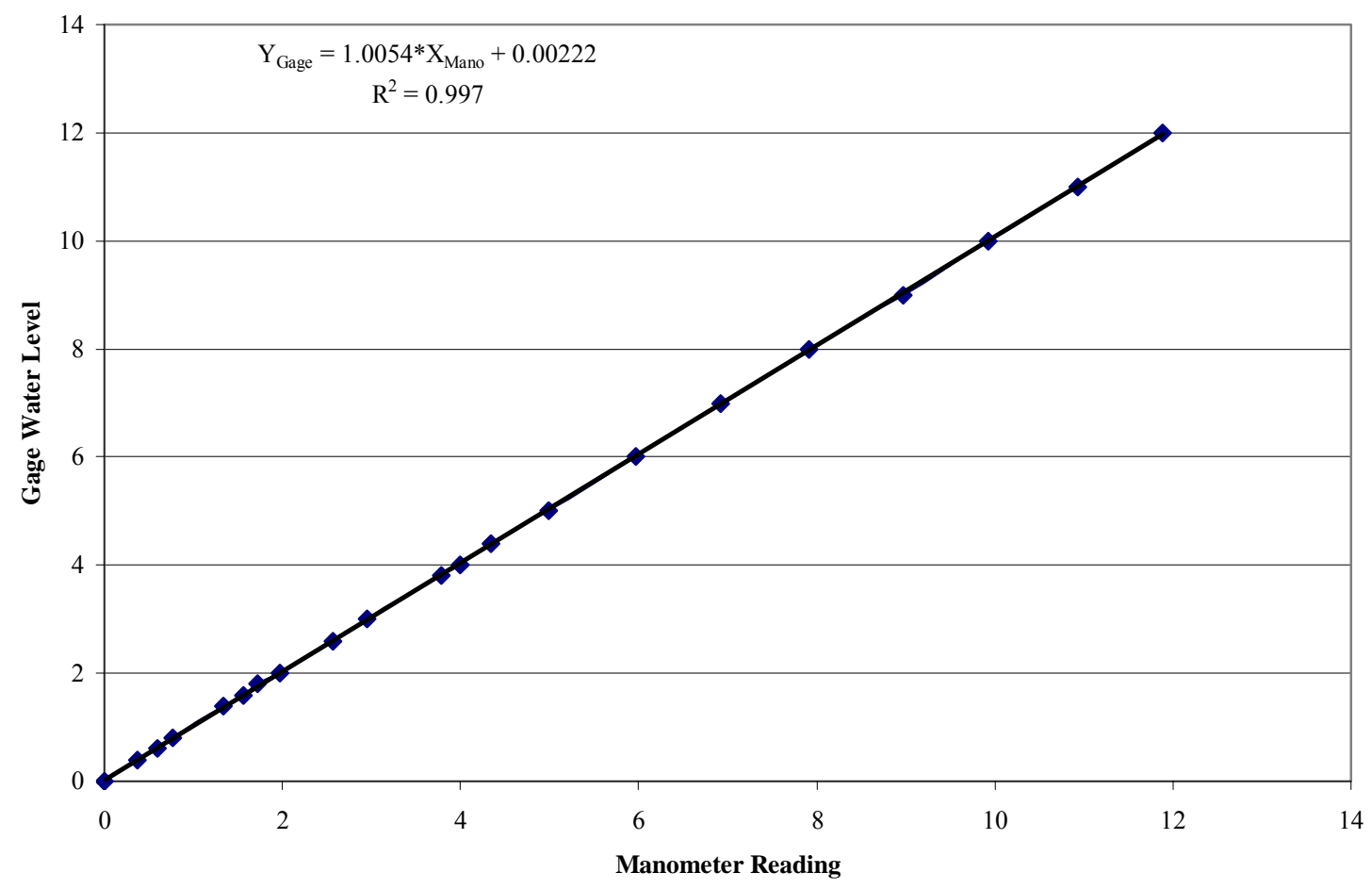

Figure 21 - Manometer calibration graph 


\subsection{Characteristics of Velocity Measurements}

The fitness measurement condition is demonstrated with velocity profile and pipe factor. The range of Reynolds number is also computed.

\subsubsection{Reynolds Number}

Reynolds number was calculated for the data measured (refer to Equation 30). The Reynolds number varied from 34,000 to 716,000 indicating a highly turbulent flow. At high Reynolds number one would expect flattened parabolic velocity contours. The broad range of Reynolds number values suggests the possibility that damper resistances could vary with velocity and diameter.

\subsubsection{Velocity Profile}

As mentioned in the literature review, the graph of velocity with respect to the distance from the duct centerline in a turbulent flow should follow a flattened, symmetric parabolic contour. Figure 22 shows the velocity profile found for 4.85 inches duct diameter, concave edge damper, air flow level of 2.103 inches of water gaze, and for side 1. Note that graphs are most parabolic at the highest velocity and are more flattened at lower velocities. The symmetry of each plot suggests that measurement conditions were conducive to high accuracy (Guffey and Booth, 1999). 


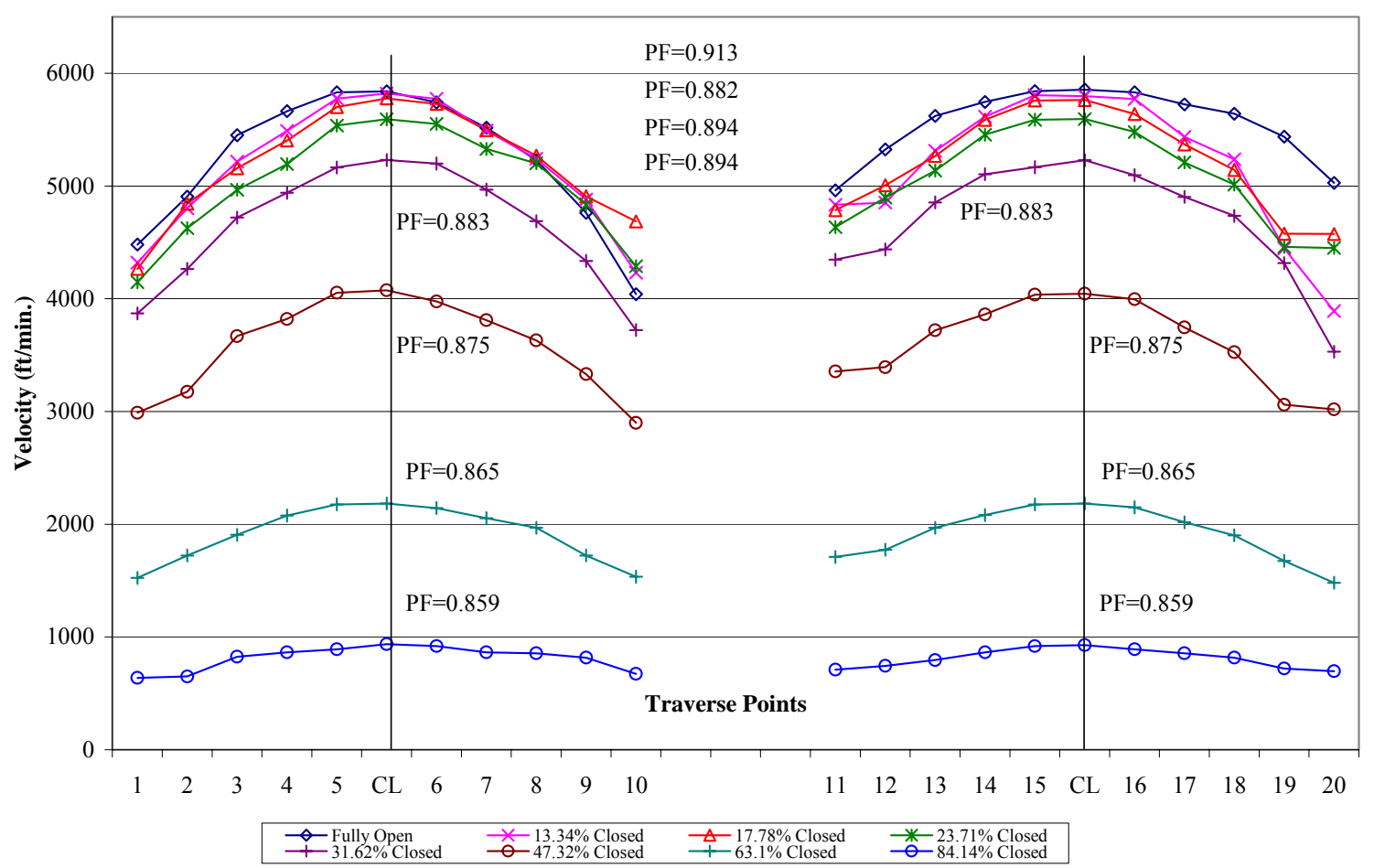

Figure 22 - Velocity Profile for $D=4.85 ”, V_{C L o p e n}=2.103$ ” of w.g., Side 1 and Concave Edge

\subsubsection{Pipe Factor}

Pipe factor was calculated for the data collected (refer to Equation 31). Maximum pipe factor obtained for the collected data was 0.935 and the least was 0.679 . The average pipe factor for the data measured was 0.870 which is fairly equal to the thumb rule pipe factor value of 0.9. A plot of pipe factor against Reynolds number (Re) (see Figure 23) indicates that the pipe factor has been consistently more than 0.85 for Re greater than 300,000 . The pipe factor appears to increase with $\mathrm{Re}$ in an exponential relationship. It appears to converge on a value of about 0.9 . It can be noted that pipe factor for both diameters are scattered in a similar fashion when plotted against Re. 


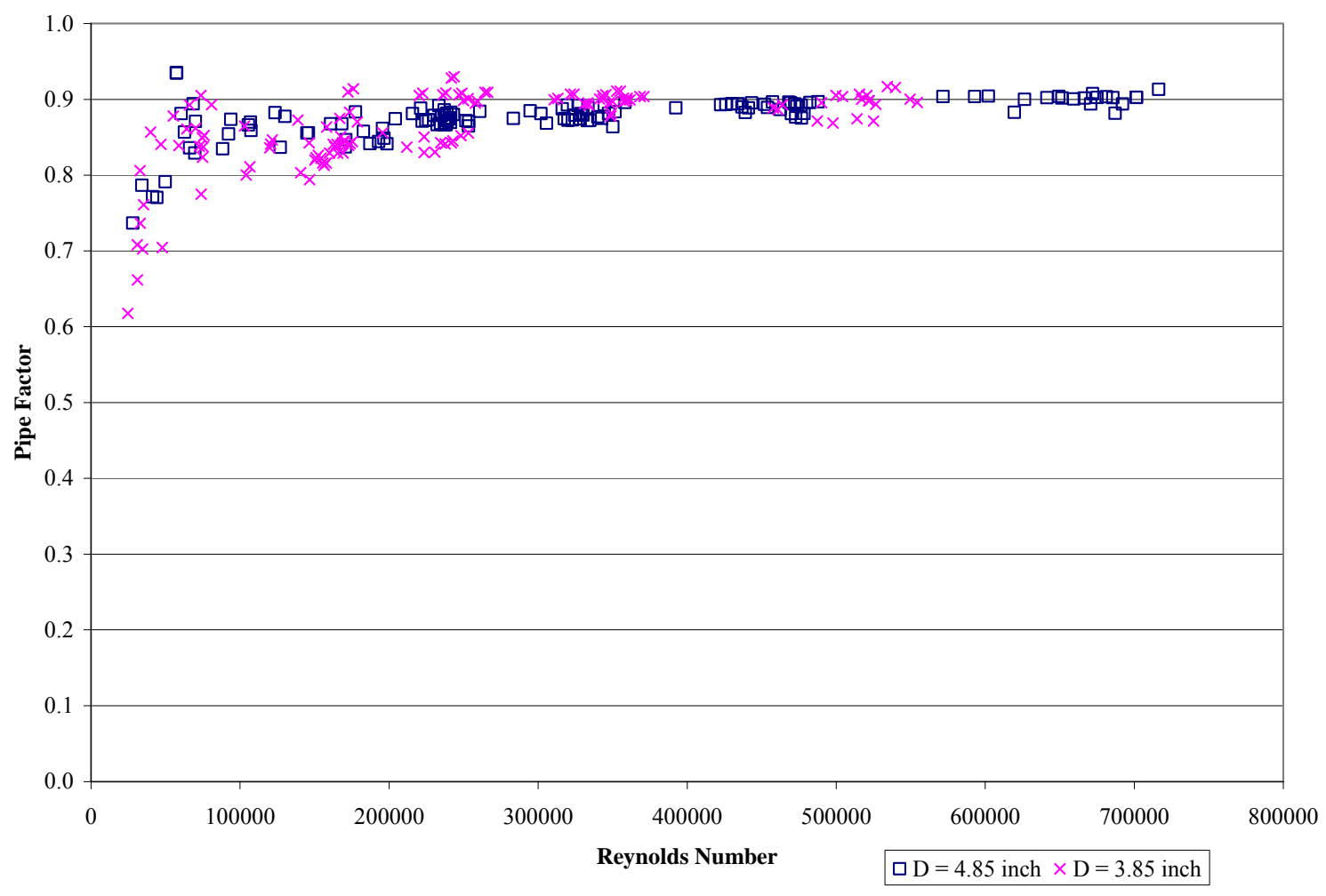

Figure 23 - Pipe Factor V/S Reynolds Number

\subsection{Results of Replicated Data}

Data collection was replicated only for certain combinations initially to see if there was a linear relationship between $\log \left(\mathrm{X}_{\text {damper }}\right)$ and insertion depth as was found by Idelchik (1972). As can be seen from the plot of $X_{\text {damper }}$ and (I/D) (see Figure 24), appear to be exponential. 


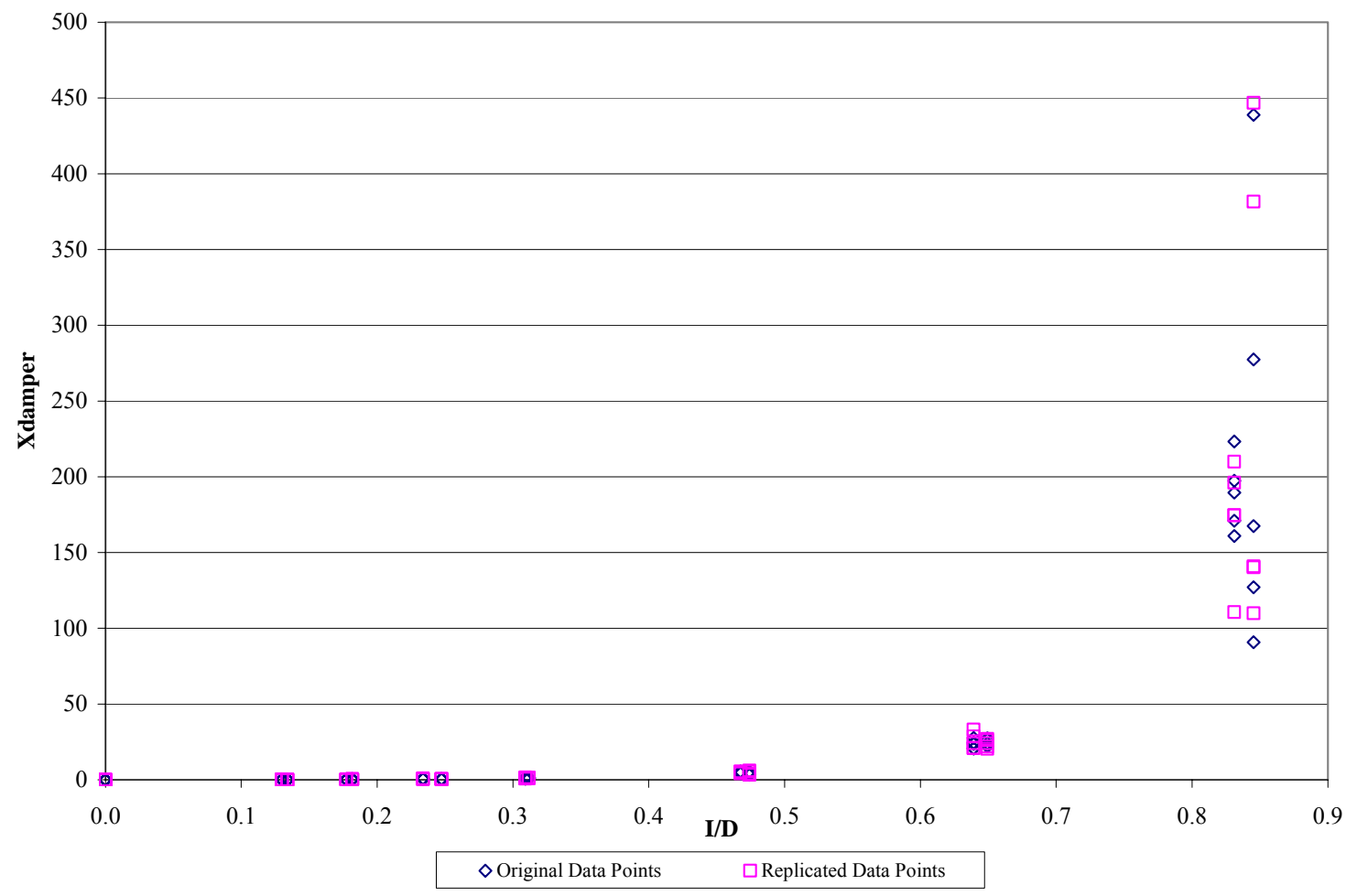

Figure $24-X_{\text {damper }}$ V/S (I/D) for original and replicated data

Log transforming the $\mathrm{X}_{\text {damper }}$ and plotting it against (I/D) gives a linear relationship for both the original data set and replicated data set (see Figure 25). With reason for confidence that a linear relationship exists, it was not necessary to take second replications for other conditions. 


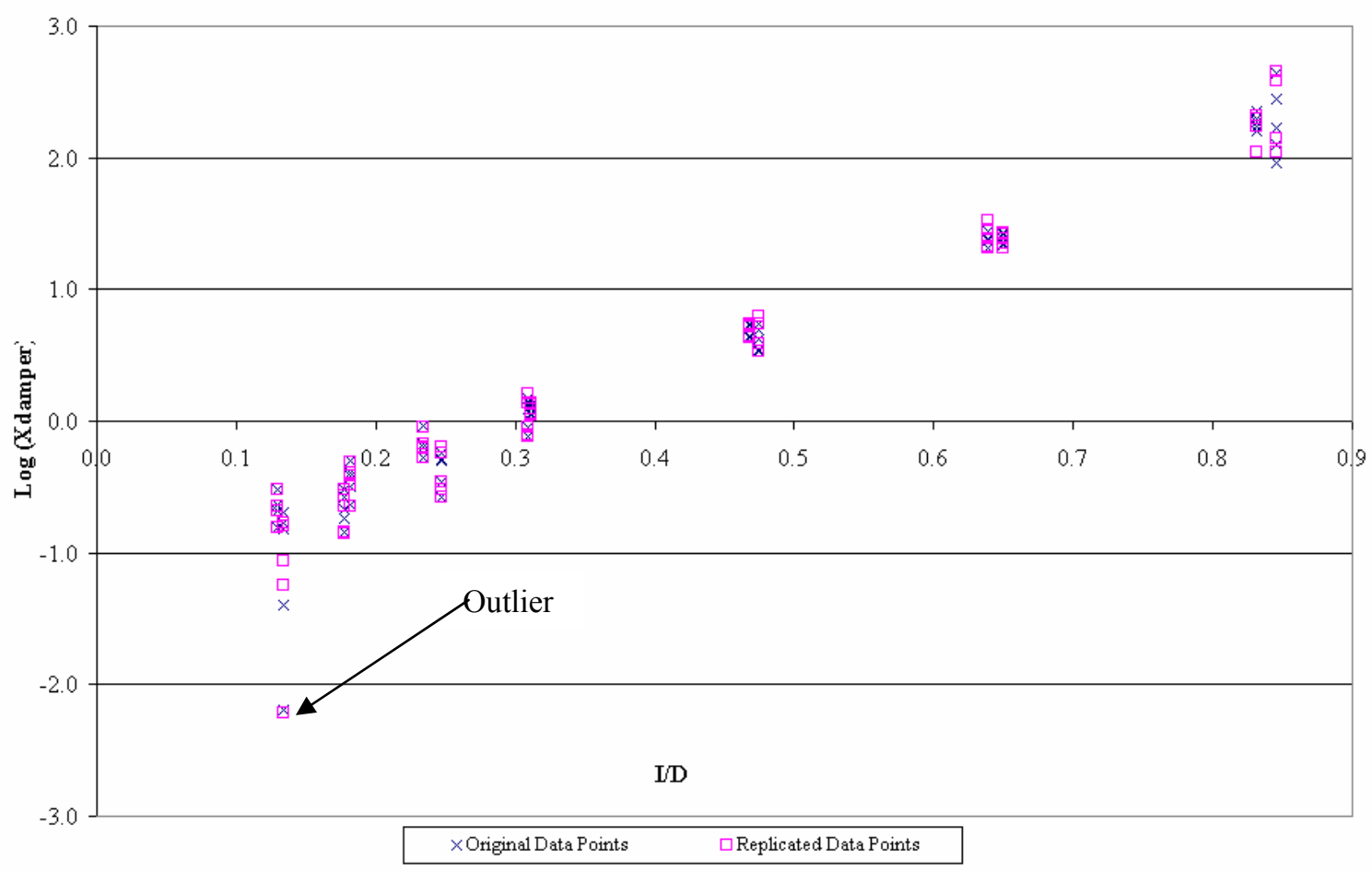

Figure 25 - $\log \left(\mathrm{X}_{\text {damper }}\right)$ V/S (I/D) for original and replicated data

\subsection{Results of Relationship between $X_{\text {damper }}$ and Relative Insertion Depth (I/D) - For All Data}

$\mathrm{X}_{\text {damper }}$ is plotted against relative insertion depth i.e. Insertion depth/Duct diameter (I/D) (see Figure 26). As can be seen from the figure there is an exponential increase in $X_{\text {damper }}$ as the relative insertion depth (I/D) increases, which is similar to the graph obtained by Idelchik (see Figure 6). The variability in $\mathrm{X}_{\text {damper }}$ is increasing as (I/D) is increasing and there is very little variability when the damper is $50 \%$ shut (see Figure 26). 


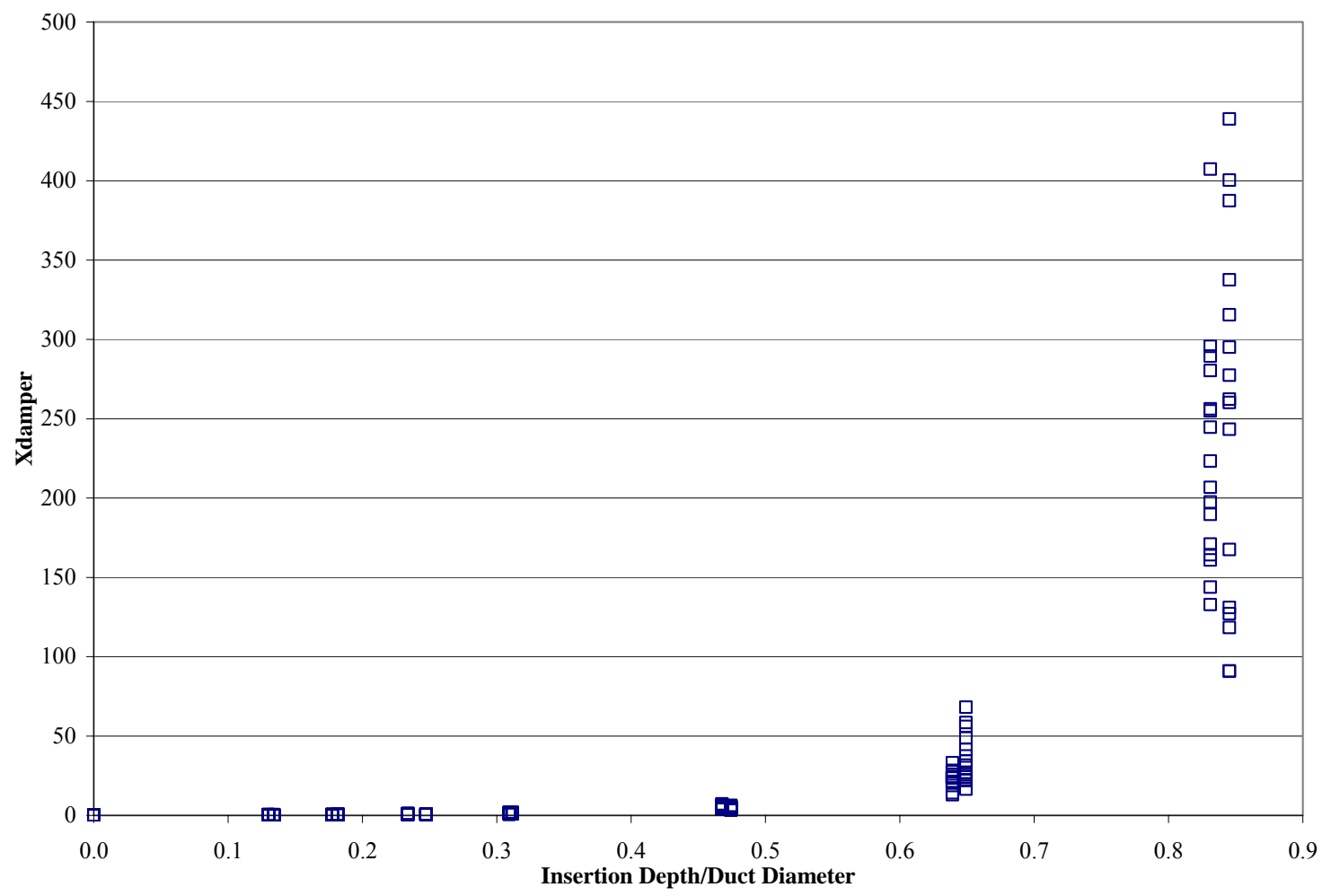

Figure $26-\mathbf{X}_{\text {damper }}$ V/S Insertion Depth/Duct Diameter

However, as shown in Figure 27, Log $\left(\mathrm{X}_{\text {damper }}\right)$ is highly linear with insertion depth/duct diameter which is also similar to the graph obtained by log transforming the plot obtained by Idelchik (see Figure 27). Authors slope is much more linear than Idelchik. The authors plot is in confirmation with Idelchik plot. Note that the variability is much more uniform over (I/D) after log transforming. It can also be observed that there is one outlying data point in the author's data set, which indicates that there is variation in log-transformed $\mathrm{X}_{\text {damper }}$ when (I/D) is $13 \%$. Note that outlier was consistent over both the replications for the data point. However the data point was excluded from statistical analysis for two reasons: 1) they represent $X_{\text {damper }}$ values less then 0.0064 , which is too low to be of interest and 2) they would skew the regression fit. Log-transformed Idelchik values have also been plotted in Figure 27. Idelchik values have been consistently below the author's data points, however measuring conditions for Idelchik values are not known. 


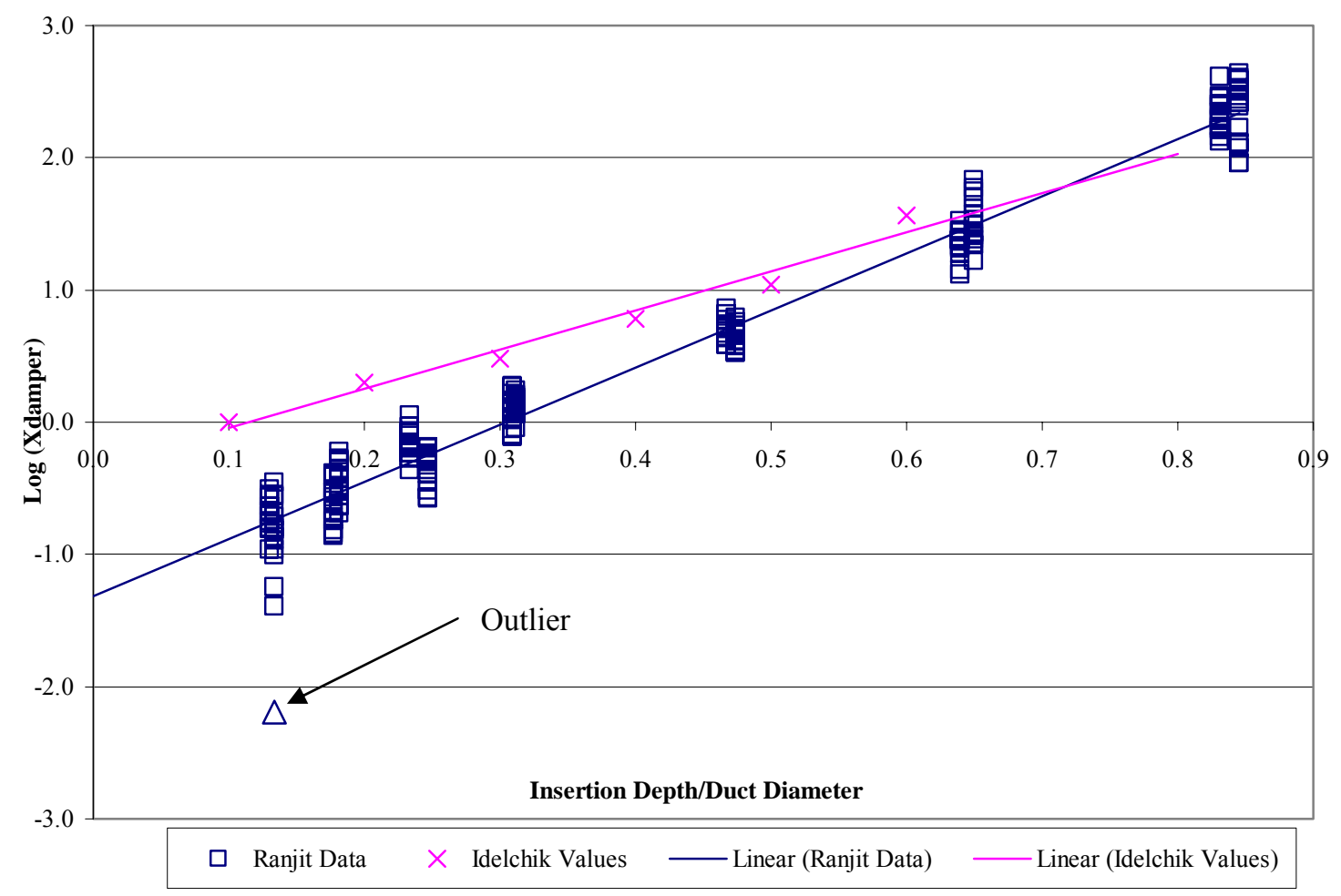

Figure 27 - Log $\left(X_{\text {damper }}\right)$ V/S Insertion Depth/Duct Diameter

\subsection{Effect of (I/D) and remaining Independent Variables on $\log \left(X_{\text {damper }}\right)$}

Statistical analysis of the data is done considering log-transformed $\mathrm{X}_{\text {damper }}$, individually for every independent variable along with Insertion Depth/Duct (I/D) to determine the presence of any interaction effect of (I/D) and the respective independent variable. Check for presence of interaction effect is done by comparing the slope of independent variable cell means which is calculated considering (I/D) for $\log \left(\mathrm{X}_{\text {damper }}\right)$. 


\subsubsection{Effect of (I/D) and Damper Edges (Edge) on Log ( $\left.X_{\text {damper }}\right)$}

Plotting the log of the $\mathrm{X}_{\text {damper }}$ means for the two damper edges (straight/concave) against (I/D) leads to two regression lines with nearly identical slopes (see Figure 28) and slightly different intercepts.

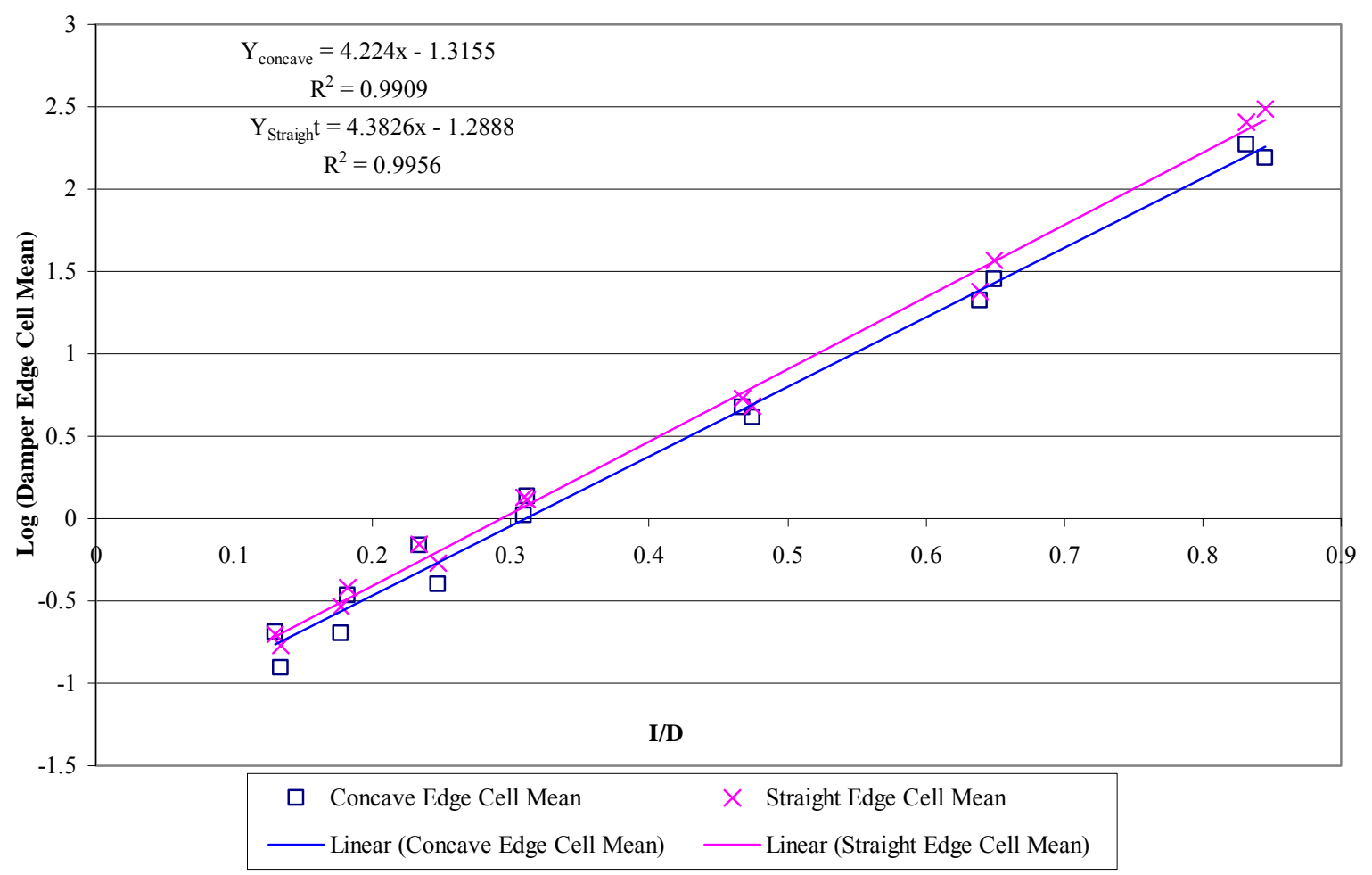

Figure 28 - Log cell means for damper edges

The concave damper edge regression line is consistently below the straight edge regression line. The slope of log cell means for straight edge is 3.6\% more than the log cell means for concave edge. The similarity of the slopes suggests that if there is an interaction between edge and (I/D), it is weak. 


\subsubsection{Effect of (I/D) and Air Flow Levels (VPCLopen) on Log ( $\left.\mathrm{X}_{\text {damper }}\right)$}

The cell means for $\log \left(\mathrm{X}_{\text {damper }}\right)$ and the four different levels of air flow are plotted against (I/D) and the regression lines are fitted in to the data for the four levels of $\mathrm{VP}_{\text {CLOpen }}$ (see Figure 29).

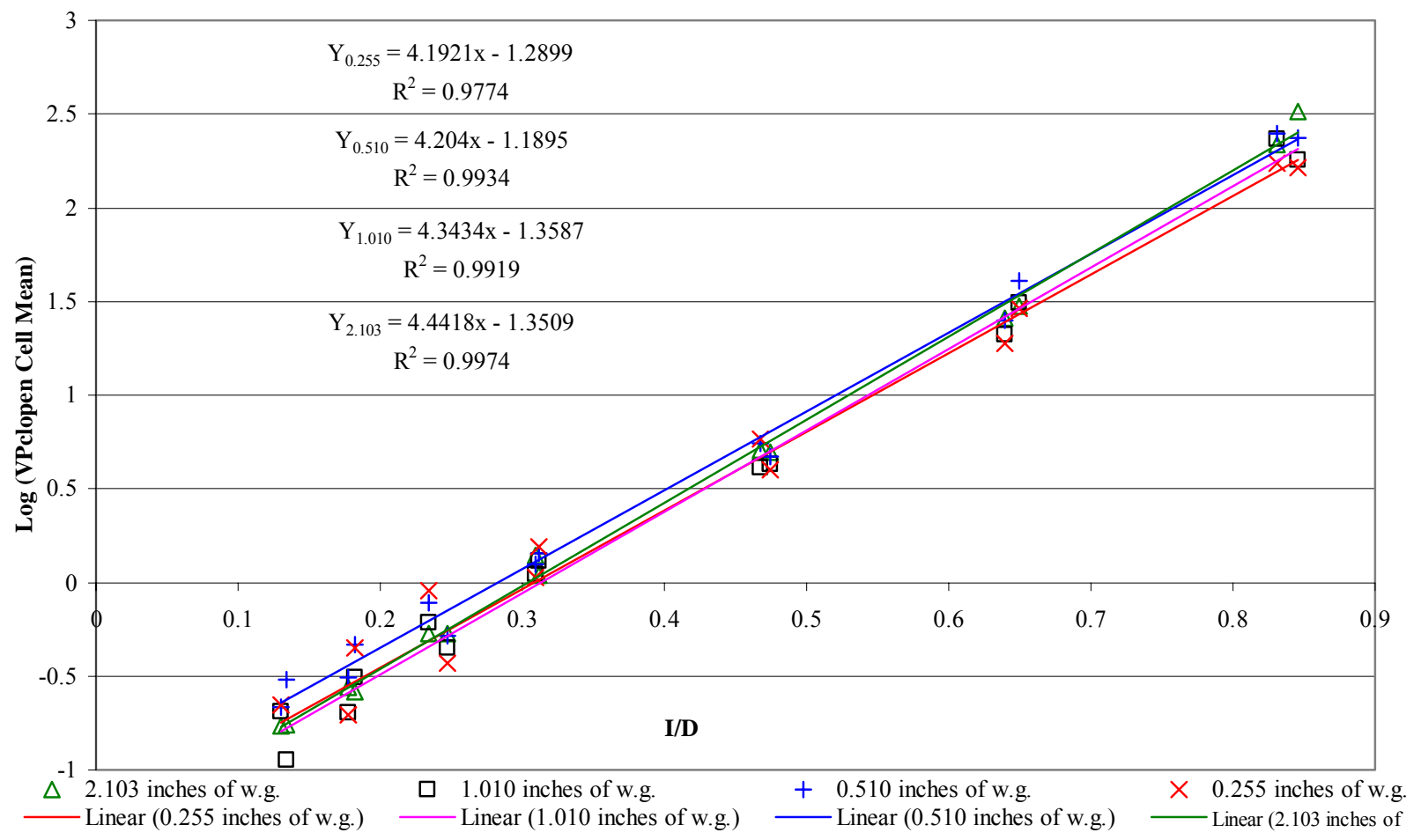

Figure 29 - Log cell means for $\mathrm{VP}_{\text {CLOpen }}$

It can be seen from Figure 29 that the regression lines for all levels of $\mathrm{VP}_{\mathrm{CLOpen}}$ have nearly identical slopes and slightly different intercepts. The value of slope of the mean regression lines for the four levels increased as the air flow level is increased. The regression lines are not parallel to each other. The slope value is increasing by approximately $5.9 \%$ from 0.255 inches of water gaze of velocity pressure to 2.103 inches of water gaze of velocity pressure. This suggests the possibility of presence of interaction effect between $\mathrm{VP}_{\mathrm{CLopen}}$ and (I/D). 


\subsubsection{Effect of (I/D) and Damper Orientation (Orient) on Log $\left(X_{\text {damper }}\right)$}

Plotting the cell means of $\log \left(\mathrm{X}_{\text {damper }}\right)$ for the two damper orientations against (I/D) leads to two regression lines with nearly identical slopes (see Figure 30).

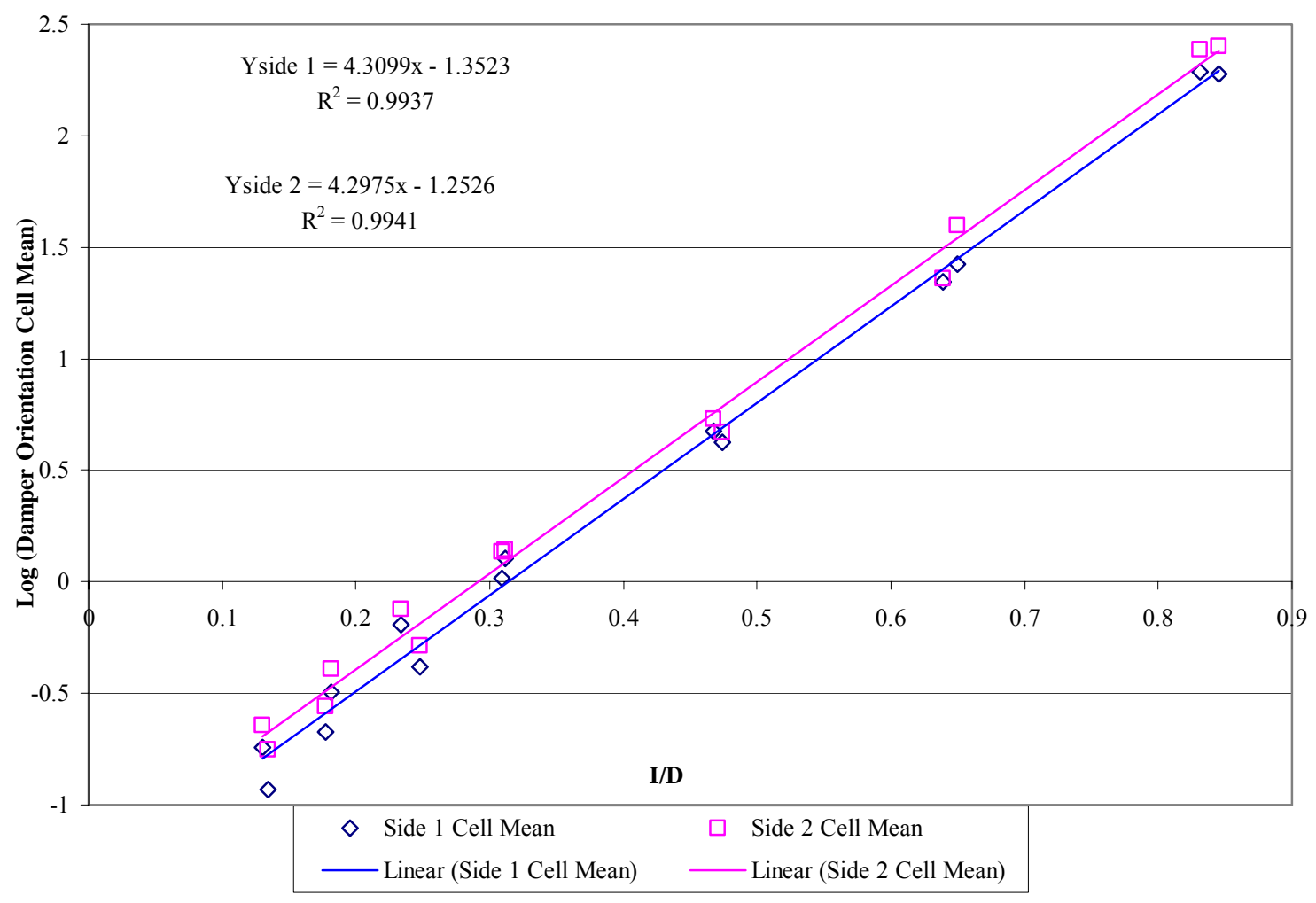

Figure 30 - Log cell means for damper orientation

The $X_{\text {damper }}$ values for the second orientation (side 2) are consistently above the values for first orientation (Side 1). The slope increases by a minimal amount of $0.47 \%$ from second orientation to first orientation. This suggests that the interaction affect of (I/D) and damper orientation is not significant. 


\subsubsection{Effect of (I/D) and Duct Diameter (D) on Log ( $\left.X_{\text {damper}}\right)$}

Plotting the cell means of $\log \left(\mathrm{X}_{\mathrm{damper}}\right)$ for the two duct diameters against percentage relative insertion depth (see Table 2) leads to two regression lines with slightly different slopes (see Figure 31) suggesting a weak interaction between duct diameter and (I/D).

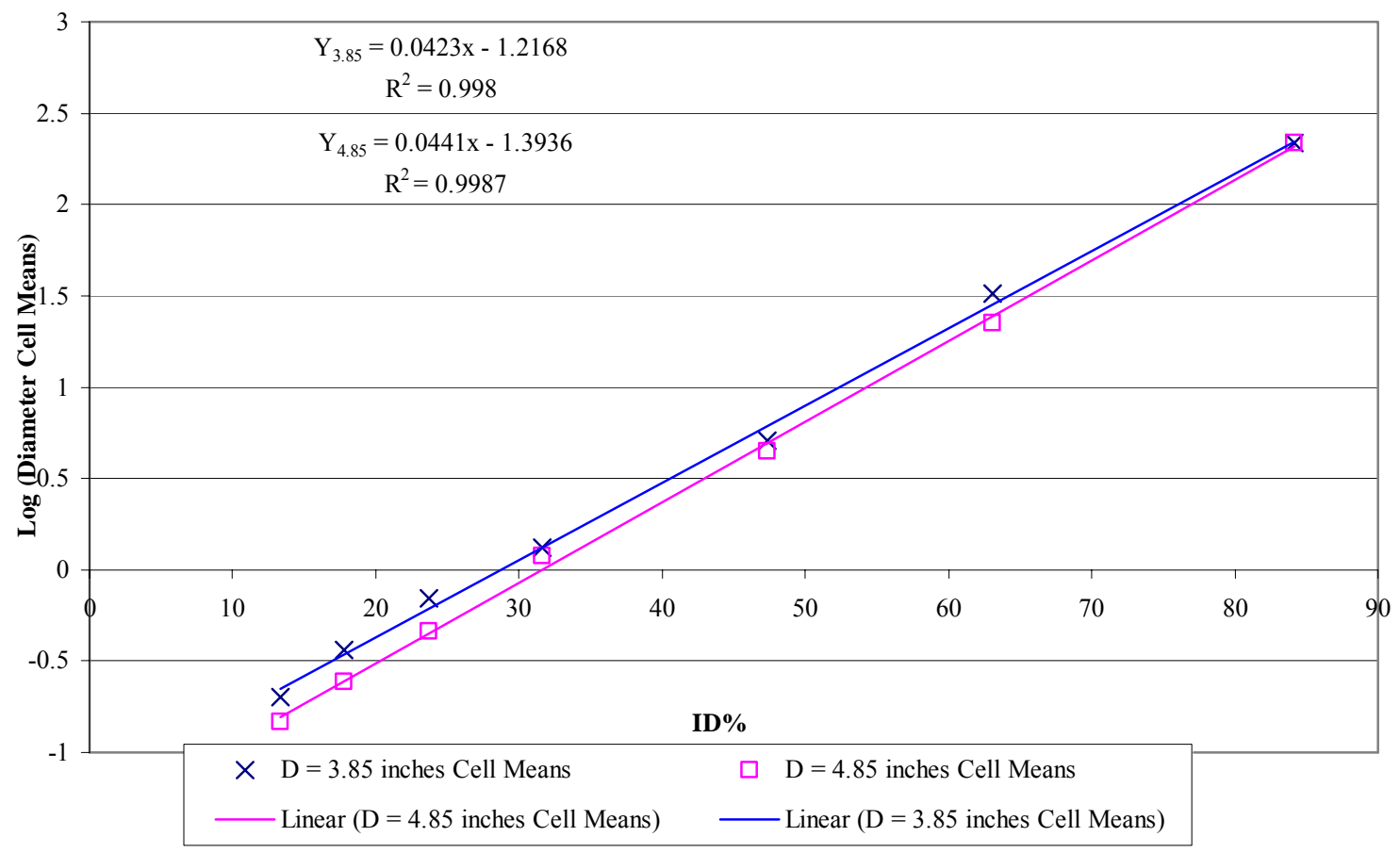

Figure 31 - Log cell means for duct diameter

The regression line for duct diameter of 3.85 inches is consistently above the regression line for duct diameter of 4.85 inches. Percentage change in slope of from 3.85 inches to 4.85 inches cell mean regression lines is about $4.3 \%$. Intercepts for both duct diameter $\log$ cell means are also different and every value for the larger diameter is slightly lower than the corresponding value of smaller diameter, suggesting that (I/D) does not fully explain the effects of diameter on $\mathrm{X}_{\text {damper }}$. 


\section{Chapter 6 Discussion}

Data analysis was done using a commercial software package, Data-Desk (Version 5.0, Data-desk of Ithaca, N.Y.), to determine the relationship between $\mathrm{X}_{\text {damper }}$ and damper insertion depth (I) considering variables damper edge (Edge), air flow levels (VP $\left.{ }_{\text {CLopen }}\right)$, damper orientation (Orient) and duct diameter (D).

\subsection{Normality of Residuals for Log-transformed Data}

A normal probability plot of residuals for $\mathrm{X}_{\text {damper }}$ did not give a straight line (see Figure 32) which suggests that the error distribution was not normal and that $X_{\text {damper }}$ should be transformed for analysis.

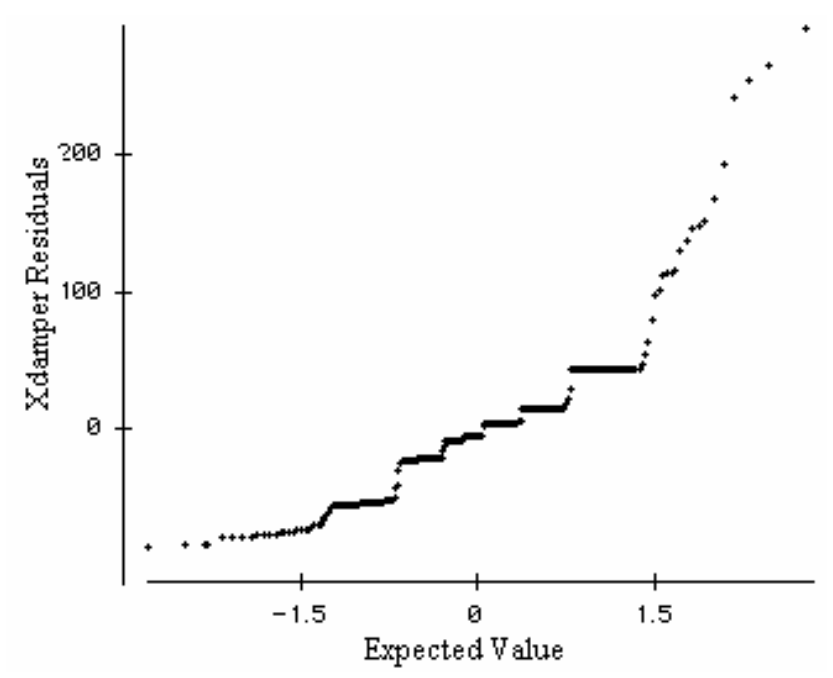

Figure 32 - Normal Probability Plot for $\mathbf{X}_{\text {damper }}$

The normal probability plot of the residuals (see Figure 33) for $\log \left(\mathrm{X}_{\text {damper }}\right)$ gives a straight line, which confirms normality and validates the fact that $\log \left(\mathrm{X}_{\text {damper }}\right)$ should be analyzed instead of $X_{\text {damper }}$. 


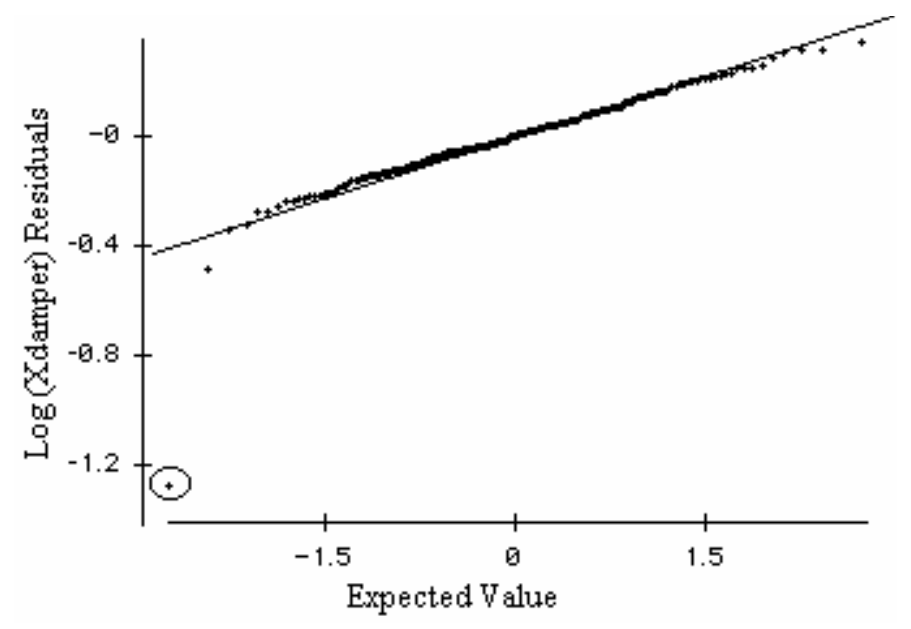

Figure 33 - Normal Probability Plot for $\log \left(\mathbf{X}_{\text {damper }}\right)$

\subsection{Identifying Outlying Observations}

Figure 33 shows the outlying observations (see circled values in Figure 33). This outlying observation corresponds to concave edge dampers for an air flow level of 0.510 inches of w.g., a duct diameter of 4.85 inches, side 1 and a relative insertion depth (I/D) of $13.34 \%$. This outlying point was measured again to check the validity of data collection. The results were consistent with previous values. However, the value of $\mathrm{X}_{\text {damper }}$ for this point is 0.0064 which is a uselessly low value for application. Rather than have this outlier strongly influence ANOVA and regression analyses, it is omitted from all statistical analyses.

\subsection{Analysis of Variance}

Analysis of variance was done (see Table 4) initially with all the independent variables (I/D), D, Edge, Orient, and $\mathrm{VP}_{\text {CLopen }}$ plus all two-way interactions. As shown in Table 4 relative insertion depth (I/D) contributed $97.6 \%$ of the total sum of squares explained by ANOVA. The remaining sum of squares for the other variables was minimal in comparison to (I/D). The error sum of squares was also very small compared to the (I/D) sum of squares. 
Table 4: - Analysis of Variance with all Independent Variables

\begin{tabular}{|c|c|c|c|c|c|}
\hline Source of Variation & Sums of Squares & df & Mean Square & F-ratio & P Value \\
\hline Constant & 42.199 & 1 & 42.199 & 3552.20 & $0.0001 *$ \\
\hline (I/D) & 241.705 & 1 & 241.705 & 20346.00 & $0.0001 *$ \\
\hline $\mathrm{D}$ & 0.466 & 1 & 0.466 & 39.21 & $0.0001 *$ \\
\hline$(\mathrm{I} / \mathrm{D}) * \mathrm{D}$ & 0.069 & 1 & 0.069 & 5.80 & $0.0170 *$ \\
\hline Orient & 0.135 & 1 & 0.135 & 11.32 & $0.0009 *$ \\
\hline$(\mathrm{I} / \mathrm{D}) *$ Orient & 0.000 & 1 & 0.000 & 0.01 & 0.9224 \\
\hline $\mathrm{D} *$ Orient & 0.000 & 1 & 0.000 & 0.03 & 0.8635 \\
\hline $\mathrm{VP}_{\text {CLopen }}$ & 0.227 & 3 & 0.076 & 6.38 & $0.0004 *$ \\
\hline$(\mathrm{I} / \mathrm{D}) * \mathrm{VP}_{\mathrm{CLopen}}$ & 0.126 & 3 & 0.042 & 3.54 & $0.0156^{*}$ \\
\hline $\mathrm{D}^{*} \mathrm{VP}_{\mathrm{CLopen}}$ & 0.542 & 3 & 0.181 & 15.21 & $0.0001 *$ \\
\hline Orient* $\mathrm{VP}_{\mathrm{CLopen}}$ & 0.024 & 3 & 0.008 & 0.67 & 0.5688 \\
\hline Edge & 0.008 & 1 & 0.008 & 0.69 & 0.4063 \\
\hline$(\mathrm{I} / \mathrm{D}) *$ Edge & 0.087 & 1 & 0.087 & 7.32 & $0.0074 *$ \\
\hline D*Edge & 0.100 & 1 & 0.100 & 8.45 & $0.0041 *$ \\
\hline Orient*Edge & 0.00045 & 1 & 0.000 & 0.01 & 0.9272 \\
\hline $\mathrm{VP}_{\text {CLopen }}{ }^{*}$ Edge & 0.334 & 3 & 0.111 & 9.38 & $0.0001 *$ \\
\hline Error & 2.340 & 197 & 0.012 & & \\
\hline Total & 247.436 & 222 & & & \\
\hline
\end{tabular}

When insignificant independent variables $(\mathrm{P}>0.05)$ were removed from the model, terms were reduced to the values shown in Table 5. It can be observed that (I/D) still contributed $97.6 \%$ of the sum of squares explained by ANOVA, whereas the remaining sum of squares for the other significant variables was minimal. Error sum of squares contributed $1 \%$ to the total sum of squares which is very low when compared to (I/D)

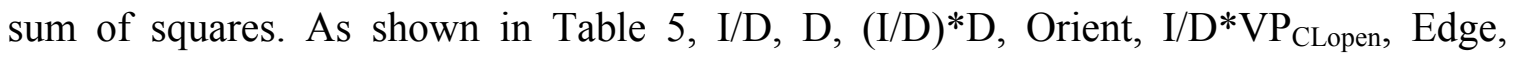
$\mathrm{D}^{*} \mathrm{VP}_{\mathrm{CLopen}},(\mathrm{I} / \mathrm{D} *$ Edge $), \mathrm{D} *$ Edge, $\mathrm{VP}_{\mathrm{CLopen}}{ }^{*}$ Edge were significant. The fact that $\mathrm{D}$ and $\mathrm{VP}_{\mathrm{CLopen}}$ were significant (but not substantial), suggests modest Reynolds number effects. Orientation was significant (but not substantial), can perhaps be explained by the difference in construction of the inlet and outlet due to the gasket protruding on side 2 . However orientation is an impractical variable in a predictive model for two reasons: 1) the asymmetry was too subtle for a practitioner to notice and 2) the manufacturer did not 
mark the direction of flow. For that reason Orientation and Orientation interactions were removed from the regression analyses.

Table 5: - Analysis of Variance with Significant Independent Variables

\begin{tabular}{|c|c|c|c|c|c|}
\hline Source of Variation & Sums of Squares & df & Mean Square & F-ratio & P Value \\
\hline Constant & 42.199 & 1 & 42.199 & 2954.40 & 0.0001 \\
\hline Edge & 0.444 & 1 & 0.444 & 31.07 & 0.0001 \\
\hline $\mathrm{I} / \mathrm{D}$ & 241.945 & 1 & 241.945 & 16939.00 & 0.0001 \\
\hline $\mathrm{VP}_{\text {CLopen }}$ & 0.417 & 3 & 0.139 & 9.72 & 0.0001 \\
\hline $\mathrm{D}$ & 0.512 & 1 & 0.512 & 35.84 & 0.0001 \\
\hline $\mathrm{I} / \mathrm{D} * \mathrm{D}$ & 0.068 & 1 & 0.068 & 4.76 & 0.0302 \\
\hline $\mathrm{D}^{*}$ Edge & 0.097 & 1 & 0.097 & 6.81 & 0.0097 \\
\hline $\mathrm{I} / \mathrm{D}^{*} \mathrm{VP}_{\text {CLopen }}$ & 0.124 & 1 & 0.124 & 8.67 & 0.0036 \\
\hline $\mathrm{VP}_{\text {CLopen }} *$ Edge & 0.341 & 3 & 0.114 & 7.96 & 0.0001 \\
\hline $\mathrm{D} * \mathrm{VP}_{\mathrm{CLopen}}$ & 0.425 & 1 & 0.425 & 29.73 & 0.0001 \\
\hline I/D*Edge & 0.092 & 1 & 0.092 & 6.48 & 0.0117 \\
\hline Error & 2.971 & 208 & 0.014 & & \\
\hline Total & 247.436 & 222 & & & \\
\hline
\end{tabular}

\subsection{Regression Analysis}

Regression analysis was done for the 10 significant variables (see Table 4) to come up with a regression model for $\log \left(\mathrm{X}_{\text {damper }}\right)$. Regression coefficients for the significant variables have been written in an equation (see Equation 32 ). $\mathrm{R}^{2}$ is also calculated to determine the fit of the regression equation which was found to be $0.985 . \mathrm{R}^{2}$ value of 0.985 indicates that the degree of linear association between the log-transformed $\mathrm{X}_{\text {damper }}$ the 10 significant independent variables is high and the model is a good fit to the data.

$$
\begin{aligned}
Y_{\log (\text { Ximper })=} & 0.524-0.310 *(E d g e)+3.286 *\left(\frac{I}{D}\right)-0.531 *\left(V P_{\text {Clopen }}\right)-0.431 * D+ \\
& 0.151 *\left(\frac{I}{D} * D\right)+0.087 *\left(E_{\text {dge }}^{*} D\right)+0.133 *\left(\frac{I}{D} * V P_{\text {Clopen }}\right)-0.042 *\left(E_{\text {dge }} * V P_{\text {Clopen }}\right)+ \\
& 0.124 *\left(V_{\text {Clopen }} * D\right)+0.159 *\left(\frac{I}{D} * E d g e\right)
\end{aligned}
$$

Equation (32) 
As shown in Figure 34, the variance does not appear to change with level of $\log \left(\mathrm{X}_{\text {damper }}\right)$. $\mathrm{R}^{2}$ for the plot is 0.985 .

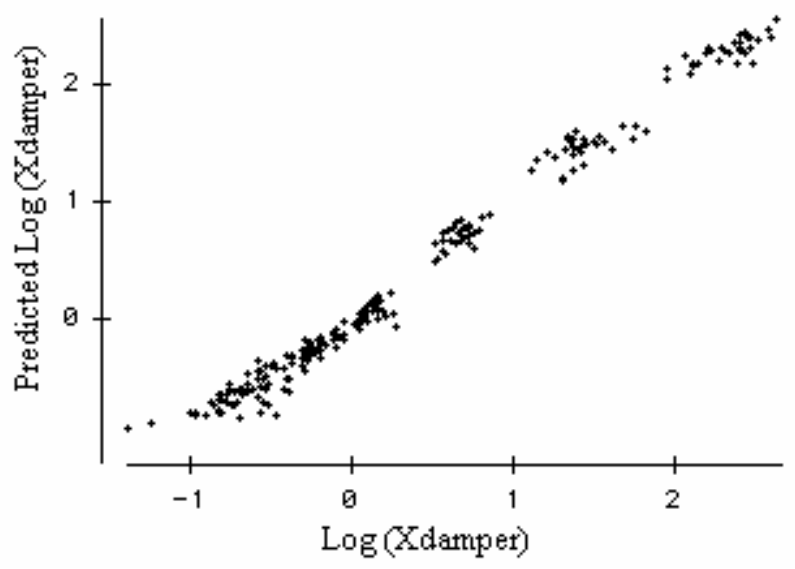

Figure 34 - Predicted Log $\left(X_{\text {damper }}\right)$ V/S Observed Log $\left(X_{\text {damper }}\right)$

\subsection{Reduced Regression Analysis Based on $\mathbf{R}^{2}$}

Further regression analysis for the model derived in Equation 32 was done to reduce the number of independent variables. Variables were removed from the regression model on their contribution to $\mathrm{R}^{2}$ (see Table 6). 
Table 6: - $\mathbf{R}^{2}$ Analysis for Reduced Regression Model

\begin{tabular}{|c|c|c|c|}
\hline Independent Variables & Variable Removed & R-Square & \% Change in $\mathrm{R}^{2}$ \\
\hline $\begin{array}{c}\text { Edge, } \mathrm{I} / \mathrm{D}, \mathrm{VP}_{\mathrm{CLopen}}, \mathrm{D},(\mathrm{I} / \mathrm{D} * \mathrm{D}), \\
\left(\text { Edge }^{*} \mathrm{D}\right),\left(\mathrm{I} / \mathrm{D} \mathrm{VP}_{\mathrm{CLopen}}\right) \\
\left(\text { Edge*VP }^{*} \mathrm{VP}_{\text {CLopen }}\right),\left(\mathrm{VP}_{\mathrm{CLopen}}{ }^{*} \mathrm{D}\right), \\
(\mathrm{I} / \mathrm{D} * \text { Edge })\end{array}$ & None & 0.9850 & - \\
\hline $\begin{array}{c}\text { Edge, I/D, VP } \\
\text { (Edge* } \mathrm{D}),\left(\mathrm{I} / \mathrm{D}^{*} \mathrm{VP}_{\mathrm{CLopen}}\right) \\
\left(\text { Edge*VP }_{\mathrm{CLopen}}\right),\left(\mathrm{VP}_{\mathrm{CLopen}}{ }^{*} \mathrm{D}\right)\end{array}$ & (I/D*Edge) & 0.9850 & $0.00 \%$ \\
\hline $\begin{array}{c}\text { Edge, I/D, } \mathrm{VP}_{\mathrm{CLopen}}, \mathrm{D},\left(\mathrm{Edge}^{*} \mathrm{D}\right), \\
\left(\mathrm{I} / \mathrm{D}^{*} \mathrm{VP}_{\mathrm{CLopen}}\right),\left(\text { Edge* }^{*} \mathrm{VP}_{\text {CLopen }}\right) \\
\left(\mathrm{VP}_{\mathrm{CLopen}}{ }^{* \mathrm{D})},\right.\end{array}$ & $(\mathrm{I} / \mathrm{D} * \mathrm{D})$ & 0.9850 & $0.00 \%$ \\
\hline $\begin{array}{l}\text { Edge, I/D, VP } \mathrm{CL}_{\mathrm{CLpen}}, \mathrm{D},\left(\mathrm{I} / \mathrm{D} * \mathrm{VP}_{\mathrm{CLopen}}\right), \\
\quad\left(\text { Edge } * \mathrm{VP}_{\mathrm{CLopen}}\right),\left(\mathrm{VP}_{\mathrm{CLopen}} * \mathrm{D}\right),\end{array}$ & $\left(\right.$ Edge $\left.^{*} \mathrm{D}\right)$ & 0.9840 & $0.10 \%$ \\
\hline $\begin{array}{c}\text { Edge, } \mathrm{I} / \mathrm{D}, \mathrm{VP}_{\mathrm{CLopen}}, \mathrm{D}, \\
\left(\text { Edge*VP }_{\text {CLopen }}\right),\left(\mathrm{VP}_{\mathrm{CLopen}}{ }^{* \mathrm{D})},\right.\end{array}$ & $\left(\mathrm{I} / \mathrm{D} * \mathrm{VP}_{\mathrm{CLopen}}\right)$ & 0.9840 & $0.10 \%$ \\
\hline Edge, I/D, $\mathrm{VP}_{\text {CLopen, }} \mathrm{D},\left(\mathrm{VP}_{\text {CLopen }}{ }^{*} \mathrm{D}\right)$ & $\left(\right.$ Edge $\left.^{*} \mathrm{VP}_{\text {CLopen }}\right)$ & 0.9830 & $0.20 \%$ \\
\hline $\mathrm{I} / \mathrm{D}, \mathrm{VP}_{\text {CLopen }}$, Edge, $\mathrm{D}$ & $\left(\mathrm{VP}_{\mathrm{CLopen}} * \mathrm{D}\right)$ & 0.9820 & $0.30 \%$ \\
\hline I/D, Edge, D, & $\mathrm{VP}_{\text {CLopen }}$ & 0.9820 & $0.30 \%$ \\
\hline $\mathrm{I} / \mathrm{D}$, Edge & $\mathrm{D}$ & 0.9780 & $0.71 \%$ \\
\hline $\mathrm{I} / \mathrm{D}$ & Edge & 0.9770 & $0.81 \%$ \\
\hline
\end{tabular}

The $\mathrm{R}^{2}$ decreases from 0.985 with all the significant independent variables to 0.977 with the model explained by just (I/D) (see Table 6). The overall percentage drop from $\mathrm{R}^{2}$ of 0.987 to $\mathrm{R}^{2}$ of 0.977 was about $.81 \%$ which can be considered negligible. Hence regression model can be explained with (I/D) and Edge with an $\mathrm{R}^{2}$ of 0.978 . The overall drop of $\mathrm{R}^{2}$ from 0.985 to 0.978 is about $.71 \%$ which can be considered negligible.

Edge has been included along with (I/D) in the reduced regression model for two reasons: 1) other edge shapes may have more substantial effects and 2) both straight and concave edges cannot be used at the same time. Thus log-transformed $\mathrm{X}_{\text {damper }}$ can be explained only in terms of (I/D) and Edge (see Equation 33). The $\mathrm{R}^{2}$ for the model was 0.978 . 


$$
Y_{\log (\text { Xamper })}=-1.434+0.089 *(E d g e)+4.30 *\left(\frac{I}{D}\right)
$$

As shown in Figure 35, the variance does not appear to change with level of $\log \left(\mathrm{X}_{\text {damper }}\right)$ for the reduced model. $\mathrm{R}^{2}$ for the plot is 0.978 .

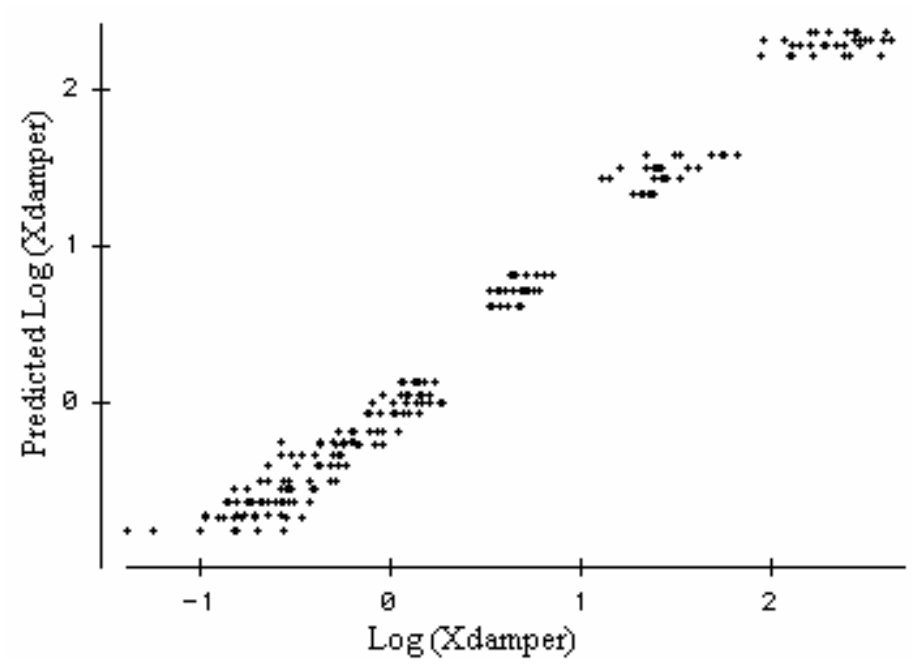

Figure 35 - Predicted Log ( $\left.X_{\text {damper }}\right)$ V/S Observed Log ( $X_{\text {damper }}$ (Reduced Model)

Reduced regression model (see Equation 33) was further broken down in to two models, each model representing a damper edge as both edges cannot be used at the same time to adjust airflow. Regression model for straight edge is as follows:

$$
Y_{\log (\text { Xamper })}=-1.289+4.383 *\left(\frac{I}{D}\right)
$$

$\mathrm{R}^{2}$ value for the model in Equation 34 was 0.986, which indicates a good fit.

Regression model for concave edge is as follows:

$$
Y_{\log (\text { Xamper })}=-1.311+4.217 *\left(\frac{I}{D}\right)
$$

$\mathrm{R}^{2}$ value for the model in Equation 35 was 0.971, which indicates a good fit.

Plots of the residuals of Equations 32 and 33 show high normality and linearly uniform variance with different levels of each independent variable. 
Further analysis was done after removing $\mathrm{VP}_{\mathrm{CLopen}}$ and $\mathrm{D}$ and including Reynolds Number as one of the independent variable. However using Reynolds Number as an independent variable for analysis lead to a regression model similar to the reduced regression model (see Equation 33) making Reynolds Number highly insignificant.

Regression analysis was also done considering damper percentage open area as one of the independent variables instead of insertion depth for the straight edge damper as damper percentage open area cannot be calculated for concave edge damper. Regression analysis was done considering $\left(\mathrm{A}_{\text {open }} / \mathrm{A}_{\text {total }}\right)$ as the independent variable for straight edge, as tested in Equation 36. The model $\mathrm{R}^{2}$ was found to be 0.987 .

$$
\begin{gathered}
Y_{\log (\text { Xalaper })}=3.108-4.401 *\left(\frac{A_{\text {open }}}{A_{\text {total }}}\right) \\
\text { Where }{ }_{\text {oppen }}=D^{2} *\left[\frac{\left(\frac{S * 2}{D}\right)-\text { Sine }\left(\frac{S * 2}{D}\right)}{8}\right]
\end{gathered}
$$

Where $\mathrm{S}=$ Arc length with the chord

$$
\mathrm{D}=\text { Duct diameter }
$$

Regression analysis for straight edge damper using relative insertion depth instead of percentage open area (see Equation 38) resulted in a $\mathrm{R}^{2}$ of 0.986 .

$$
Y_{\log (\text { Xamper })}=-1.289+4.383 *\left(\frac{I}{D}\right)
$$

Comparing both models (see Equation 36 and 38) it can be seen that both models have the same $\mathrm{R}^{2}$ and hence percentage open area has the same effect on $\mathrm{X}_{\text {damper }}$ as relative insertion depth. 


\subsection{Non Log-Transformed Predictive Models}

The two regression models listed in Equation 32 and Equation 33 are compared on the basis of residual error plots against (I/D). The residuals are untransformed in both cases in order to determine the untransformed error rather than the log-transformed error.

\subsubsection{Predictive Models for $\mathbf{X}_{\text {damper }}$}

For application, Equations 32, 33, 34, and 35, should be transformed to the following non-log versions: The untransformed predicted model for $\mathrm{X}_{\text {damper }}$ for complete model from Equation 32 is as follows:

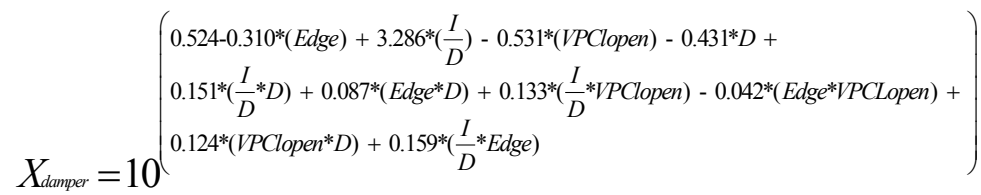

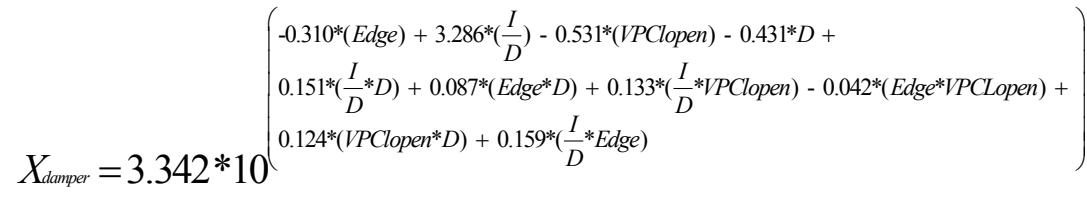

The untransformed predicted model for $\mathrm{X}_{\text {damper }}$ for reduced model from Equation 33 is as follows:

$$
\begin{aligned}
& X_{\text {damper }}=10^{\left(-1.434+0.089 *(\text { Edge })+4.3 * \frac{I}{D}\right)} \\
& X_{\text {damper }}=0.037 * 10^{\left(0.089 *(E d g e)+4.3 * \frac{I}{D}\right)}
\end{aligned}
$$

The predicted model for $\mathrm{X}_{\text {damper }}$ for straight edge from Equation 34 is as follows:

$$
\begin{aligned}
& X_{\text {damper }}=10^{\left(-1.289+4.383 * \frac{I}{D}\right)} \\
& X_{\text {damper }}=0.051 * 10^{\left(4.383 * \frac{I}{D}\right)}
\end{aligned}
$$


The predicted model for $\mathrm{X}_{\mathrm{damper}}$ for concave edge from Equation 35 is as follows:

$$
\begin{aligned}
& X_{\text {damper }}=10^{\left(-1.311+4.217 * \frac{I}{D}\right)} \\
& X_{\text {damper }}=0.049 * 10^{\left(4.217 * \frac{I}{D}\right)}
\end{aligned}
$$

Where $\mathrm{X}_{\text {damper }}$ is damper resistance

Edge is damper edge

(I/D) is insertion depth/duct diameter

\subsubsection{Complete Regression Model}

It can be noted from Figure 36 that the observed and predicted $\mathrm{X}_{\text {damper }}$ behave similarly with (I/D).
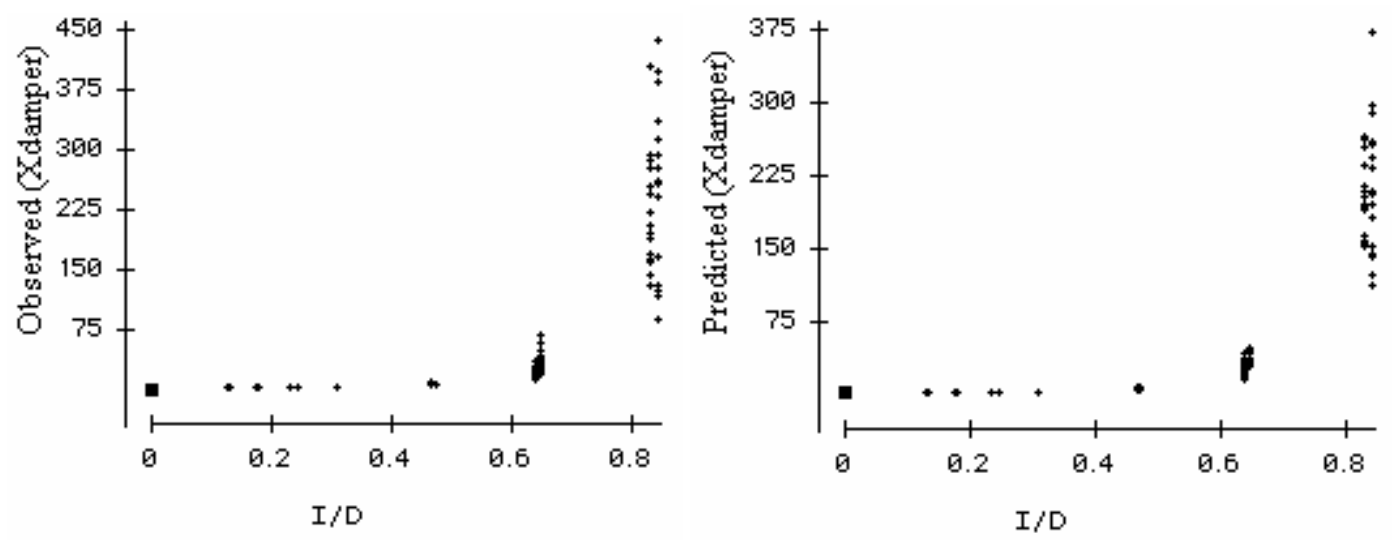

Figure 36 - Observed and Predicted ( $\left.\mathrm{X}_{\text {damper }}\right)$ V/S (I/D) (Complete Model)

A plot of $\mathrm{X}_{\text {damper }}$ residuals (obtained by transforming the $\log \left(\mathrm{X}_{\text {damper }}\right)$ residuals back to $\mathrm{X}_{\text {damper }}$ residuals) against (I/D) indicates that the absolute error (see Figure 37) increases sharply with (I/D). 


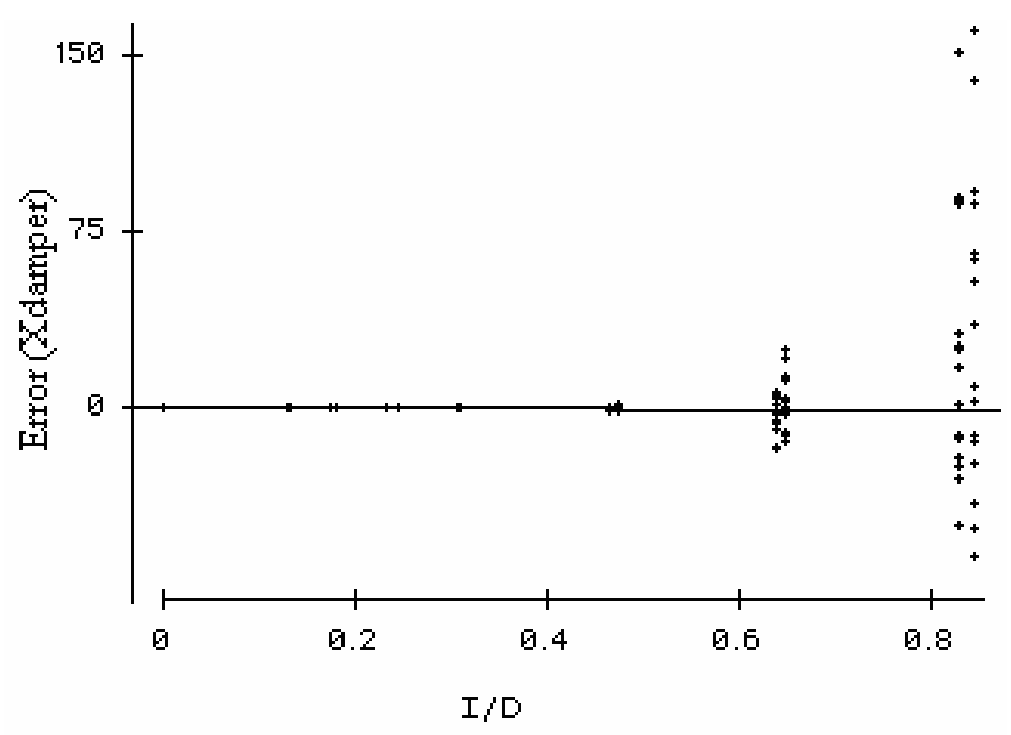

Figure 37 - Residuals ( $\mathrm{X}_{\text {damper}}$ ) V/S (I/D) (Complete Model)

As would be expected from Figure 37, a plot of $X_{\text {damper }}$ residuals against predicted $\left(\mathrm{X}_{\text {damper }}\right)$ indicates that the absolute error (see Figure 38 ) increases sharply with predicted $\left(\mathrm{X}_{\text {damper }}\right)$.

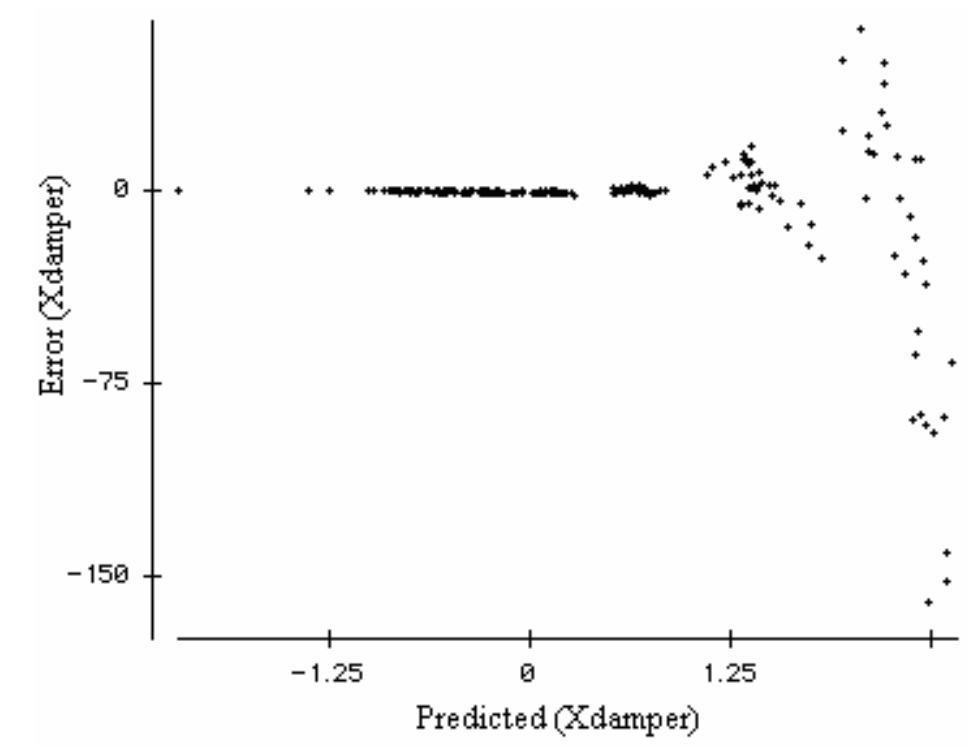

Figure 38 - Residuals $\left(\mathbf{X}_{\text {damper }}\right)$ V/S Predicted ( $\left.\mathbf{X}_{\text {damper }}\right)$ (Complete Model) 
The maximum percent error of $X_{\text {damper }}$ is around $125 \%$ (see Figure 39), which is very high. As shown in Figure 39, errors commonly exceed $\pm 25 \%$ throughout the range of $\mathrm{X}_{\text {damper }}$. The ratio of airflows for ducts at a junction fitting is proportional to square root of the ratios of their end damper resistance $\left(X_{\text {end }}\right)$ (Guffey, 1993). Hence the errors in achieving airflows would be proportional to the square root of $\mathrm{X}$ values. For low values of $X_{\text {damper, }}$, the $X_{\text {end }}$ values typically range from 1 to 3 when no dampers are present. As noted in Equation 28 and 29, $\mathrm{X}_{\text {damper }}$ adds to $\mathrm{X}_{\text {end }}$ when a damper is inserted.

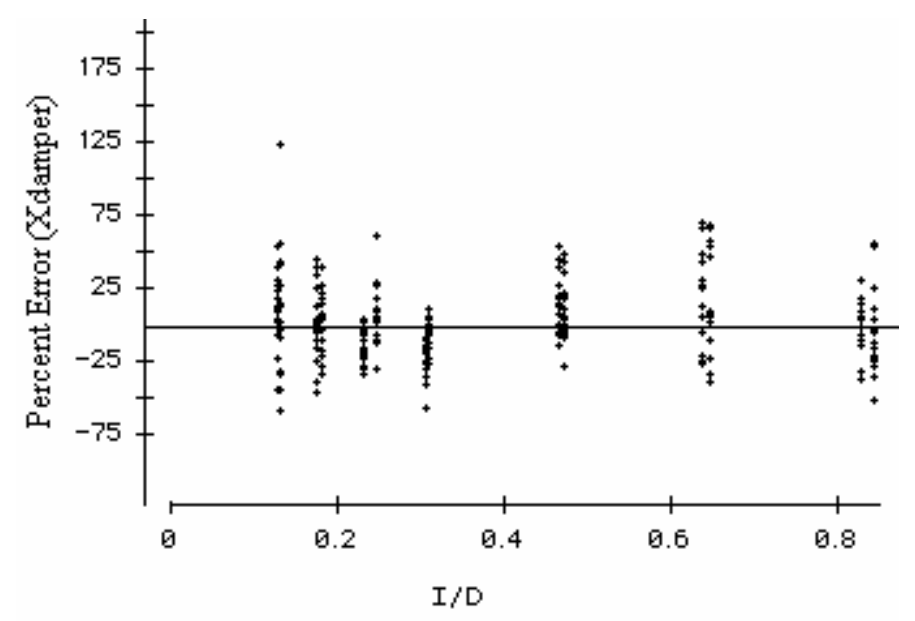

Figure 39 - Percent Error $\left(\mathrm{X}_{\text {damper }}\right)$ V/S (I/D) (Complete Model)

\subsubsection{Reduced Regression Model}

Reduced model is expected to behave in a similar manner as the complete model as shown in the following section. It can be noted from Figure 40 that the observed and predicted $\mathrm{X}_{\text {damper }}$ behave similarly with $(\mathrm{I} / \mathrm{D})$. However most of the $\mathrm{X}_{\text {damper }}$ values in the predicted plot are clustered around only few points as the reduced model is explained only in terms of Edge and (I/D). 

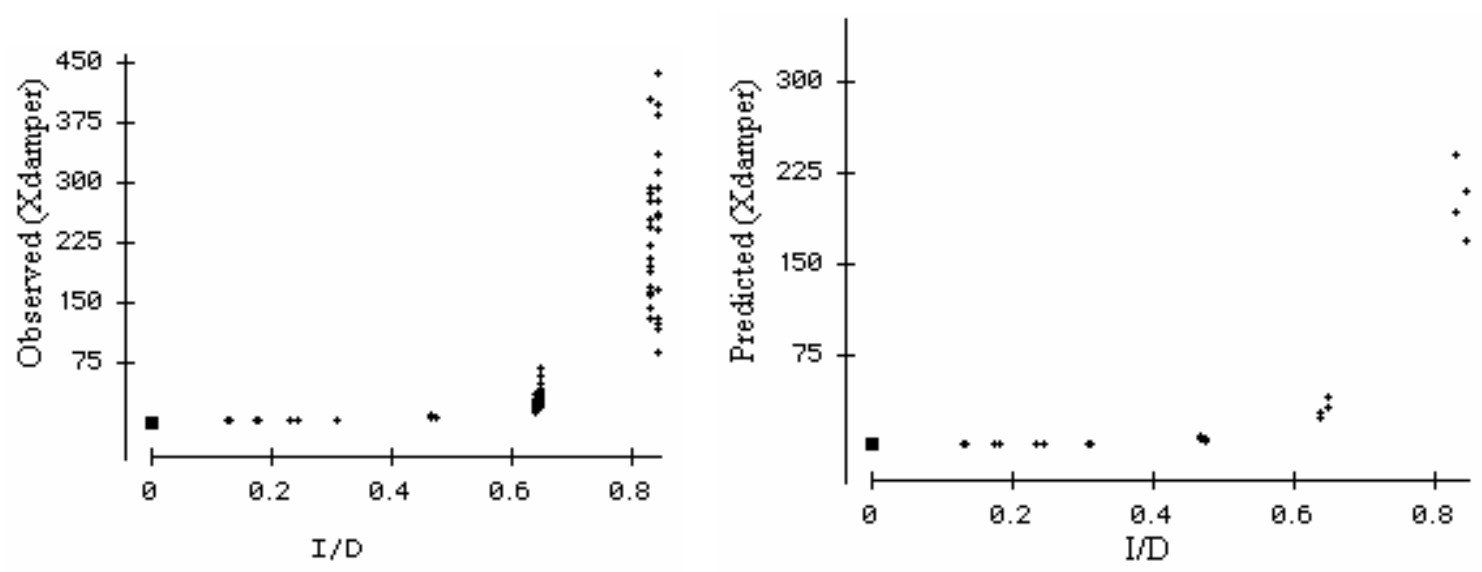

Figure 40 - Observed and Predicted ( $\left.X_{\text {damper }}\right)$ V/S (I/D) (Reduced Model)

A plot of $\mathrm{X}_{\text {damper }}$ residuals (obtained by transforming the $\log \left(\mathrm{X}_{\text {damper }}\right)$ residuals back to $\mathrm{X}_{\text {damper }}$ residuals) against (I/D) indicates that the absolute error (see Figure 41) increases sharply with (I/D).

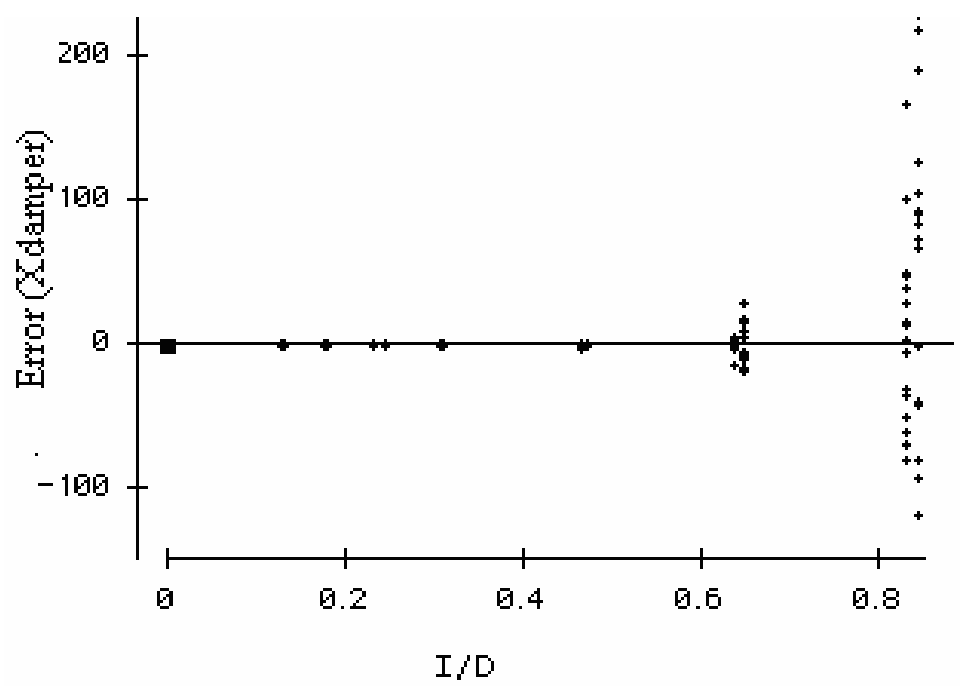

Figure 41 - Residuals ( $\left.\mathbf{X}_{\text {damper}}\right)$ V/S Predicted (X $\mathbf{X}_{\text {damper }}$ ) (Reduced Model)

As would be expected from Figure 41, a plot of $\mathrm{X}_{\text {damper }}$ residuals against predicted $\left(\mathrm{X}_{\text {damper }}\right)$ indicates that the absolute error (see Figure 42) increases sharply with predicted ( $\left.\mathrm{X}_{\text {damper }}\right)$. 


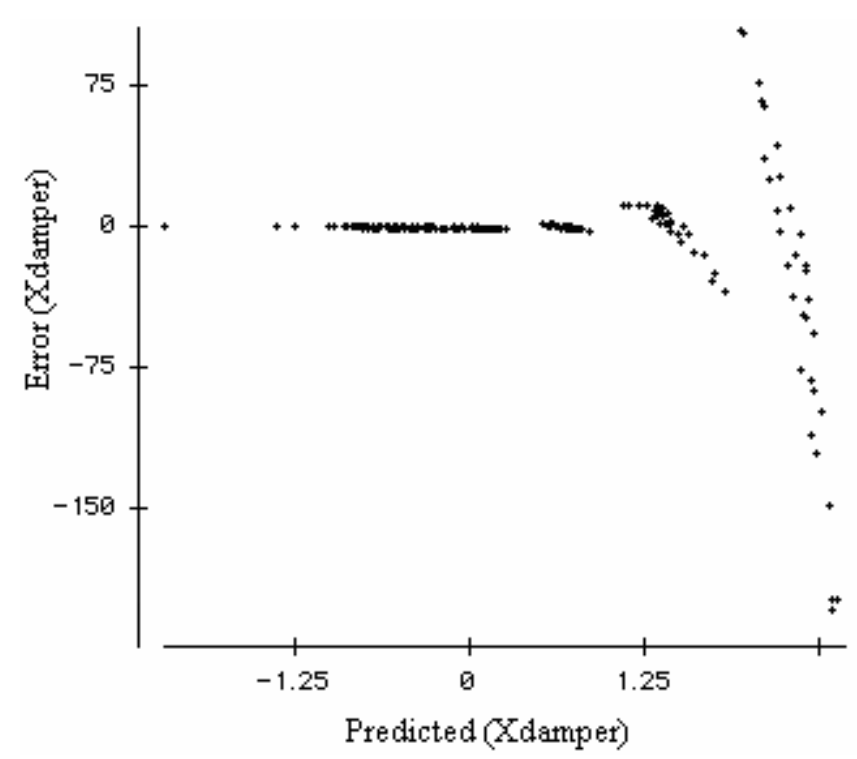

Figure 42- Residuals ( $\mathrm{X}_{\text {damper}}$ ) V/S (I/D) (Reduced Model)

The maximum percent error of $X_{\text {damper }}$ is about $125 \%$ which is very high (see Figure 43 ). As shown in Figure 43, errors commonly exceed $\pm 25 \%$ throughout the range of $X_{\text {damper }}$.

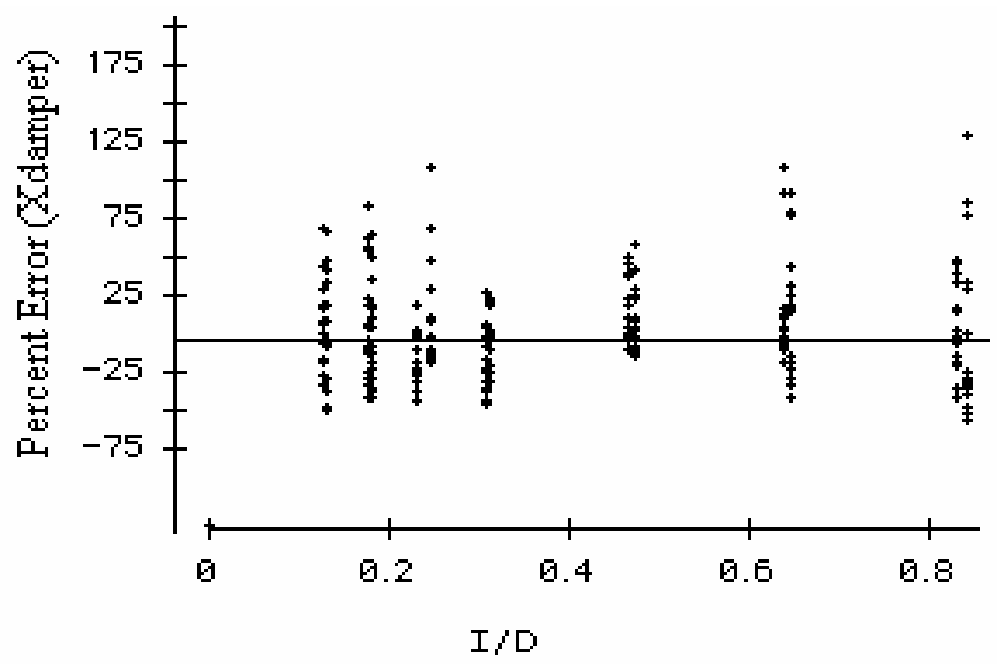

Figure 43 - Percent Error $\left(X_{\text {damper }}\right)$ V/S (I/D) (Reduced Model)

Complete and reduced regression models derived earlier (see Equation 32 and 33) have approximately the same absolute and percent error. $\mathrm{R}^{2}$ value is high and approximately same for both models hence both models are statistically accurate even though the 
absolute and percent error is high. Both models can be used to define $\mathrm{X}_{\text {damper }}$. However the reduced model is selected to determine the log-transformed $\mathrm{X}_{\text {damper }}$ as it has lesser number of variables.

Percent error in shifts in air flow (refer Equation 28 and 29) were plotted against (I/D) for the reduced model (see Figure 44). It can be noted from Figure 44, that for adjusting airflows $\left(\mathrm{X}_{\text {damper }}\right)$, the percent errors in shifts in airflow would reach a maximum value of $40 \%$.

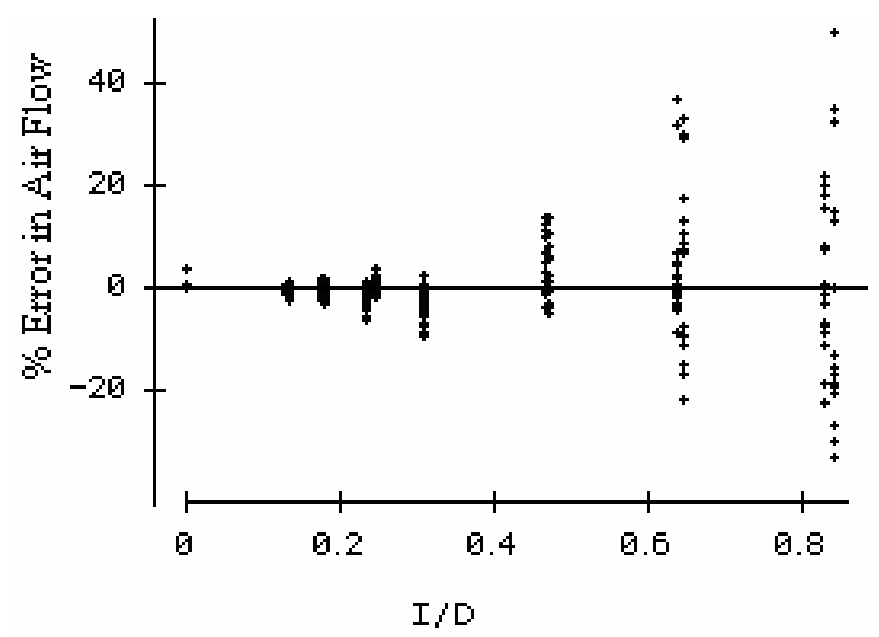

Figure 44 - Percent Error in Airflow V/S (I/D) (Reduced Model) 


\section{Chapter 7 Conclusions}

Values of $\mathrm{X}_{\text {damper }}$ varied exponentially with the relative insertion depth (I/D) as demonstrated by the highly linear relationship between $\log \left(\mathrm{X}_{\text {damper }}\right)$ and $\mathrm{I} / \mathrm{D}\left(\mathrm{R}^{2}=\right.$ 0.978). Orientation, Edge, duct diameter, and level of airflow were individually highly significant $(\mathrm{p}<0.01)$ with $\log \left(\mathrm{X}_{\mathrm{damper}}\right)$ as were most two-way interactions of independent variables. However, including all independent variables and all significant interactions increased the $\mathrm{R}^{2}$ by a very small amount for an $\mathrm{R}^{2}$ of 0.985 . Since Orientation, diameter, and airflow level significantly complicate the predictive model without adding much predictive power, they and their interactions were omitted from the "Reduced Model." The latter included Edge since other edge shapes may have more substantial effects.

$$
Y_{\log (\text { Xamper })}=-1.434+0.089 *(E d g e)+4.30 *\left(\frac{I}{D}\right)
$$

Although the log-transformed model fits the data with an $\mathrm{R}^{2}=0.978$, the recommended predictive models (Equations 32 and 33) each have errors that increase sharply with increasing I/D values with percent errors as high as $75 \%$ across the range of I/D. However non log-transformed $\mathrm{X}_{\text {damper }}$ errors in shifts in airflows would be as large as $40 \%$. This suggests that it would be nearly impossible to make substantial adjustment to airflow by setting insertion depth using only the predicted models for $\mathrm{X}_{\text {damper }}$. However the predicted models may be useful for an initial rough adjustment. Final adjustments could be done by trial and error adjustment to goal airflow.

Given the very good fit $\left(\mathrm{R}^{2}=0.978\right)$ for $\log \left(\mathrm{X}_{\text {damper }}\right)$, it is unlikely that superior methods can produce a substantially more useful predictive model for $\mathrm{X}_{\text {damper }}$. 


\section{Bibliography}

1. Steven E. Guffey and Jeffrey G. Spann (1999): Experimental Investigation of Power Loss Coefficients and Static Pressure Ratios in an Industrial Exhaust Ventilation System. American Industrial Hygiene Association Journal (May/June 1999): $60: 367-376$.

2. Michael Winifred Dodrill: Experimental Validation of the "Target Hood Static Pressure" Balancing Method for Exhaust Ventilation Systems. Masters Thesis, West Virginia University (2004)

3. Robert Van Becelaere, Harry J. Sauer and Fathi Finaish (January 2005): Flow Resistance Characteristics of Airflow Control Dampers. HVAC\&R Research: RP - 1157

4. Steven E. Guffey (1993): Airflow Redistribution in Exhaust Ventilation Systems Using Dampers and Static Pressure ratios. Applied Occupational Environmental Hygiene 8(3): 168 - 177 (1993b)

5. Haines, R. W.: HVAC Systems Design Handbook. Blue Ridge Summit, PA, 1988.

6. Holly M. Geiger: Evaluation of Proposed Static Pressure Ratio Balancing Method for Exhaust Ventilation Systems. Masters Thesis, University of Washington.

7. Sheet Metal and Air Conditioning Contractors' National Association. Inc. (1993). HVAC Systems Testing, Adjusting, \& Balancing. Published by SMACNA.

8. American Conference of Governmental Industrial Hygienists (ACGIH) Committee on Industrial Ventilation: Industrial Ventilation: A Manual of Recommended Practice, 23 ${ }^{\text {rd }}$ ed. Cincinnati, OH:ACGIH, 1997.

9. Steven E. Guffey (1994): Quantitative Troubleshooting of Industrial Exhaust Ventilation Systems. Applied Occupational Environmental Hygiene. 9:267 - 280 (1994) 
10. Crowder, J.W., \& Loudermilk, K.J.: Balancing of Industrial Ventilation Systems. Control Technology News. (1982) Vol. 32, No. 1

11. Steven E. Guffey, Derrick W. Booth: Comparison of Pitot Traverses Taken at Varying Distances Downstream of Obstructions. American Industrial Hygiene Association Journal. (1999) 60: 165 - 174.

12. American Conference of Governmental Industrial Hygienists (ACGIH) Committee on Industrial Ventilation: Industrial Ventilation: A Manual of Recommended Practice, $23^{\text {rd }}$ ed. Cincinnati, OH:ACGIH, 1998.

13. Ower, E., and Parkhurst, R.C.: The Measurement of Air Flow, $5^{\text {th }}$ edition. New York: Pergamon, 1977.

14. Hugh E. McLoone, Steven E. Guffey, \& James P. Curran: Effects of Shape, Size, and Air Velocity on Entry Loss Factors of Suction Hoods. American Industrial Hygiene Association Journal. (1993) 54(3): 87 - 94

15. Steven E. Guffey: Unpublished Manuscript. (2005)

16. Idelchik, I.E. (1972): Handbook of Hydraulic Resistance Coefficients of Local Resistance and Friction. US Atomic Energy Commission, AEC - TR - 6630, 1972. 


\section{Appendix I: HVAC Regulation Dampers}

In addition to the exhaust ventilation dampers there are other heating, ventilation and air conditioning (HVAC) dampers used to control the flow of air used for HVAC. HVAC installation dampers are generally installed on the fan inlet or outlet. Based on the fan performance, there are two types of dampers namely outlet dampers and inlet dampers. Outlet dampers mount on the fan outlet to add resistance to the system when partially closed. These dampers are available with either Back-draft or with outlet volume control dampers (see Figure 45). Outlet volume control dampers are further classified in to parallel and opposed blade dampers.
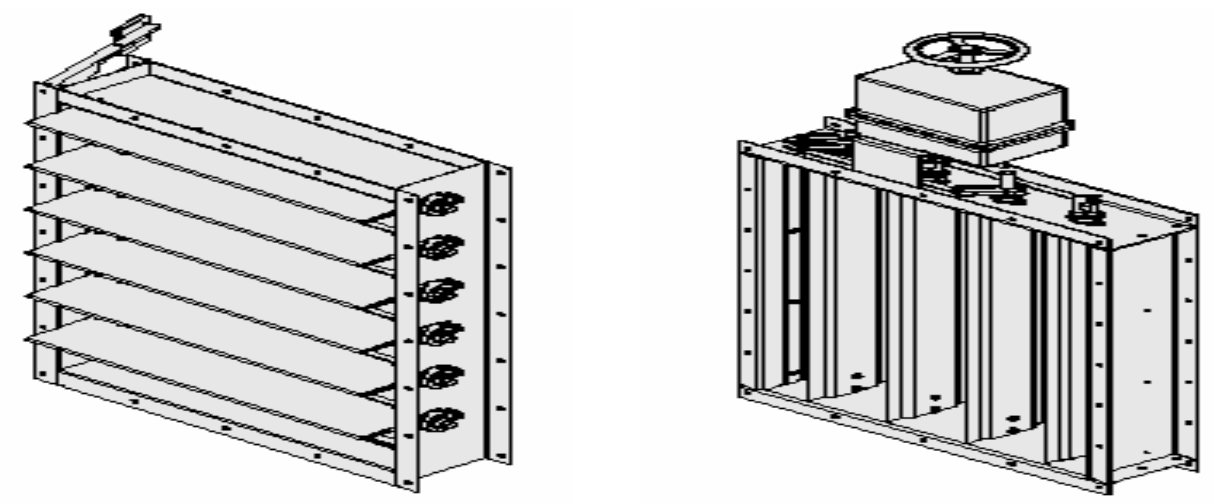

Figure 45 - Back draft Damper and Outlet Control Damper

Back draft dampers allow air to pass air in one direction and restrict the flow in opposite direction. Outlet volume control dampers regulate the airflow by modulating of damper blades. Actuators may be manual or pneumatic and are mounted out of the air stream. Control dampers are specially designed so blades are all perpendicular to the fan shaft. Parallel blade dampers (see Figure 46) have excellent control over the range of $75 \%$ to $100 \%$ wide-open volume due to the amount of control arm swing required to modulate the blades. Opposed blade dampers (see Figure 46) offer the best control over the entire operating range. 


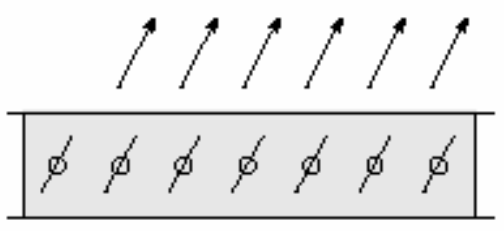

Parallel Blade

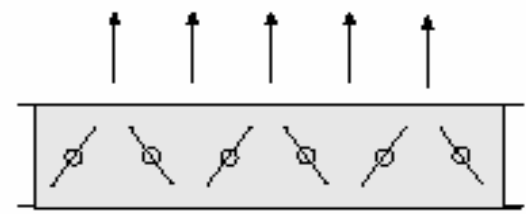

Opposed Blade

Figure 46 - Parallel Blade and Opposed Blade Outlet Dampers

Inlet dampers mount on the fan inlet to pre-spin air into the impeller. This reduces fan output and lowers operating horsepower. Because of the power savings, inlet dampers should be considered when the fan would operate for longer periods at reduced capacities. Inlet dampers include nested inlet vane, external inlet vane and inlet box dampers. Nested Inlet vane dampers (see Figure 47) are primarily used in non-ducted applications with space constraints. External Inlet Vane damper (see Figure 47) is intended for ducted applications and those with higher pressures and velocities. These dampers are mounted in the air stream or directly to the fan housing. Inlet box damper are used in standard or heavy-duty clean air applications with inlet boxes.
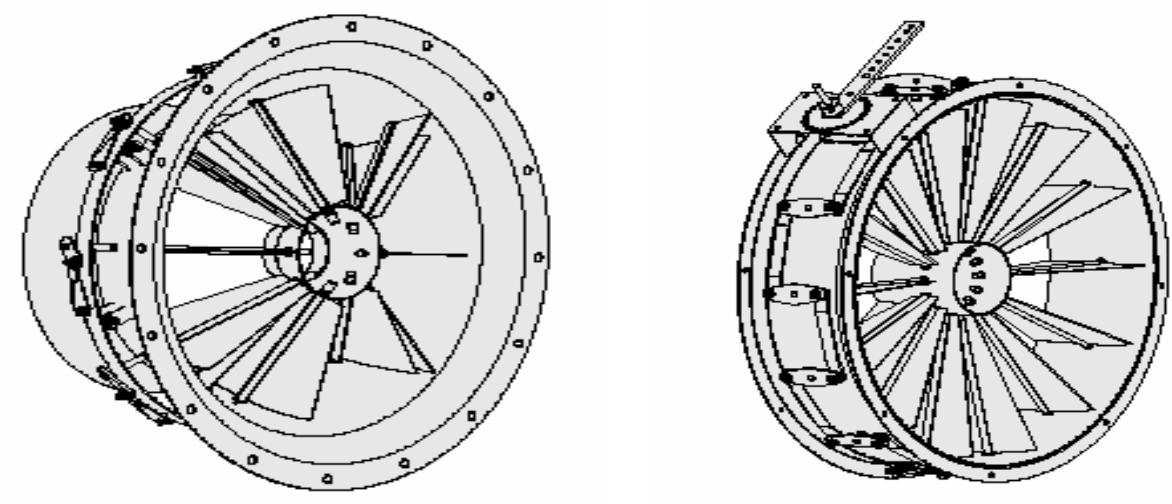

Figure 47 - Nested Inlet Vane Damper and External Inlet Vane Damper 


\section{Appendix II: Calibration of Digital Manometer}

\section{Equipment Used:}

Digital Manometer: TSI DP - Calc. Digital manometer Model: 8702 Serial: 96071045

Hook Gauge: Dwyer Instruments Inc. Pressure No. 1425 Hook Gauge.

The manometer was calibrated before data measurement was made and was verified after collecting the data. The manometer was calibrated first on 30 August 2005 and was calibrated again on the 10 September 2005, 30 September 2005 and 11 January 2006. 
Calibration Data for the Determination of the Original Distribution and Calibration Verification

\begin{tabular}{|c|c|c|c|c|}
\hline \multirow[t]{2}{*}{ Trial } & Date & \multirow[t]{2}{*}{ Time } & $\begin{array}{c}\text { Gage Water } \\
\text { Level }\end{array}$ & $\begin{array}{l}\text { Manometer } \\
\text { Reading }\end{array}$ \\
\hline & $\mathrm{mm} / \mathrm{dd} / \mathrm{yyyy}$ & & (Inches) & (Inches) \\
\hline \multirow{21}{*}{ Original } & \multirow{21}{*}{$8 / 30 / 2005$} & \multirow{21}{*}{ 11:50 P.M. } & 0 & 0 \\
\hline & & & 0.4 & 0.377 \\
\hline & & & 0.6 & 0.59 \\
\hline & & & 0.8 & 0.761 \\
\hline & & & 1.4 & 1.342 \\
\hline & & & 1.6 & 1.56 \\
\hline & & & 1.8 & 1.722 \\
\hline & & & 2 & 1.968 \\
\hline & & & 2.6 & 2.569 \\
\hline & & & 3 & 2.947 \\
\hline & & & 3.8 & 3.779 \\
\hline & & & 4 & 3.995 \\
\hline & & & 4.4 & 4.338 \\
\hline & & & 5 & 4.986 \\
\hline & & & 6 & 5.967 \\
\hline & & & 7 & 6.917 \\
\hline & & & 8 & 7.911 \\
\hline & & & 9 & 8.968 \\
\hline & & & 10 & 9.922 \\
\hline & & & 11 & 10.93 \\
\hline & & & 12 & 11.88 \\
\hline
\end{tabular}




\begin{tabular}{|c|c|c|c|c|}
\hline \multirow{2}{*}{ Trial } & Date & \multirow{2}{*}{ Time } & $\begin{array}{l}\text { Gage Water } \\
\text { Level }\end{array}$ & $\begin{array}{l}\text { Manometer } \\
\text { Reading }\end{array}$ \\
\hline & mm/dd/yyyy & & (Inches) & (Inches) \\
\hline \multirow{21}{*}{ Original } & \multirow{21}{*}{$9 / 10 / 2005$} & \multirow{21}{*}{ 9:15 P.M. } & 0 & 0 \\
\hline & & & 0.4 & 0.387 \\
\hline & & & 0.6 & 0.61 \\
\hline & & & 0.8 & 0.771 \\
\hline & & & 1.4 & 1.354 \\
\hline & & & 1.6 & 1.57 \\
\hline & & & 1.8 & 1.729 \\
\hline & & & 2 & 1.977 \\
\hline & & & 2.6 & 2.578 \\
\hline & & & 3 & 2.959 \\
\hline & & & 3.8 & 3.788 \\
\hline & & & 4 & 3.999 \\
\hline & & & 4.4 & 4.349 \\
\hline & & & 5 & 4.996 \\
\hline & & & 6 & 5.973 \\
\hline & & & 7 & 6.925 \\
\hline & & & 8 & 7.918 \\
\hline & & & 9 & 8.976 \\
\hline & & & 10 & 9.934 \\
\hline & & & 11 & 10.98 \\
\hline & & & 12 & 11.92 \\
\hline
\end{tabular}




\begin{tabular}{|c|c|c|c|c|}
\hline \multirow[t]{2}{*}{ Trial } & Date & \multirow[t]{2}{*}{ Time } & $\begin{array}{l}\text { Gage Water } \\
\text { Level }\end{array}$ & $\begin{array}{l}\text { Manometer } \\
\text { Reading }\end{array}$ \\
\hline & mm/dd/yyyy & & (Inches) & (Inches) \\
\hline \multirow{21}{*}{$\begin{array}{l}\text { Calibration } \\
\text { Verification }\end{array}$} & \multirow{21}{*}{$9 / 30 / 2005$} & \multirow{21}{*}{ 8.00 P.M. } & 0 & 0 \\
\hline & & & 0.4 & 0.396 \\
\hline & & & 0.6 & 0.72 \\
\hline & & & 0.8 & 0.793 \\
\hline & & & 1.4 & 1.362 \\
\hline & & & 1.6 & 1.58 \\
\hline & & & 1.8 & 1.733 \\
\hline & & & 2 & 1.979 \\
\hline & & & 2.6 & 2.68 \\
\hline & & & 3 & 2.971 \\
\hline & & & 3.8 & 3.81 \\
\hline & & & 4 & 4.01 \\
\hline & & & 4.4 & 4.392 \\
\hline & & & 5 & 5.11 \\
\hline & & & 6 & 6.09 \\
\hline & & & 7 & 6.946 \\
\hline & & & 8 & 7.939 \\
\hline & & & 9 & 9.161 \\
\hline & & & 10 & 9.987 \\
\hline & & & 11 & 11.231 \\
\hline & & & 12 & 12.19 \\
\hline
\end{tabular}




\begin{tabular}{|c|c|c|c|c|}
\hline \multirow[t]{2}{*}{ Trial } & Date & \multirow[t]{2}{*}{ Time } & $\begin{array}{l}\text { Gage Water } \\
\text { Level }\end{array}$ & $\begin{array}{l}\text { Manometer } \\
\text { Reading }\end{array}$ \\
\hline & mm/dd/yyyy & & (Inches) & (Inches) \\
\hline \multirow{21}{*}{$\begin{array}{l}\text { Calibration } \\
\text { Verification }\end{array}$} & \multirow{21}{*}{$1 / 11 / 2006$} & \multirow{21}{*}{ 6.00 P.M. } & 0 & 0 \\
\hline & & & 0.4 & 0.386 \\
\hline & & & 0.6 & 0.599 \\
\hline & & & 0.8 & 0.77 \\
\hline & & & 1.4 & 1.351 \\
\hline & & & 1.6 & 1.569 \\
\hline & & & 1.8 & 1.731 \\
\hline & & & 2 & 1.977 \\
\hline & & & 2.6 & 2.578 \\
\hline & & & 3 & 2.956 \\
\hline & & & 3.8 & 3.788 \\
\hline & & & 4 & 4.004 \\
\hline & & & 4.4 & 4.347 \\
\hline & & & 5 & 4.995 \\
\hline & & & 6 & 5.976 \\
\hline & & & 7 & 6.926 \\
\hline & & & 8 & 7.92 \\
\hline & & & 9 & 8.977 \\
\hline & & & 10 & 9.931 \\
\hline & & & 11 & 10.939 \\
\hline & & & 12 & 11.889 \\
\hline
\end{tabular}




\section{Appendix - III - (Flow chart for running the experiment)}

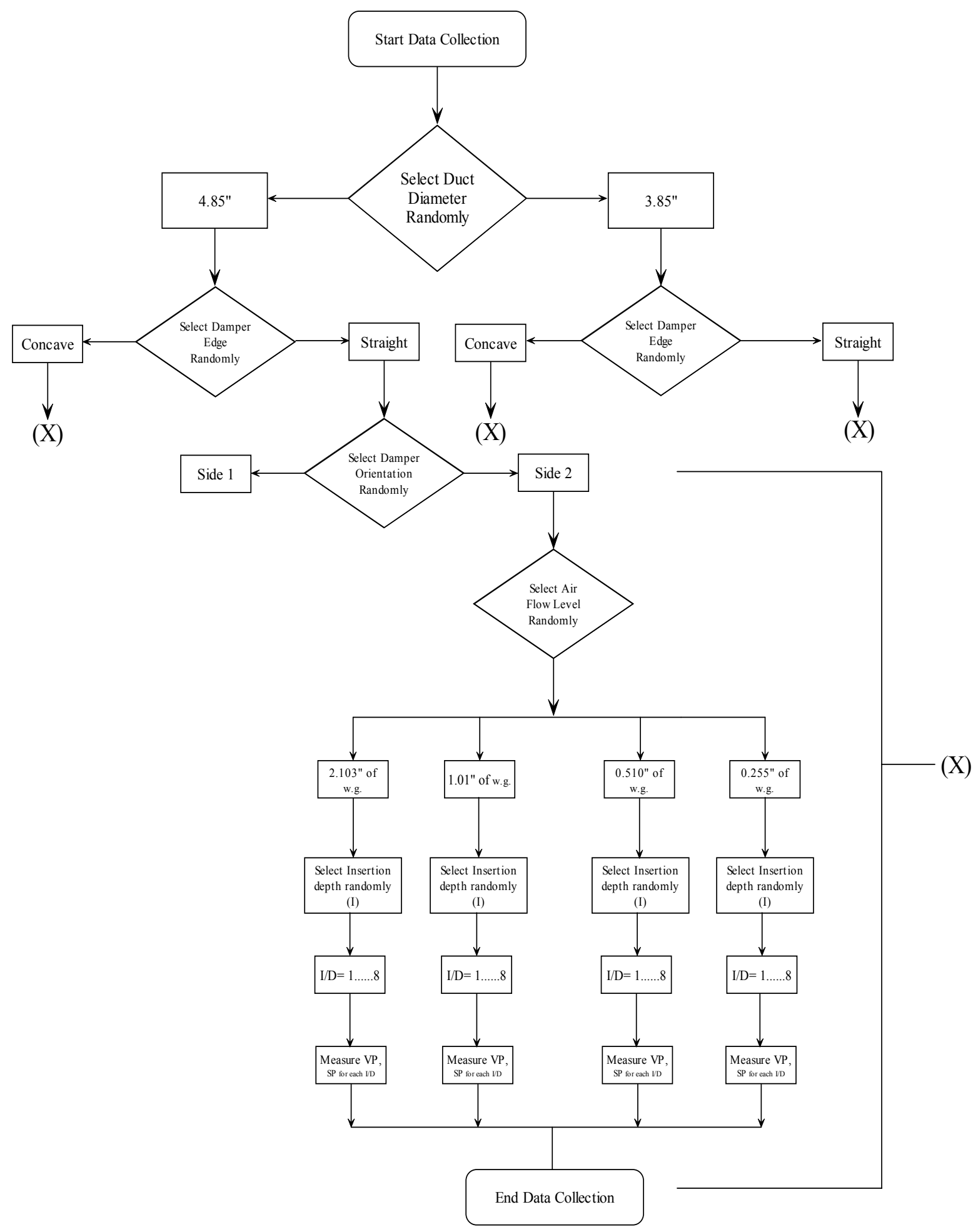




\section{Appendix - IV - Replication Combinations}

\begin{tabular}{|c|c|c|c|c|c|}
\hline Iteration & Duct Diameter & Damper Edge & Damper Orientation & Air Flow Level & Replicated \\
\hline 1 & 4.85 & Concave & Side 1 & $0.255^{\prime \prime}$ of w.g. & Yes \\
\hline 2 & 4.85 & Concave & Side 1 & $0.510 "$ of w.g. & Yes \\
\hline 3 & 4.85 & Concave & Side 1 & $1.010^{\prime \prime}$ of w.g. & No \\
\hline 4 & 4.85 & Concave & Side 1 & 2.103 " of w.g. & Yes \\
\hline 5 & 4.85 & Concave & Side 2 & $0.255^{\prime \prime}$ of w.g. & No \\
\hline 6 & 4.85 & Concave & Side 2 & $0.510 "$ of w.g. & No \\
\hline 7 & 4.85 & Concave & Side 2 & $1.010^{\prime \prime}$ of w.g. & No \\
\hline 8 & 4.85 & Concave & Side 2 & 2.103" of w.g. & No \\
\hline 9 & 4.85 & Straight & Side 1 & $0.255^{\prime \prime}$ of w.g. & No \\
\hline 10 & 4.85 & Straight & Side 1 & $0.510 "$ of w.g. & No \\
\hline 11 & 4.85 & Straight & Side 1 & $1.010 "$ of w.g. & No \\
\hline 12 & 4.85 & Straight & Side 1 & 2.103" of w.g. & No \\
\hline 13 & 4.85 & Straight & Side 2 & $0.255^{\prime \prime}$ of w.g. & No \\
\hline 14 & 4.85 & Straight & Side 2 & 0.510 " of w.g. & No \\
\hline 15 & 4.85 & Straight & Side 2 & $1.010 "$ of w.g. & Yes \\
\hline 16 & 4.85 & Straight & Side 2 & $2.103 "$ of w.g. & Yes \\
\hline 17 & 3.85 & Concave & Side 1 & $0.255^{\prime \prime}$ of w.g. & No \\
\hline 18 & 3.85 & Concave & Side 1 & $0.510 "$ of w.g. & No \\
\hline 19 & 3.85 & Concave & Side 1 & $1.010 "$ of w.g. & No \\
\hline 20 & 3.85 & Concave & Side 1 & 2.103" of w.g. & Yes \\
\hline 21 & 3.85 & Concave & Side 2 & $0.255^{\prime \prime}$ of w.g. & Yes \\
\hline 22 & 3.85 & Concave & Side 2 & $0.510^{\prime \prime}$ of w.g. & No \\
\hline 23 & 3.85 & Concave & Side 2 & $1.010^{\prime \prime}$ of w.g. & Yes \\
\hline 24 & 3.85 & Concave & Side 2 & 2.103" of w.g. & No \\
\hline 25 & 3.85 & Straight & Side 1 & $0.255^{\prime \prime}$ of w.g. & No \\
\hline 26 & 3.85 & Straight & Side 1 & $0.510 "$ of w.g. & Yes \\
\hline 27 & 3.85 & Straight & Side 1 & $1.010^{\prime \prime}$ of w.g. & No \\
\hline 28 & 3.85 & Straight & Side 1 & 2.103" of w.g. & Yes \\
\hline 29 & 3.85 & Straight & Side 2 & $0.255^{\prime \prime}$ of w.g. & No \\
\hline 30 & 3.85 & Straight & Side 2 & $0.510^{\prime \prime}$ of w.g. & No \\
\hline 31 & 3.85 & Straight & Side 2 & $1.010^{\prime \prime}$ of w.g. & No \\
\hline 32 & 3.85 & Straight & Side 2 & 2.103" of w.g. & No \\
\hline
\end{tabular}




\section{Appendix - V - Data}

Data collected in Ventilation Exposure Laboratory is as follows with their abbreviations:

I - Insertion depth

D - Duct diameter

$\mathrm{VP}_{\text {CLopen }}-$ Airflow levels

Orient - Damper orientation ( 0 - Side1, 1 - Side2)

Edge - Damper edge (Con - Concave, Strt. - Straight)

$\mathrm{SP}_{\text {end }}-$ End static pressure

$\mathrm{SP}_{\text {hood }}-$ Hood static pressure

$\mathrm{VP}_{1} \ldots \mathrm{VP}_{20}-$ Velocity traverses (Velocity pressure)

$\mathrm{VP}_{\mathrm{CL}}-$ Centerline velocity pressure

TP - Total Pressure

$\mathrm{X}_{\mathrm{w} / \mathrm{o}}$ - Resistance without damper

$\mathrm{X}_{\text {end }}$ - End damper resistance

$\mathrm{X}_{\text {damper }}$ - Damper resistance

$\mathrm{V}_{\text {avg. }}-$ Average velocity

$\mathrm{Re}$ - Reynolds number 


\begin{tabular}{|c|c|c|c|c|c|c|c|c|c|c|c|c|}
\hline Seq. & Year & Month & Date & Time & $\mathbf{T}_{\text {act }}$ & $\mathbf{P}_{\text {bar }}$ & I & D & $\mathbf{V P}_{\text {CLopen }}$ & Orient & Edge & I/D \\
\hline 1 & 2005 & 8 & 31 & 12.75 & 72 & 29.70 & 0 & 4.85 & 2.103 & 0 & Con & 0.000 \\
\hline 2 & 2005 & 8 & 31 & 12.75 & 72 & 29.70 & 0.65 & 4.85 & 2.103 & 0 & Con & 0.134 \\
\hline 3 & 2005 & 8 & 31 & 12.75 & 72 & 29.70 & 0.86 & 4.85 & 2.103 & 0 & Con & 0.177 \\
\hline 4 & 2005 & 8 & 31 & 12.75 & 72 & 29.70 & 1.2 & 4.85 & 2.103 & 0 & Con & 0.247 \\
\hline 5 & 2005 & 8 & 31 & 12.75 & 72 & 29.70 & 1.5 & 4.85 & 2.103 & 0 & Con & 0.309 \\
\hline 6 & 2005 & 8 & 31 & 12.75 & 72 & 29.70 & 2.3 & 4.85 & 2.103 & 0 & Con & 0.474 \\
\hline 7 & 2005 & 8 & 31 & 12.75 & 72 & 29.70 & 3.1 & 4.85 & 2.103 & 0 & Con & 0.639 \\
\hline 8 & 2005 & 8 & 31 & 12.75 & 72 & 29.70 & 4.1 & 4.85 & 2.103 & 0 & Con & 0.845 \\
\hline 9 & 2005 & 8 & 31 & 15.00 & 72 & 29.70 & 0 & 4.85 & 1.010 & 0 & Con & 0.000 \\
\hline 10 & 2005 & 8 & 31 & 15.00 & 72 & 29.70 & 0.65 & 4.85 & 1.010 & 0 & Con & 0.134 \\
\hline 11 & 2005 & 8 & 31 & 15.00 & 72 & 29.70 & 0.86 & 4.85 & 1.010 & 0 & Con & 0.177 \\
\hline 12 & 2005 & 8 & 31 & 15.00 & 72 & 29.70 & 1.2 & 4.85 & 1.010 & 0 & Con & 0.247 \\
\hline 13 & 2005 & 8 & 31 & 15.00 & 72 & 29.70 & 1.5 & 4.85 & 1.010 & 0 & Con & 0.309 \\
\hline 14 & 2005 & 8 & 31 & 15.00 & 72 & 29.70 & 2.3 & 4.85 & 1.010 & 0 & on & 0.474 \\
\hline 15 & 2005 & 8 & 31 & 15.00 & 72 & 29.70 & 3.1 & 4.85 & 1.010 & 0 & Son & 0.639 \\
\hline 16 & 2005 & 8 & 31 & 15.00 & 72 & 29.70 & 4.1 & 4.85 & 1.010 & 0 & Con & 0.845 \\
\hline 17 & 2005 & 8 & 31 & 16.25 & 73 & 29.80 & 0 & 4.85 & 0.510 & 0 & Con & 0.000 \\
\hline 18 & 2005 & 8 & 31 & 16.25 & 73 & 29.80 & 0.65 & 4.85 & 0.510 & 0 & on & 0.134 \\
\hline 19 & 2005 & 8 & 31 & 16.25 & 73 & 29.80 & 0.86 & 4.85 & 0.510 & 0 & Con & 0.177 \\
\hline 20 & 2005 & 8 & 31 & 16.25 & 73 & 29.80 & 1.2 & 4.85 & 0.510 & 0 & Con & 0.247 \\
\hline 21 & 2005 & 8 & 31 & 16.25 & 73 & 29.80 & 1.5 & 4.85 & 0.510 & 0 & Con & 0.309 \\
\hline 22 & 2005 & 8 & 31 & 16.25 & 73 & 29.80 & 2.3 & 4.85 & 0.510 & 0 & Con & 0.474 \\
\hline 23 & 2005 & 8 & 31 & 16.25 & 73 & 29.80 & 3.1 & 4.85 & 0.510 & 0 & Con & 0.639 \\
\hline 24 & 2005 & 8 & 31 & 16.25 & 73 & 29.80 & 4.1 & 4.85 & 0.510 & 0 & on & 0.845 \\
\hline 25 & 2005 & 8 & 31 & 17.50 & 72 & 29.80 & 0 & 4.85 & 0.255 & 0 & Con & 0.000 \\
\hline 26 & 2005 & 8 & 31 & 17.50 & 72 & 29.80 & 0.65 & 4.85 & 0.255 & 0 & Con & 0.134 \\
\hline 27 & 2005 & 8 & 31 & 17.50 & 72 & 29.80 & 0.86 & 4.85 & 0.255 & 0 & on & 0.177 \\
\hline 28 & 2005 & 8 & 31 & 17.50 & 72 & 29.80 & 1.2 & 4.85 & 0.255 & 0 & Con & 0.247 \\
\hline 29 & 2005 & 8 & 31 & 17.50 & 72 & 29.80 & 1.5 & 4.85 & 0.255 & 0 & Con & 0.309 \\
\hline 30 & 2005 & 8 & 31 & 17.50 & 72 & 29.80 & 2.3 & 4.85 & 0.255 & 0 & Con & 0.474 \\
\hline 31 & 2005 & 8 & 31 & 17.50 & 72 & 29.80 & 3.1 & 4.85 & 0.255 & 0 & Con & 0.639 \\
\hline 32 & 2005 & 8 & 31 & 17.50 & 72 & 29.80 & 4.1 & 4.85 & 0.255 & 0 & Con & 0.845 \\
\hline 33 & 2005 & 9 & 13 & 11.75 & 72 & 30.13 & 0 & 4.85 & 2.103 & 1 & Con & 0.000 \\
\hline 34 & 2005 & 9 & 13 & 11.75 & 72 & 30.13 & 0.65 & 4.85 & 2.103 & 1 & Con & 0.134 \\
\hline 35 & 2005 & 9 & 13 & 11.75 & 72 & 30.13 & 0.86 & 4.85 & 2.103 & 1 & Con & 0.177 \\
\hline 36 & 2005 & 9 & 13 & 11.75 & 72 & 30.13 & 1.2 & 4.85 & 2.103 & 1 & Con & 0.247 \\
\hline 37 & 2005 & 9 & 13 & 11.75 & 72 & 30.13 & 1.5 & 4.85 & 2.103 & 1 & Con & 0.309 \\
\hline 38 & 2005 & 9 & 13 & 11.75 & 72 & 30.13 & 2.3 & 4.85 & 2.103 & 1 & Con & 0.474 \\
\hline 39 & 2005 & 9 & 13 & 11.75 & 72 & 30.13 & 3.1 & 4.85 & 2.103 & 1 & Con & 0.639 \\
\hline 40 & 2005 & 9 & 13 & 11.75 & 72 & 30.13 & 4.1 & 4.85 & 2.103 & 1 & Con & 0.845 \\
\hline 41 & 2005 & 9 & 13 & 13.00 & 72 & 30.13 & 0 & 4.85 & 0.510 & 1 & Con & 0.000 \\
\hline 42 & 2005 & 9 & 13 & 13.00 & 72 & 30.13 & 0.65 & 4.85 & 0.510 & 1 & Con & 0.134 \\
\hline 43 & 2005 & 9 & 13 & 13.00 & 72 & 30.13 & 0.86 & 4.85 & 0.510 & 1 & Con & 0.177 \\
\hline 44 & 2005 & 9 & 13 & 13.00 & 72 & 30.13 & 1.2 & 4.85 & 0.510 & 1 & Con & 0.247 \\
\hline
\end{tabular}




\begin{tabular}{|c|c|c|c|c|c|c|c|c|c|c|c|c|c|}
\hline Seq. & end & Hood & $V P_{1}$ & $\mathbf{P}_{2}$ & $\mathrm{VP}_{3}$ & $\mathrm{VP}_{4}$ & $\mathbf{P}_{5}$ & CLa & $V_{P_{6}}$ & $\mathbf{P}_{7}$ & $V_{P_{8}}$ & $\mathrm{VP}_{9}$ & $\mathbf{P}_{10}$ \\
\hline 1 & & 3202 & 1.238 & 484 & 1.832 & & & & & 876 & & & \\
\hline 2 & & & 51 & 22 & 77 & & 57 & 88 & & 359 & 94 & & 02 \\
\hline 3 & 128 & 3.093 & 1.121 & 47 & 641 & .800 & .004 & 058 & & 862 & & & .354 \\
\hline 4 & & & 61 & & 20 & & & 28 & & 51 & & & \\
\hline 5 & 34 & & & & 374 & & & 687 & 666 & 522 & & & \\
\hline 6 & 561 & 1.518 & 0.551 & 622 & 0.830 & 0.900 & 013 & 1.024 & 0.975 & 895 & 313 & 84 & .518 \\
\hline 7 & 861 & & 0 & & .224 & 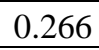 & & & 283 & 260 & & & \\
\hline 8 & & & & & & & & & & & & & \\
\hline 9 & 432 & & 0. & & 0.855 & 14 & 06 & 010 & .988 & 933 & & 695 & .524 \\
\hline 10 & 2.428 & 1.483 & 0.532 & 28 & 0.805 & & & 998 & 967 & 06 & & & \\
\hline 11 & & & & & & & & & & & & & \\
\hline 12 & 3 & & & & 0. & & & 28 & 923 & 842 & & & 564 \\
\hline 13 & 584 & 1.259 & 0.470 & 0 & 0.688 & 0.778 & 8 & 853 & 816 & 757 & 32 & & .446 \\
\hline 14 & & & & & & & & & & & & & \\
\hline 15 & 28 & & & & & & & & 72 & 57 & & & 085 \\
\hline 16 & 3.917 & & 0.018 & 9 & 0.030 & & & 39 & 37 & 034 & & 27 & 23 \\
\hline 17 & & & & & & & & & & 52 & & & \\
\hline 18 & 1.203 & & & & 0.416 & & & & 0.475 & 453 & & & 250 \\
\hline 19 & 1.233 & & & & 0.376 & & & & 75 & 439 & & & 253 \\
\hline 20 & & & & & & & & & & & & & \\
\hline 21 & 1.300 & & & & & & & & 107 & 74 & & & 221 \\
\hline 22 & 1 & & & & 0 . & & & & 68 & 52 & & 07 & 0.146 \\
\hline 23 & & & & & & & & & & & & & \\
\hline 24 & 1.960 & & & & & & & & & & & & 15 \\
\hline 25 & & & & & 0.208 & & & & 58 & 36 & & & .139 \\
\hline 26 & & & & & & & & & & & & & 25 \\
\hline 27 & & & & & & & & & & 33 & & & 148 \\
\hline 28 & 0.693 & & & & & & & & 52 & 230 & & & 0.143 \\
\hline 29 & 0.686 & & & & & & & & 20 & 200 & & & 120 \\
\hline 30 & & & & & & & & & 53 & .129 & & 96 & 0.081 \\
\hline 31 & 0.928 & & & & 0.039 & & & & & .044 & & & 0.025 \\
\hline 32 & 1.07 & & & & & & & & & .012 & & & 0.010 \\
\hline 33 & 4.928 & & & & 1 & & & & & 876 & & & 351 \\
\hline 34 & 4.981 & & & 1.492 & 1.725 & & & 1.976 & 1.924 & 1.711 & 998 & 412 & 1.292 \\
\hline 35 & 5.032 & & & & 1.644 & & & & 1.868 & 1.683 & & 10 & .243 \\
\hline 36 & 5 & & & & 1.509 & & & & 35 & .566 & & 77 & .142 \\
\hline 37 & 5.543 & & 0.909 & 1.111 & 1.296 & 1.378 & 1.475 & 1.512 & 1.455 & 1.297 & 1.214 & .121 & 0.941 \\
\hline 38 & 5.995 & 1.209 & 0.483 & 0.587 & 0.688 & 0.74 & .810 & 0.828 & 0.783 & 0.729 & .643 & .531 & 0.473 \\
\hline 39 & 6.450 & & & & 34 & & & & 26 & 206 & & 46 & .126 \\
\hline 40 & 6.780 & & & & 0.015 & & & & 0.021 & 0.020 & & 0.017 & 0.014 \\
\hline 41 & 1.206 & 0.753 & 0.327 & 0.374 & 0.439 & 0.471 & .513 & 0.524 & 0.511 & 0.470 & 0.416 & 0.358 & 0.316 \\
\hline 42 & 1.23 & & & & ? & & & & & .449 & & .357 & .267 \\
\hline 43 & 1.245 & 0.678 & 0.287 & 0.335 & 0.387 & 0.423 & 0.459 & 0.468 & 0.451 & 0.399 & 0.368 & 0.331 & 0.272 \\
\hline 44 & 1.274 & 0.644 & 0.262 & 0.319 & 0.367 & 0.401 & 0.435 & 0.448 & 0.422 & 0.384 & 0.359 & 0.319 & 0.261 \\
\hline
\end{tabular}




\begin{tabular}{|c|c|c|c|c|c|c|c|c|c|c|c|c|c|}
\hline seq. & $V_{P_{11}}$ & $\mathrm{VP}_{12}$ & $\mathrm{VP}_{13}$ & $V_{P_{14}}$ & $\mathbf{V P}_{15}$ & $V_{P_{C L b}}$ & $V_{P_{16}}$ & $\mathbf{V P}_{17}$ & $\mathbf{V P}_{18}$ & $V_{P_{19}}$ & $\mathbf{V P}_{20}$ & $\mathbf{V P}_{\text {avg. }}$ & TP \\
\hline 1 & 1.518 & 1.748 & 1.948 & 2.036 & 2.104 & 2.114 & 2.096 & 2.021 & 1.962 & 1.823 & 1.559 & 1.758 & 3.341 \\
\hline 2 & 40 & 52 & 40 & 944 & 70 & & 053 & 822 & 691 & 219 & 933 & 617 & 427 \\
\hline 3 & 112 & 45 & & 925 & & & 961 & .777 & & & & & \\
\hline 4 & 324 & 479 & 627 & 1.834 & .925 & 930 & .851 & 1.673 & 1.549 & .226 & .221 & 541 & 3.726 \\
\hline 5 & 165 & 214 & 453 & 1.606 & .646 & 686 & .601 & 1.482 & .382 & .149 & 0.768 & 315 & 3.919 \\
\hline 6 & 594 & 710 & 353 & .919 & 004 & 009 & 984 & 0.865 & 766 & 577 & 562 & 778 & 783 \\
\hline 7 & 180 & 94 & & .267 & .292 & 294 & 285 & 0.251 & 223 & 173 & 135 & 220 & 5.641 \\
\hline 8 & 031 & .034 & 39 & 0.046 & 0.052 & 53 & 049 & 0.045 & & & 030 & 39 & 6.696 \\
\hline 9 & 680 & & 366 & .955 & 01 & 009 & 955 & 0.832 & & 578 & 522 & 784 & .648 \\
\hline 10 & 3 & & & .918 & 0.994 & 995 & 930 & 0.858 & & & 584 & 766 & .662 \\
\hline 11 & 596 & 614 & 34 & 0.910 & 0.959 & 0.969 & 0.932 & 0.842 & 0.766 & & 0.583 & 757 & 1.705 \\
\hline 2 & 640 & 62 & & .833 & 928 & 34 & 06 & 0.827 & & & 592 & 732 & .771 \\
\hline 3 & & & & & & & & & & & 87 & & $\theta<4$ \\
\hline 14 & 371 & 5 & & 0.511 & 0.552 & 62 & 37 & 0.470 & 97 & & 0.287 & & 515 \\
\hline 15 & 6 & & & 4 & 167 & 70 & 76 & 59 & & & 81 & & 397 \\
\hline 0 & & & & & & & & & & & & & \\
\hline 17 & 7 & & & 0.453 & 95 & & 85 & 0.435 & 92 & & 0.278 & & 0.822 \\
\hline 18 & 343 & 5 & 3 & 0.453 & 500 & 03 & 483 & 0.400 & 74 & 76 & 0.284 & 81 & 0.822 \\
\hline 9 & & & & & & & & & & & & & 859 \\
\hline 20 & 98 & & & 0.419 & 0.464 & 0.469 & 0.445 & 0.397 & 366 & & 274 & 58 & 0.897 \\
\hline 21 & 0.272 & 80 & & 0.380 & 0 & & & & 66 & & 40 & 20 & 0.980 \\
\hline 22 & & & & & & & & & & & & & \\
\hline 23 & 0.061 & & & & 99 & & & 0.089 & 72 & & 53 & 73 & 1.674 \\
\hline 24 & 1 & & & 0.014 & & & & & & & & & 1.945 \\
\hline 25 & & & & & & & & & & & & & 0.449 \\
\hline 26 & 0 & & & & & & & & & & 26 & & .448 \\
\hline 27 & & & & 0.226 & & & & & & & & & 0.485 \\
\hline 28 & & & & & & & & & & & & & 0.497 \\
\hline 29 & 0 & & & & & & & & 78 & & 21 & & .516 \\
\hline 30 & 0.090 & & & & & & & & & & 0.080 & & 0.652 \\
\hline 31 & 00 & & & & & & & & & & 0.026 & & 0.890 \\
\hline 32 & 6 & & & & & & & & & & 0.070 & & 1.059 \\
\hline 33 & 1.501 & & & 1.986 & 2.054 & 2.089 & 2.033 & 1.827 & 1.636 & 421 & 1.416 & 1.710 & 3.218 \\
\hline 34 & 1.399 & & & 1.842 & $3 /$ & 1.976 & & 1.698 & 42 & & 1.341 & 1.612 & 3.369 \\
\hline 35 & 1.365 & & & & & & 52 & 85 & 1.622 & & .308 & 69 & 3.463 \\
\hline 36 & 1.269 & 1.305 & 1.544 & 1.647 & 1.740 & 1.787 & 1.702 & 1.532 & 1.416 & 1.321 & 1.270 & 1.465 & 3.711 \\
\hline 37 & 1.044 & & & & 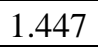 & & & & 1.228 & & 1.021 & 1.221 & 4.322 \\
\hline 38 & & & & & 09 & & 4 & 21 & 579 & & 45 & 55 & 5.340 \\
\hline 39 & 0.154 & & & & 0.230 & & 0.222 & 0.202 & 0.172 & & 0.129 & 0.178 & 6.272 \\
\hline 40 & 0.012 & 0.014 & 0.017 & 0.018 & 0.021 & 0.022 & 0.021 & 0.018 & 0.017 & 0.015 & 0.013 & 0.017 & 6.763 \\
\hline 41 & 0 & & & 0.469 & 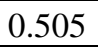 & 4 & 4 & & 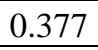 & & 0.341 & .412 & 0.794 \\
\hline 42 & & & 0.422 & 0.446 & & 0.492 & 0.474 & 0.411 & 0.371 & & 0.287 & 0.374 & 0.858 \\
\hline 43 & 0.309 & 0.322 & 0.401 & 0.422 & 0.455 & 0.465 & 0.452 & 0.392 & 0.375 & 0.322 & 0.307 & 0.371 & 0.874 \\
\hline 44 & 0.300 & 0.311 & 0.373 & 0.407 & 0.423 & 0.443 & 0.421 & 0.379 & 0.365 & 0.321 & 0.310 & 0.355 & 0.919 \\
\hline
\end{tabular}




\begin{tabular}{|c|c|c|c|c|c|c|c|}
\hline Seq. & $\mathbf{X}_{\mathrm{w} / \mathbf{0}}$ & $X_{\text {end }}$ & $\mathbf{X}_{\text {damper }}$ & Log $\left(X_{\text {damper }}\right)$ & $\mathrm{V}_{\text {avg. }}$ & $\operatorname{Re}$ & Pipe Factor \\
\hline 1 & 1.9012 & 1.901 & 0.0000 & & 5339.21 & 716426.25 & 0.913 \\
\hline 2 & 1.9012 & 2.120 & 0.2054 & -0.687 & 5121.00 & 687146.32 & 0.882 \\
\hline 3 & 1.9012 & 2.126 & 0.2124 & -0.673 & 5158.28 & 692149.39 & 0.894 \\
\hline 4 & 1.9012 & 2.417 & 0.5007 & -0.300 & 4999.90 & 670896.79 & 0.894 \\
\hline 5 & 1.9012 & 2.981 & 1.0564 & 0.024 & 4618.03 & 619657.27 & 0.883 \\
\hline 6 & 1.9012 & 6.144 & 4.1944 & 0.623 & 3553.25 & 476783.14 & 0.875 \\
\hline 7 & 1.9012 & 25.670 & 23.6615 & 1.374 & 1888.00 & 253335.35 & 0.865 \\
\hline 8 & 1.9012 & 169.661 & 167.5800 & 2.224 & 800.06 & 107354.08 & 0.859 \\
\hline 9 & 2.1015 & 2.101 & 0.0000 & & 3566.32 & 478536.18 & 0.881 \\
\hline 10 & 2.1015 & 2.171 & 0.0563 & -1.250 & 3523.83 & 472834.98 & 0.877 \\
\hline 11 & 2.1015 & 2.254 & 0.1380 & -0.860 & 3503.26 & 470074.74 & 0.881 \\
\hline 12 & 2.1015 & 2.421 & 0.3033 & -0.518 & 3445.02 & 462259.71 & 0.887 \\
\hline 13 & 2.1015 & 2.915 & 0.7928 & -0.101 & 3271.77 & 439013.34 & 0.883 \\
\hline 14 & 2.1015 & 5.991 & 3.8463 & 0.585 & 2609.55 & 350154.85 & 0.864 \\
\hline 15 & 2.1015 & 25.920 & 23.7217 & 1.375 & 1457.97 & 195632.98 & 0.862 \\
\hline 16 & 2.1015 & 133.219 & 130.9555 & 2.117 & 688.01 & 92318.07 & 0.854 \\
\hline 17 & 2.1393 & 2.139 & 0.0000 & & 2494.37 & 334699.52 & 0.872 \\
\hline 18 & 2.1393 & 2.160 & 0.0064 & -2.195 & 2483.01 & 333175.39 & 0.872 \\
\hline 19 & 2.1393 & 2.299 & 0.1447 & -0.839 & 2460.16 & 330110.03 & 0.879 \\
\hline 20 & 2.1393 & 2.506 & 0.3493 & -0.457 & 2407.75 & 323077.41 & 0.873 \\
\hline 21 & 2.1393 & 3.057 & 0.8950 & -0.048 & 2278.02 & 305669.96 & 0.868 \\
\hline 22 & 2.1393 & 5.630 & 3.4499 & 0.538 & 1888.47 & 253398.83 & 0.871 \\
\hline 23 & 2.1393 & 22.976 & 20.7439 & 1.317 & 1086.33 & 145765.52 & 0.856 \\
\hline 24 & 2.1393 & 129.418 & 127.1175 & 2.104 & 493.36 & 66199.42 & 0.836 \\
\hline 25 & 2.2460 & 2.246 & 0.0000 & & 1797.80 & 241232.75 & 0.869 \\
\hline 26 & 2.2460 & 2.299 & 0.0401 & -1.396 & 1774.91 & 238160.47 & 0.867 \\
\hline 27 & 2.2460 & 2.441 & 0.1829 & -0.738 & 1791.18 & 240343.95 & 0.875 \\
\hline 28 & 2.2460 & 2.527 & 0.2678 & -0.572 & 1782.26 & 239147.05 & 0.872 \\
\hline 29 & 2.2460 & 3.042 & 0.7763 & -0.110 & 1656.28 & 222243.18 & 0.871 \\
\hline 30 & 2.2460 & 5.687 & 3.4019 & 0.532 & 1361.68 & 182712.97 & 0.857 \\
\hline 31 & 2.2460 & 23.248 & 20.9116 & 1.320 & 786.55 & 105541.54 & 0.866 \\
\hline 32 & 2.2460 & 93.181 & 90.7908 & 1.958 & 428.55 & 57504.02 & 0.935 \\
\hline 33 & 1.8826 & 1.883 & 0.0000 & & 5228.07 & 701513.64 & 0.903 \\
\hline 34 & 1.8826 & 2.090 & 0.1939 & -0.712 & 5076.89 & 681227.67 & 0.903 \\
\hline 35 & 1.8826 & 2.206 & 0.3092 & -0.510 & 5009.19 & 672142.92 & 0.908 \\
\hline 36 & 1.8826 & 2.533 & 0.6326 & -0.199 & 4839.71 & 649402.05 & 0.904 \\
\hline 37 & 1.8826 & 3.539 & 1.6291 & 0.212 & 4418.91 & 592938.77 & 0.904 \\
\hline 38 & 1.8826 & 8.155 & 6.2156 & 0.793 & 3235.70 & 434173.10 & 0.894 \\
\hline 39 & 1.8826 & 35.157 & 33.1586 & 1.521 & 1688.82 & 226609.43 & 0.873 \\
\hline 40 & 1.8826 & 402.403 & 400.3054 & 2.602 & 518.38 & 69557.14 & 0.829 \\
\hline 41 & 1.9257 & 1.926 & 0.0000 & & 2567.20 & 344472.21 & 0.893 \\
\hline 42 & 1.9257 & 2.292 & 0.3511 & -0.455 & 2446.04 & 328215.03 & 0.874 \\
\hline 43 & 1.9257 & 2.355 & 0.4131 & -0.384 & 2435.96 & 326862.23 & 0.892 \\
\hline 44 & 1.9257 & 2.589 & 0.6454 & -0.190 & 2382.30 & 319662.22 & 0.893 \\
\hline
\end{tabular}




\begin{tabular}{|c|c|c|c|c|c|c|c|c|c|c|c|c|}
\hline Seq. & Year & Month & Date & Time & $\mathbf{T}_{\text {act }}$ & $\mathbf{P}_{\mathrm{bar}}$ & I & D & $\mathbf{V P}_{\text {CLopen }}$ & Orient & Edge & I/D \\
\hline 45 & 2005 & 9 & 13 & 13.00 & 72 & 30.13 & 1.5 & 4.85 & 0.510 & 1 & Con & 0.309 \\
\hline 46 & 2005 & 9 & 13 & 13.00 & 72 & 30.13 & 2.3 & 4.85 & .510 & 1 & on & 0.474 \\
\hline 47 & 2005 & 9 & 13 & 13.00 & 72 & 30.13 & 3.1 & 4.85 & 0.510 & 1 & Con & 0.639 \\
\hline 48 & 2005 & 9 & 13 & 13.00 & 72 & 30.13 & 4.1 & 4.85 & 0.510 & 1 & Con & 0.845 \\
\hline 49 & 2005 & 9 & 14 & 11.50 & 74 & 30.19 & 0 & 4.85 & 1.010 & 1 & Con & 0.000 \\
\hline 50 & 2005 & 9 & 14 & 11.50 & 74 & 30.19 & 0.65 & 4.85 & 1.010 & 1 & Con & 0.134 \\
\hline 51 & 2005 & 9 & 14 & 11.50 & 74 & 30.19 & 0.86 & 4.85 & 1.010 & 1 & Con & 0.177 \\
\hline 52 & 2005 & 9 & 14 & 11.50 & 74 & 30.19 & 1.2 & 4.85 & 1.010 & 1 & Con & 0.247 \\
\hline 53 & 2005 & 9 & 14 & 11.50 & 74 & 30.19 & 1.5 & 4.85 & 1.010 & 1 & Con & 0.309 \\
\hline 54 & 2005 & 9 & 14 & 11.50 & 74 & 30.19 & 2.3 & 4.85 & 1.010 & 1 & Con & 0.474 \\
\hline 55 & 2005 & 9 & 14 & 11.50 & 74 & 30.19 & 3.1 & 4.85 & 1.010 & 1 & Con & 0.639 \\
\hline 56 & 2005 & 9 & 14 & 11.50 & 74 & 30.19 & 4.1 & 4.85 & 1.010 & 1 & Con & 0.845 \\
\hline 57 & 2005 & 9 & 14 & 13.00 & 74 & 30.19 & 0 & 4.85 & 0.255 & 1 & Con & 0.000 \\
\hline 58 & 2005 & 9 & 14 & 13.00 & 74 & 30.19 & 0.65 & 4.85 & 0.255 & 1 & Con & 0.134 \\
\hline 59 & 2005 & 9 & 14 & 13.00 & 74 & 30.19 & 0.86 & 4.85 & 0.255 & 1 & on & 0.177 \\
\hline 60 & 2005 & 9 & 14 & 13.00 & 74 & 30.19 & 1.2 & 4.85 & 0.255 & 1 & Con & 0.247 \\
\hline 61 & 2005 & 9 & 14 & 13.00 & 74 & 30.19 & 1.5 & 4.85 & 0.255 & 1 & Con & 0.309 \\
\hline 62 & 2005 & 9 & 14 & 13.00 & 74 & 30.19 & 2.3 & 4.85 & 0.255 & 1 & Con & 0.474 \\
\hline 63 & 2005 & 9 & 14 & 13.00 & 74 & 30.19 & 3.1 & 4.85 & 0.255 & 1 & Con & 0.639 \\
\hline 64 & 2005 & 9 & 14 & 13.00 & 74 & 30.19 & 4.1 & 4.85 & 0.255 & 1 & Con & 0.845 \\
\hline 65 & 2005 & 9 & 14 & 15.25 & 74 & 30.19 & 0 & 4.85 & 2.103 & 0 & Strt. & 0.000 \\
\hline 66 & 2005 & 9 & 14 & 15.25 & 74 & 30.19 & 0.65 & 4.85 & 2.103 & 0 & Strt. & 0.134 \\
\hline 67 & 2005 & 9 & 14 & 15.25 & 74 & 30.19 & 0.86 & 4.85 & 2.103 & 0 & Strt. & 0.177 \\
\hline 68 & 2005 & 9 & 14 & 15.25 & 74 & 30.19 & 1.2 & 4.85 & 2.103 & 0 & Strt. & 0.247 \\
\hline 69 & 2005 & 9 & 14 & 15.25 & 74 & 30.19 & 1.5 & 4.85 & 2.103 & 0 & Strt. & 0.309 \\
\hline 70 & 2005 & 9 & 14 & 15.25 & 74 & 30.19 & 2.3 & 4.85 & 2.103 & 0 & Strt. & 0.474 \\
\hline 71 & 2005 & 9 & 14 & 15.25 & 74 & 30.19 & 3.1 & 4.85 & 2.103 & 0 & Strt. & 0.639 \\
\hline 72 & 2005 & 9 & 14 & 15.25 & 74 & 30.19 & 4.1 & 4.85 & 2.103 & 0 & Strt. & 0.845 \\
\hline 73 & 2005 & 9 & 25 & 11.50 & 84 & 30.16 & 0 & 4.85 & 1.010 & 0 & Strt. & 0.000 \\
\hline 74 & 2005 & 9 & 25 & 11.50 & 84 & 30.16 & 0.65 & 4.85 & 1.010 & 0 & Strt. & 0.134 \\
\hline 75 & 2005 & 9 & 25 & 11.50 & 84 & 30.16 & 0.86 & 4.85 & 1.010 & 0 & Strt. & 0.177 \\
\hline 76 & 2005 & 9 & 25 & 11.50 & 84 & 30.16 & 1.2 & 4.85 & 1.010 & 0 & Strt. & 0.247 \\
\hline 77 & 2005 & 9 & 25 & 11.50 & 84 & 30.16 & 1.5 & 4.85 & 1.010 & 0 & Strt. & 0.309 \\
\hline 78 & 2005 & 9 & 25 & 11.50 & 84 & 30.16 & 2.3 & 4.85 & 1.010 & 0 & Strt. & 0.474 \\
\hline 79 & 2005 & 9 & 25 & 11.50 & 84 & 30.16 & 3.1 & 4.85 & 1.010 & 0 & Strt. & 0.639 \\
\hline 80 & 2005 & 9 & 25 & 11.50 & 84 & 30.16 & 4.1 & 4.85 & 1.010 & 0 & Strt. & 0.845 \\
\hline 81 & 2005 & 9 & 25 & 13.00 & 84 & 30.16 & 0 & 4.85 & 0.510 & 0 & Strt. & 0.000 \\
\hline 82 & 2005 & 9 & 25 & 13.00 & 84 & 30.16 & 0.65 & 4.85 & 0.510 & 0 & Strt. & 0.134 \\
\hline 83 & 2005 & 9 & 25 & 13.00 & 84 & 30.16 & 0.86 & 4.85 & 0.510 & 0 & Strt. & 0.177 \\
\hline 84 & 2005 & 9 & 25 & 13.00 & 84 & 30.16 & 1.2 & 4.85 & 0.510 & 0 & Strt. & 0.247 \\
\hline 85 & 2005 & 9 & 25 & 13.00 & 84 & 30.16 & 1.5 & 4.85 & 0.510 & 0 & Strt. & 0.309 \\
\hline 86 & 2005 & 9 & 25 & 13.00 & 84 & 30.16 & 2.3 & 4.85 & 0.510 & 0 & Strt. & 0.474 \\
\hline 87 & 2005 & 9 & 25 & 13.00 & 84 & 30.16 & 3.1 & 4.85 & 0.510 & 0 & Strt. & 0.639 \\
\hline 88 & 2005 & 9 & 25 & 13.00 & 84 & 30.16 & 4.1 & 4.85 & 0.510 & 0 & Strt. & 0.845 \\
\hline
\end{tabular}




\begin{tabular}{|c|c|c|c|c|c|c|c|c|c|c|c|c|c|}
\hline seq. & $P_{\text {end }}$ & Hood & $V_{P_{1}}$ & $\mathbf{V P}_{2}$ & $\mathbf{V P}_{3}$ & $\mathrm{VP}_{4}$ & $\mathbf{V P}_{5}$ & $\mathbf{V P}_{\text {CLa }}$ & $\mathrm{VP}_{6}$ & $\mathbf{V P}_{7}$ & $\mathrm{VP}_{8}$ & $\mathrm{VP}_{9}$ & $\mathrm{VP}_{10}$ \\
\hline 45 & 352 & & 179 & & 278 & 0.312 & 0.352 & .363 & & 331 & & & \\
\hline 46 & 532 & 329 & 114 & & 0.178 & 0.194 & 0.222 & 228 & 226 & 0.207 & 194 & 65 & 128 \\
\hline 47 & 791 & 04 & 39 & 51 & 0.060 & 0.064 & 0.073 & 075 & 69 & 0.067 & 62 & & 039 \\
\hline 48 & 892 & & 04 & & 007 & 0.008 & 0.009 & 011 & 08 & 007 & 005 & & \\
\hline 49 & 312 & 482 & 632 & & 0.855 & 0.931 & 0.986 & 013 & 82 & 0 & 0.806 & & 02 \\
\hline 50 & 2.323 & 451 & 2 & 0 & 329 & 0.880 & 0.963 & 88 & 58 & 839 & 0.773 & 19 & 600 \\
\hline 51 & 2.336 & 415 & .588 & & 0.813 & 0.881 & 0.955 & 956 & 940 & 0.835 & 0.761 & 10 & 581 \\
\hline 52 & 368 & 354 & .543 & 81 & 0.753 & 0.805 & 0.886 & 907 & 878 & 0.787 & 0.725 & & 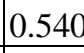 \\
\hline 53 & 521 & 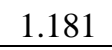 & & & 0.680 & 0.723 & 0.790 & & 780 & 0.697 & 0.620 & & 482 \\
\hline 54 & 2.784 & 29 & 333 & & 0.457 & 0.503 & 0.549 & 555 & 23 & 176 & 138 & & 329 \\
\hline 55 & 263 & & & & & 0.220 & 44 & & & 211 & 90 & & 112 \\
\hline 56 & 3.706 & 46 & 24 & 0 & 0.031 & 0.037 & 0.038 & 39 & 037 & 0.034 & 0.029 & & 023 \\
\hline 57 & .611 & 73 & 56 & & - & 0.232 & 0.251 & 59 & 52 & .225 & 0.203 & & - \\
\hline 58 & 317 & 62 & & & 0.200 & 0.230 & 0.253 & & 254 & 0.235 & 0.213 & & 125 \\
\hline 59 & 0.621 & 0.355 & 46 & & 0.200 & 0.222 & 0.243 & 50 & 44 & 0.212 & 0.184 & & 148 \\
\hline 60 & 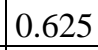 & & & & & 218 & 40 & & & 213 & & & 133 \\
\hline 61 & 0.653 & 306 & & & 0.177 & 0.192 & 0.213 & 18 & 208 & 0.190 & 0.169 & & 125 \\
\hline 62 & 744 & & & & & 0.130 & 41 & & & 0.119 & & & 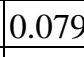 \\
\hline 63 & 53 & 4 & & & 63 & 0.063 & 0.069 & & 67 & 0.060 & 0.058 & & 0.041 \\
\hline 64 & 1.070 & 0.014 & 05 & 0. & 0.009 & 0.010 & 0.012 & 13 & 13 & 0.012 & 0.010 & & 010 \\
\hline 65 & 20 & & & & & 1.914 & 2.056 & & 52 & 1.817 & 1.658 & & 299 \\
\hline 66 & 4.970 & 3.043 & 267 & & 25 & 1.821 & 1.972 & 001 & 1.950 & 1.743 & 1.605 & & 1.198 \\
\hline 67 & 5.050 & 945 & 14 & & 32 & 1.773 & 1.9 & & 96 & 1.692 & 1.590 & & 22 \\
\hline 68 & 5.141 & 816 & 66 & 1. & 84 & 1.702 & 1.852 & 58 & 798 & 1.620 & 1.444 & 62 & 1.114 \\
\hline 69 & 5.487 & 30 & 31 & & 1. & 1.417 & 1.526 & 10 & 494 & 1.365 & 1.243 & & 0.960 \\
\hline 70 & 867 & 403 & 83 & & 0.800 & 0.858 & 0.932 & 52 & 923 & 0.827 & 0.736 & 59 & 0.571 \\
\hline 71 & 6.226 & 0.437 & 76 & & 0. & 0.265 & 0.298 & 5 & 95 & 0.265 & 0.240 & & 171 \\
\hline 72 & 6.654 & 26 & & & 0.016 & 0.020 & 0.021 & 24 & 21 & 0.017 & 0.015 & & 0.012 \\
\hline 73 & 352 & 491 & 29 & & 352 & 0.930 & 0.990 & & 971 & 0.851 & 0.797 & & 0.620 \\
\hline 74 & 2.377 & 33 & & & 0.806 & 0.872 & 0.951 & & 937 & 0.843 & 0.752 & & 0.599 \\
\hline 75 & 2.406 & 1.402 & 96 & 0.667 & 0.798 & \begin{tabular}{|l|l|}
0.847 \\
\end{tabular} & 0.913 & 51 & 916 & 0.829 & 0.744 & 16 & 0.589 \\
\hline 76 & 2.459 & 1.326 & 0.530 & 0.650 & 0.762 & 0.808 & 0.863 & 31 & 68 & 0.777 & 0.708 & & 0.539 \\
\hline 77 & 2.601 & 1.127 & 0.461 & 0.5 & 0.636 & 0.712 & 0.761 & \begin{tabular}{|l|l|}
0.778 \\
\end{tabular} & 0.746 & 0.664 & 0.617 & 41 & 0.447 \\
\hline 78 & 2.960 & 0.695 & 0.271 & 0.3 & 0.389 & 0.426 & 0.469 & .475 & 0.456 & 0.410 & 0.382 & 21 & 0.286 \\
\hline 79 & 3.455 & 54 & & & & 0.161 & 0.170 & & & 0.158 & 0.139 & & L \\
\hline 80 & 3.938 & 0.016 & 0.013 & & 0.015 & 0.016 & 0.018 & 0.019 & 0.018 & 0.017 & 0.016 & 0.014 & 0.013 \\
\hline 81 & 1.264 & 0.797 & 0.315 & & 0.461 & 0.498 & 0.537 & 51 & 24 & 0.466 & 0.450 & & 0.30 \\
\hline 82 & 1.351 & 0.811 & 0.312 & 0.380 & 0.454 & 0.475 & 0.519 & 0.531 & 0.503 & 0.459 & 0.433 & 0.347 & 0.301 \\
\hline 83 & 1.359 & 0.781 & 0.321 & 0.3 & 0.441 & 0.477 & 0.511 & 0.521 & 0.498 & 0.451 & 0.406 & 41 & 0.291 \\
\hline 84 & 1.405 & 0.749 & 97 & 0.360 & 0.42 & 0.469 & 0.506 & 0.511 & 0.500 & 0.434 & 0.389 & & 0.263 \\
\hline 85 & 1.435 & 0.634 & 0.239 & 0.307 & 0.361 & 0.383 & 0.421 & 0.428 & 0.412 & 0.371 & 0.350 & 0.298 & 0.221 \\
\hline 86 & 1.687 & 0.407 & 68 & & 0.236 & 0.247 & 0.281 & 85 & 65 & 0.239 & 0.217 & 73 & .152 \\
\hline 87 & 1.957 & 0.130 & 0.051 & 0.063 & 0.078 & 0.083 & 0.097 & 0.099 & 0.085 & 0.081 & 0.075 & 0.059 & 0.050 \\
\hline 88 & 2.243 & 0.013 & 0.005 & 0.007 & 0.008 & 0.011 & 0.012 & 0.013 & 0.011 & 0.009 & 0.007 & 0.005 & 0.0 \\
\hline
\end{tabular}




\begin{tabular}{|c|c|c|c|c|c|c|c|c|c|c|c|c|c|}
\hline & 11 & $P_{12}$ & 13 & $P_{14}$ & $P_{15}$ & CLb & $P_{16}$ & $\mathbf{V P}_{\mathbf{1 7}}$ & 18 & $P_{19}$ & $\mathbf{P}_{20}$ & $P_{\text {avg. }}$ & TP \\
\hline 15 & & & & & & & & & & & & & \\
\hline & & & & & & & & & & & & & \\
\hline 17 & & & & & & & & & & & & & \\
\hline & & & & & & & & & & & & & \\
\hline 49 & & & & & & & & & & & & & \\
\hline 0 & & & & & & & & & & & & & \\
\hline & & & & & & & & & & & & & \\
\hline 2 & & 40 & 72 & 8 & 96 & & & & & & & 5 & \\
\hline & & & & & & & & & & & & & \\
\hline 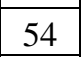 & & 396 & 482 & .517 & 48 & & 543 & 0.50 & & & & & \\
\hline & & & & & & & & & & & & & \\
\hline & & & 31 & & & & & & & & & & \\
\hline 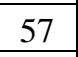 & & 77 & 09 & & & & & & & & & & \\
\hline & & & & & & & & & & & & & \\
\hline 59 & & 168 & 208 & 0.230 & & & 233 & 0.218 & & 79 & & & .4 \\
\hline & & & & & & & & & & & & & \\
\hline & & 47 & 80 & & & & & & & & & & \\
\hline & & 1 & & & & & & & & & & & \\
\hline & & & & & & & & & & & & & \\
\hline & & 07 & 009 & 0 & & & 12 & a & & & & & \\
\hline & & & & & & & & & & & & & \\
\hline & & 76 & 35 & 1 & & & 88 & 0 & & 1 & & & 3. \\
\hline & & & 82 & & & & & & & & & & \\
\hline & & 9 & 82 & 4 & & & & 29 & & & & & 63 \\
\hline & & 3 & 326 & 7 & & & 06 & 8 & & & & & \\
\hline & & & & & & & & & & & & & \\
\hline 11 & & 08 & 250 & 3 & & & 293 & $t$ & & & & & 5.9 \\
\hline & & & & & & & & & & & & & \\
\hline & & 34 & 349 & c & & & 961 & $t$ & & & & & 54 \\
\hline & & 0.663 & 0.800 & & & & & & & & & & \\
\hline & & & & & & & & & & & & & \\
\hline & & 26 & 729 & c & & & & 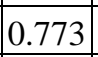 & & & & & \\
\hline & & & & & & & & & & & & & \\
\hline & & 35 & 0.404 & 6 & & & 54 & & & & & & 7 \\
\hline 7 & & & 44 & & & & & & & & & & 3 \\
\hline & & & & & & & & & & & & & (2) \\
\hline & & 365 & 0.446 & 3 & & & 517 & & & & & & 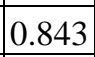 \\
\hline & & & 0.431 & & & & & & & & & & \\
\hline$x_{2}$ & & 336 & 0.351 & 0.473 & & & 502 & 0.4 & & & & & 0.96 \\
\hline & & 5 & 24 & 0 & & & & 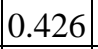 & & & & & 01 \\
\hline & & 294 & 351 & . & & & & & & & & & \\
\hline & & 184 & 213 & 0.243 & 76 & & 271 & 23 & & 179 & 0.16 & 15 & 1.4 \\
\hline & & & & & & & & & & & & & \\
\hline 00 & & & $\overline{0 c}$ & & & & & & & 0 & & 0.008 & \\
\hline
\end{tabular}




\begin{tabular}{|c|c|c|c|c|c|c|c|}
\hline Seq. & $\mathbf{X}_{\mathrm{w} / \mathbf{0}}$ & $\mathbf{X}_{\text {end }}$ & $\mathbf{X}_{\text {damper }}$ & $\log \left(X_{\text {damper }}\right)$ & $V_{\text {avg. }}$ & Re & Pipe Factor \\
\hline 45 & 1.9257 & 3.846 & 1.8904 & 0.277 & 2112.06 & 283401.18 & 0.875 \\
\hline 46 & 1.9257 & 7.738 & 5.7599 & 0.760 & 1674.31 & 224661.83 & 0.872 \\
\hline 47 & 1.9257 & 29.420 & 27.3918 & 1.438 & 970.22 & 130186.43 & 0.877 \\
\hline 48 & 1.9257 & 317.590 & 315.4647 & 2.499 & 308.14 & 41346.68 & 0.772 \\
\hline 49 & 1.8642 & 1.864 & 0.0000 & & 3595.66 & 482473.68 & 0.896 \\
\hline 50 & 1.8642 & 1.987 & 0.1094 & -0.961 & 3529.58 & 473605.81 & 0.891 \\
\hline 51 & 1.8642 & 2.058 & 0.1797 & -0.745 & 3497.99 & 469368.15 & 0.895 \\
\hline 52 & 1.8642 & 2.313 & 0.4320 & -0.364 & 3383.32 & 453980.37 & 0.889 \\
\hline 53 & 1.8642 & 2.933 & 1.0463 & 0.020 & 3204.14 & 429937.85 & 0.894 \\
\hline 54 & 1.8642 & 5.256 & 3.3515 & 0.525 & 2669.80 & 358238.78 & 0.896 \\
\hline 55 & 1.8642 & 16.109 & 14.1651 & 1.151 & 1747.75 & 234516.17 & 0.868 \\
\hline 56 & 1.8642 & 120.394 & 118.3695 & 2.073 & 699.26 & 93828.08 & 0.874 \\
\hline 57 & 2.0251 & 2.025 & 0.0000 & & 1798.61 & 241340.88 & 0.883 \\
\hline 58 & 2.0251 & 2.166 & 0.1276 & -0.894 & 1766.72 & 237061.52 & 0.867 \\
\hline 59 & 2.0251 & 2.190 & 0.1515 & -0.820 & 1765.77 & 236934.70 & 0.886 \\
\hline 60 & 2.0251 & 2.309 & 0.2693 & -0.570 & 1739.24 & 233374.58 & 0.892 \\
\hline 61 & 2.0251 & 2.849 & 0.8041 & -0.095 & 1648.34 & 221177.97 & 0.888 \\
\hline 62 & 2.0251 & 5.811 & 3.7449 & 0.573 & 1322.67 & 177478.51 & 0.883 \\
\hline 63 & 2.0251 & 15.111 & 13.0102 & 1.114 & 920.87 & 123564.47 & 0.882 \\
\hline 64 & 2.0251 & 93.181 & 91.0117 & 1.959 & 426.57 & 57238.68 & 0.935 \\
\hline 65 & 1.8833 & \begin{tabular}{|l|l|}
1.883 \\
\end{tabular} & 0.0000 & & 5227.81 & 701478.93 & 0.902 \\
\hline 66 & 1.8833 & \begin{tabular}{|l|} 
\\
\end{tabular} & 0.1524 & -0.817 & 5110.13 & 685687.70 & 0.902 \\
\hline 67 & 1.8833 & 2.195 & 0.2974 & -0.527 & 5031.58 & 675147.23 & 0.903 \\
\hline 68 & 1.8833 & 2.409 & 0.5093 & -0.293 & 4914.63 & 659454.65 & 0.900 \\
\hline 69 & 1.8833 & 3.363 & 1.4544 & 0.163 & 4487.99 & 602207.60 & 0.904 \\
\hline 70 & 1.8833 & 6.715 & 4.7816 & 0.680 & 3490.10 & 468308.27 & 0.896 \\
\hline 71 & 1.8833 & 25.371 & 23.3845 & 1.369 & 1944.56 & 260925.63 & 0.884 \\
\hline 72 & 1.8833 & 389.392 & 387.2943 & 2.588 & 522.49 & 70108.41 & 0.871 \\
\hline 73 & 1.9058 & 1.906 & 0.0000 & & 3635.94 & 487878.39 & 0.897 \\
\hline 74 & 1.9058 & 2.078 & 0.1590 & -0.798 & 3551.40 & 476533.64 & 0.892 \\
\hline 75 & 1.9058 & 2.173 & 0.2532 & -0.597 & 3519.07 & 472196.79 & 0.894 \\
\hline 76 & 1.9058 & 2.458 & 0.5345 & -0.272 & 3408.14 & 457311.04 & 0.897 \\
\hline 77 & 1.9058 & 3.214 & 1.2838 & 0.108 & 3175.10 & 426041.53 & 0.894 \\
\hline 78 & 1.9058 & 6.832 & 4.8782 & 0.688 & 2484.51 & 333376.32 & 0.889 \\
\hline 79 & 1.9058 & 23.374 & 21.3748 & 1.330 & 1521.56 & 204166.05 & 0.874 \\
\hline 80 & 1.9058 & 245.495 & 243.4024 & 2.386 & 510.81 & 68542.05 & 0.894 \\
\hline 81 & 2.0041 & 2.004 & 0.0000 & & 2621.48: & 351756.04 & 0.884 \\
\hline 82 & 2.0041 & 2.293 & 0.2781 & -0.556 & 2588.59: & 347343.06 & 0.881 \\
\hline 83 & 2.0041 & 2.403 & 0.3869 & -0.412 & 2553.86 & 342682.90 & 0.875 \\
\hline 84 & 2.0041 & 2.573 & 0.5561 & -0.255 & 2534.24: & 340049.35 & 0.877 \\
\hline 85 & 2.0041 & 3.221 & 1.1964 & 0.078 & 2356.52 & 316202.27 & 0.888 \\
\hline 86 & 2.0041 & 6.842 & 4.7955 & 0.681 & 1874.47 & 251520.94 & 0.872 \\
\hline 87 & 2.0041 & 26.429 & 24.3317 & 1.386 & 1079.48 & 144847.35 & 0.855 \\
\hline 88 & 2.0041 & 264.446 & 262.2564 & 2.419 & \begin{tabular}{|l|}
371.50 \\
\end{tabular} & 49848.30 & 0.791 \\
\hline
\end{tabular}




\begin{tabular}{|c|c|c|c|c|c|c|c|c|c|c|c|c|}
\hline Seq. & Year & Month & Date & Time & $\mathbf{T}_{\text {act }}$ & $\mathbf{P}_{\text {bar }}$ & I & D & $\mathbf{V P}_{\text {CLopen }}$ & Orient & Edge & I/D \\
\hline 89 & 2005 & 9 & 14 & 14.00 & 74 & 30.19 & 0 & 4.85 & 0.255 & 0 & Strt. & 0.000 \\
\hline 90 & 2005 & 9 & 14 & 14.00 & 74 & 30.19 & 0.65 & 4.85 & .255 & 0 & Strt. & 0.134 \\
\hline 91 & 2005 & 9 & 14 & 14.00 & 74 & 30.19 & 0.86 & 4.85 & 0.255 & 0 & Strt. & 0.177 \\
\hline 92 & 2005 & 9 & 14 & 14.00 & 74 & 30.19 & 1.2 & 4.85 & 0.255 & 0 & Strt. & 0.247 \\
\hline 93 & 2005 & 9 & 14 & 14.00 & 74 & 30.19 & 1.5 & 4.85 & 0.255 & 0 & Strt. & 0.309 \\
\hline 94 & 2005 & 9 & 14 & 14.00 & 74 & 30.19 & 2.3 & 4.85 & 0.255 & 0 & Strt. & 0.474 \\
\hline 95 & 2005 & 9 & 14 & 14.00 & 74 & 30.19 & 3.1 & 4.85 & 0.255 & 0 & Strt. & 0.639 \\
\hline 96 & 2005 & 9 & 14 & 14.00 & 74 & 30.19 & 4.1 & 4.85 & 0.255 & 0 & Strt. & 0.845 \\
\hline 97 & 2005 & 12 & 29 & 15.25 & 25 & 30.19 & 0 & 4.85 & 2.103 & 1 & Strt. & 0.000 \\
\hline 98 & 2005 & 12 & 29 & 15.25 & 25 & 30.19 & 0.65 & 4.85 & 2.103 & 1 & Strt. & 0.134 \\
\hline 99 & 2005 & 12 & 29 & 15.25 & 25 & 30.19 & 0.86 & 4.85 & 2.103 & 1 & Strt. & 0.177 \\
\hline 100 & 2005 & 12 & 29 & 15.25 & 25 & 30.19 & 1.2 & 4.85 & 2.103 & 1 & Strt. & 0.247 \\
\hline 101 & 2005 & 12 & 29 & 15.25 & 25 & 30.19 & 1.5 & 4.85 & 2.103 & 1 & Strt. & 0.309 \\
\hline 102 & 2005 & 12 & 29 & 15.25 & 25 & 30.19 & 2.3 & 4.85 & 2.103 & 1 & Strt. & 0.474 \\
\hline 103 & 2005 & 12 & 29 & 15.25 & 25 & 30.19 & 3.1 & 4.85 & 2.103 & 1 & trt. & 0.639 \\
\hline 104 & 2005 & 12 & 29 & 15.25 & 25 & 30.19 & 4.1 & 4.85 & 2.103 & 1 & Strt. & 0.845 \\
\hline 105 & 2005 & 12 & 29 & 17.50 & 25 & 30.16 & 0 & 4.85 & 1.010 & 1 & Strt. & 0.000 \\
\hline 106 & 2005 & 12 & 29 & 17.50 & 25 & 30.16 & 0.65 & 4.85 & 1.010 & 1 & Strt. & 0.134 \\
\hline 107 & 2005 & 12 & 29 & 17.50 & 25 & 30.16 & 0.86 & 4.85 & 1.010 & 1 & Strt. & 0.177 \\
\hline 108 & 2005 & 12 & 29 & 17.50 & 25 & 30.16 & 1.2 & 4.85 & 1.010 & 1 & Strt. & 0.247 \\
\hline 109 & 2005 & 12 & 29 & 17.50 & 25 & 30.16 & 1.5 & 4.85 & 1.010 & 1 & Strt. & 0.309 \\
\hline 110 & 2005 & 12 & 29 & 17.50 & 25 & 30.16 & 2.3 & 4.85 & 1.010 & 1 & Strt. & 0.474 \\
\hline 111 & 2005 & 12 & 29 & 17.50 & 25 & 30.16 & 3.1 & 4.85 & 1.010 & 1 & Strt. & 0.639 \\
\hline 112 & 2005 & 12 & 29 & 17.50 & 25 & 30.16 & 4.1 & 4.85 & 1.010 & 1 & Strt. & 0.845 \\
\hline 113 & 2005 & 12 & 30 & 11.00 & 27 & 30.16 & 0 & 4.85 & 0.510 & 1 & Strt. & 0.000 \\
\hline 114 & 2005 & 12 & 30 & 11.00 & 27 & 30.16 & 0.65 & 4.85 & 0.510 & 1 & Strt. & 0.134 \\
\hline 115 & 2005 & 12 & 30 & 11.00 & 27 & 30.16 & 0.86 & 4.85 & 0.510 & 1 & Strt. & 0.177 \\
\hline 116 & 2005 & 12 & 30 & 11.00 & 27 & 30.16 & 1.2 & 4.85 & 0.510 & 1 & Strt. & 0.247 \\
\hline 117 & 2005 & 12 & 30 & 11.00 & 27 & 30.16 & 1.5 & 4.85 & 0.510 & 1 & Strt. & 0.309 \\
\hline 118 & 2005 & 12 & 30 & 11.00 & 27 & 30.16 & 2.3 & 4.85 & 0.510 & 1 & Strt. & 0.474 \\
\hline 119 & 2005 & 12 & 30 & 11.00 & 27 & 30.16 & 3.1 & 4.85 & 0.510 & 1 & Strt. & 0.639 \\
\hline 120 & 2005 & 12 & 30 & 11.00 & 27 & 30.16 & 4.1 & 4.85 & 0.510 & 1 & Strt. & 0.845 \\
\hline 121 & 2005 & 12 & 30 & 12.50 & 27 & 30.19 & 0 & 4.85 & 0.255 & 1 & Strt. & 0.000 \\
\hline 122 & 2005 & 12 & 30 & 12.50 & 27 & 30.19 & 0.65 & 4.85 & 0.255 & 1 & Strt. & 0.134 \\
\hline 123 & 2005 & 12 & 30 & 12.50 & 27 & 30.19 & 0.86 & 4.85 & 0.255 & 1 & Strt. & 0.177 \\
\hline 124 & 2005 & 12 & 30 & 12.50 & 27 & 30.19 & 1.2 & 4.85 & 0.255 & 1 & Strt. & 0.247 \\
\hline 125 & 2005 & 12 & 30 & 12.50 & 27 & 30.19 & 1.5 & 4.85 & 0.255 & 1 & Strt. & 0.309 \\
\hline 126 & 2005 & 12 & 30 & 12.50 & 27 & 30.19 & 2.3 & 4.85 & 0.255 & 1 & Strt. & 0.474 \\
\hline 127 & 2005 & 12 & 30 & 12.50 & 27 & 30.19 & 3.1 & 4.85 & 0.255 & 1 & Strt. & 0.639 \\
\hline 128 & 2005 & 12 & 30 & 12.50 & 27 & 30.19 & 4.1 & 4.85 & 0.255 & 1 & Strt. & 0.845 \\
\hline 129 & 2005 & 11 & 25 & 11.00 & 10 & 30.00 & 0 & 3.85 & 2.103 & 0 & Con & 0.000 \\
\hline 130 & 2005 & 11 & 25 & 11.00 & 10 & 30.00 & 0.5 & 3.85 & 2.103 & 0 & Con & 0.130 \\
\hline 131 & 2005 & 11 & 25 & 11.00 & 10 & 30.00 & 0.7 & 3.85 & 2.103 & 0 & Con & 0.182 \\
\hline 132 & 2005 & 11 & 25 & 11.00 & 10 & 30.00 & 0.9 & 3.85 & 2.103 & 0 & Con & 0.234 \\
\hline
\end{tabular}




\begin{tabular}{|c|c|c|c|c|c|c|c|c|c|c|c|c|c|}
\hline eq. & $P_{\text {end }}$ & Hood & $V_{P_{1}}$ & $V_{2}$ & $\mathbf{V P}_{3}$ & $\mathrm{VP}_{4}$ & $\mathbf{V P}_{5}$ & $\mathbf{V P}_{\text {CLa }}$ & $\mathrm{VP}_{6}$ & $\mathbf{V P}_{7}$ & $V P_{8}$ & $\mathrm{VP}_{9}$ & $V^{V} P_{10}$ \\
\hline 89 & 631 & 378 & 159 & & 217 & 235 & 0.260 & 0.262 & 0.250 & 229 & & & \\
\hline 90 & 643 & 370 & 145 & & 0.211 & 0.219 & 0.247 & 252 & 245 & 0.222 & 202 & 71 & 147 \\
\hline 91 & 0.643 & 58 & 42 & 5 & 0.203 & 0.227 & 0.243 & 49 & & 217 & & & 141 \\
\hline 92 & 655 & 39 & 36 & & 193 & 0.209 & 0.232 & 238 & 231 & 202 & 86 & 50 & 136 \\
\hline 93 & 0.686 & 293 & 17 & & 175 & 0.187 & 0.203 & 208 & & 175 & & 40 & 10 \\
\hline 94 & 793 & 78 & 2 & & 03 & 0.112 & 0.124 & 32 & 24 & 10 & 96 & 75 & 69 \\
\hline 95 & 0.876 & 087 & .028 & & 0.042 & 0.043 & 0.051 & 052 & 050 & 43 & 0.042 & 32 & 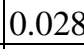 \\
\hline 96 & 1.058 & 05 & 002 & 0 & 04 & .005 & 0.005 & 06 & 05 & 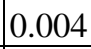 & 04 & & 002 \\
\hline 97 & 910 & 74 & & & 785 & 1.904 & 2.046 & & 342 & & 1.648 & & 289 \\
\hline 98 & 4.960 & 33 & 257 & & & 1.811 & 1.962 & 991 & & & 1.595 & & 00 \\
\hline 99 & 40 & & & & & 1.763 & 15 & & & & 1.580 & & 217 \\
\hline 100 & 5.131 & 306 & 56 & & 74 & 1.692 & 1.842 & 358 & & 1.610 & 1.434 & & 10 \\
\hline 101 & 477 & 320 & 21 & & 296 & 1.407 & 1.516 & 530 & 84 & & 1.233 & & - \\
\hline 102 & 857 & 93 & & & 0.790 & 0.848 & 0.922 & 42 & 13 & 0.817 & 0.726 & & 561 \\
\hline 103 & 6.216 & 0.427 & 66 & & 0.242 & 0.255 & 0.288 & 95 & 85 & 55 & 0.230 & & 161 \\
\hline 104 & 344 & & & & & 0.018 & & & & & 013 & & 010 \\
\hline 105 & 2.332 & 1.471 & & & 22 & 0.900 & 0.960 & 76 & & & 0.767 & & 590 \\
\hline 106 & 357 & 1 & & & & 0.842 & & & & & & & \\
\hline 107 & 386 & 382 & & & 68 & 0.817 & 0.883 & 21 & & & 0.714 & & 559 \\
\hline 108 & 439 & 1.306 & 00 & 0. & 0.732 & 0.778 & 0.833 & 51 & 38 & 47 & 0.678 & & 0.509 \\
\hline 109 & 581 & 07 & & & & 0.682 & 731 & & 16 & & 0.587 & & 417 \\
\hline 110 & 2.940 & 0.675 & 41 & & 0.359 & 0.396 & 0.439 & 45 & 26 & 80 & 0.352 & 91 & 256 \\
\hline 111 & 435 & 34 & & & 正 & 0.131 & & & & & & & 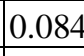 \\
\hline 112 & 3.918 & 14 & 11 & 0. & 0.013 & 0.014 & 0.016 & 17 & 016 & 15 & 0.014 & 12 & 0.011 \\
\hline 113 & 234 & 0.767 & & 0. & 0.451 & 0.488 & 0.527 & 11 & 14 & & 0.440 & & 296 \\
\hline 114 & 1.321 & 781 & & & 0.444 & 0.465 & 0.509 & 21 & 493 & 149 & 0.423 & 37 & .291 \\
\hline 115 & 329 & 0.751 & & & 0.431 & 0.467 & 0.501 & 11 & 88 & & 96 & & 281 \\
\hline 116 & 375 & 19 & & & 0. & 0.459 & 0.496 & & & & 0.379 & & 0.253 \\
\hline 117 & 405 & 04 & 29 & & 0.351 & 0.373 & 0.411 & 18 & 402 & 0.361 & 0.340 & & 0.211 \\
\hline 118 & 657 & 77 & & & & 0.237 & 0.271 & & & & 0.207 & & 0.142 \\
\hline 119 & 1.927 & 00 & 41 & & 0.068 & 0.073 & 0.087 & 89 & 975 & 0.071 & 0.065 & 49 & .040 \\
\hline 120 & 2.213 & 0.010 & 0.004 & & 0.007 & 0.010 & 0.011 & 2 & 10 & 0. & 0.006 & & .003 \\
\hline 121 & 0.591 & 0.338 & 0.109 & & 0.167 & 0.185 & 0.210 & 212 & 0.200 & 0.179 & 0.162 & 04 & 0.103 \\
\hline 122 & 0.603 & 0.330 & 0.095 & 0. & 0.161 & 0.169 & 0.197 & 202 & 0.195 & 0.172 & 0.152 & 21 & 0.097 \\
\hline 123 & 0.603 & 18 & & & 53 & 0.177 & 0.193 & & & & 0.144 & & 0.091 \\
\hline 124 & 0.615 & 0.299 & 0.086 & 0.111 & 0.143 & 0.159 & 0.182 & 88 & 0.181 & 0.152 & 0.136 & 100 & 0.086 \\
\hline 125 & 0.646 & 0.253 & \begin{tabular}{|l|}
0.067 \\
\end{tabular} & & 0.12 & 0.137 & 0.153 & 58 & 47 & 0.1 & 0.108 & 90 & 0.05 \\
\hline 126 & 0.793 & 0.178 & 0.072 & 0.089 & 0.103 & 0.112 & 0.124 & 0.132 & 0.124 & 0.110 & 0.096 & 0.075 & 0.069 \\
\hline 127 & 0.836 & 0.047 & 0.018 & 0.0 & 0.032 & 0.033 & 0.041 & 042 & 0.040 & 0.033 & 0.032 & 22 & 0.018 \\
\hline 128 & 1.018 & 0.001 & & & 0.000 & 0.004 & 0.004 & 0.005 & 0.004 & 0.000 & 0.003 & & 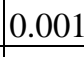 \\
\hline 129 & 5.031 & 3.097 & 1.282 & 1.541 & 1.819 & 1.982 & 2.071 & 2.097 & 2.029 & 1.886 & 1.707 & 1.413 & 1.071 \\
\hline 130 & 4.992 & 3.046 & 66 & & 1.646 & 1.826 & 2.002 & 2.041 & 17 & 32 & 1.686 & 1.474 & .13 \\
\hline 131 & 5.085 & 2.980 & 1.136 & 1.475 & 1.627 & 1.766 & 1.955 & 2.013 & 1.982 & 1.831 & 1.698 & 1.480 & 1.382 \\
\hline 132 & 5.245 & 2.781 & 1.094 & 1.321 & 1.510 & 1.670 & 1.863 & 1.892 & 1.871 & 1.726 & 1.647 & 1.418 & 1.15 \\
\hline
\end{tabular}




\begin{tabular}{|c|c|c|c|c|c|c|c|c|c|c|c|c|c|}
\hline Seq. & $V_{P_{11}}$ & $V_{P_{12}}$ & $\mathbf{V P}_{13}$ & $\mathbf{V P}_{14}$ & $\mathbf{V P}_{15}$ & $\mathbf{V P}_{\mathrm{CLb}}$ & $\mathbf{V P}_{16}$ & $\mathbf{V P}_{\mathbf{1 7}}$ & $V_{P_{18}}$ & $\mathbf{V P}_{19}$ & $\mathbf{V P}_{\mathbf{2 0}}$ & $\mathbf{V P}_{\text {avg. }}$ & TP \\
\hline 89 & 0.169 & 0.173 & 0.214 & 0.240 & 0.260 & 0.262 & 0.243 & 0.210 & 0.195 & 0.149 & 0.140 & 0.201 & 0.430 \\
\hline 90 & 0.163 & 0.171 & 0.211 & 0.230 & 0.253 & 0.256 & 0.248 & 0.209 & 0.183 & 0.165 & 0.161 & 0.197 & 0.446 \\
\hline 91 & 0.164 & 0.167 & 0.207 & 0.217 & 0.245 & \begin{tabular}{|l|}
0.248 \\
\end{tabular} & 0.243 & 0.206 & 0.182 & 0.161 & 0.153 & 0.192 & 0.451 \\
\hline 92 & 0.153 & 0.162 & 0.198 & 0.215 & 0.237 & \begin{tabular}{|l|}
0.238 \\
\end{tabular} & 0.226 & 0.205 & 0.173 & 0.153 & \begin{tabular}{|l|}
0.147 \\
\end{tabular} & \begin{tabular}{|l|}
0.184 \\
\end{tabular} & 0.471 \\
\hline 93 & 0.130 & 0.141 & 0.177 & 0.191 & 0.204 & 0.208 & $\mid 0.199$ & 0.172 & 0.169 & 0.140 & 0.134 & 0.161 & 0.525 \\
\hline 94 & 0.080 & 0.090 & 0.110 & 0.118 & 0.128 & \begin{tabular}{|l|}
0.129 \\
\end{tabular} & 0.122 & 0.107 & 0.093 & 0.088 & 0.074 & 0.098 & 0.695 \\
\hline 95 & 0.033 & 0.037 & 0.044 & 0.047 & 0.051 & 0.053 & 0.050 & 0.044 & 0.038 & 0.035 & 0.031 & 0.040 & 0.836 \\
\hline 96 & 0.003 & 0.004 & 0.005 & 0.005 & 0.006 & \begin{tabular}{|l|}
0.007 \\
\end{tabular} & 0.006 & 0.005 & 0.004 & 0.004 & 0.003 & 0.004 & 1.054 \\
\hline 97 & 1.456 & 1.499 & 1.804 & 1.917 & 2.065 & 2.080 & 2.067 & 1.831 & 1.751 & 1.566 & 1.382 & 1.696 & 3.214 \\
\hline 98 & 1.414 & 1.466 & 1.675 & 1.823 & 1.981 & 1.995 & 1.978 & 1.820 & & 1.469 & 1.372 & 1.620 & 3.340 \\
\hline 99 & 1.352 & 1.373 & 1.672 & 1.805 & 1.905 & 1.922 & 1.916 & 1.662 & 1.573 & 1.474 & 1.204 & 1.571 & 3.469 \\
\hline 100 & 1.263 & 1.319 & 1.572 & 1.704 & 1.823 & 1.842 & 1.807 & 1.719 & 1.534 & 1.358 & 1.188 & 1.498 & 3.633 \\
\hline 101 & 1.078 & 1.093 & 1.316 & 1.407 & 1.518 & \begin{tabular}{|l|}
1.525 \\
\end{tabular} & 1.486 & 1.412 & 1.296 & 1.110 & 0.986 & \begin{tabular}{|l}
1.248 \\
\end{tabular} & 4.229 \\
\hline 102 & 0.645 & 0.660 & \begin{tabular}{|l|}
0.779 \\
\end{tabular} & 0.853 & 0.927 & \begin{tabular}{|l|}
0.931 \\
\end{tabular} & 0.903 & \begin{tabular}{|l|}
0.864 \\
\end{tabular} & 0.735 & 0.636 & 0.614 & \begin{tabular}{|l|l|}
0.750 \\
\end{tabular} & 5.107 \\
\hline 103 & 0.185 & 0.198 & 0.240 & 0.268 & 0.285 & \begin{tabular}{|l|}
0.289 \\
\end{tabular} & 0.283 & 0.253 & 0.240 & 0.181 & 0.177 & \begin{tabular}{|l|l|}
0.226 \\
\end{tabular} & 5.990 \\
\hline 104 & 0.014 & 0.015 & 0.016 & 0.017 & 0.018 & 0.019 & 0.018 & 0.017 & 0.016 & 0.015 & 0.014 & 0.015 & 6.629 \\
\hline 105 & 0.652 & 0.704 & 0.819 & 0.890 & 0.949 & 0.976 & 0.931 & 0.845 & 0.829 & 0.717 & 0.649 & 0.779 & 1.553 \\
\hline 106 & 0.648 & 0.633 & 0.770 & 0.855 & 0.917 & \begin{tabular}{|l|}
0.935 \\
\end{tabular} & 0.883 & 0.810 & 0. & 0.641 & 0.621 & 742 & 1.615 \\
\hline 107 & 0.625 & 0.639 & \begin{tabular}{|l|}
0.758 \\
\end{tabular} & 0.833 & 0.901 & \begin{tabular}{|l|}
0.917 \\
\end{tabular} & 0.880 & 0.802 & 0.748 & 0.630 & 0.619 & 0.728 & 1.658 \\
\hline 108 & 0.570 & 0.596 & 0.699 & 0.771 & 0.837 & \begin{tabular}{|l|}
0.858 \\
\end{tabular} & 0.823 & \begin{tabular}{|l|} 
\\
\end{tabular} & & 0.591 & 0.561 & 0.681 & 1.758 \\
\hline 109 & 0.474 & 0.497 & 0.566 & 0.658 & 0.729 & \begin{tabular}{|l|}
0.738 \\
\end{tabular} & 0.728 & 0.678 & 0.615 & 0.542 & 0.491 & 0.587 & 1.994 \\
\hline 110 & 0.285 & 0.305 & 0.374 & 0.406 & 0.440 & \begin{tabular}{|l|}
0.451 \\
\end{tabular} & 0.424 & 0.387 & 0.362 & 0.311 & 0.271 & \begin{tabular}{|l}
0.348 \\
\end{tabular} & 2.592 \\
\hline 111 & 0.084 & 0.090 & 0.114 & 0.134 & 0.147 & \begin{tabular}{|l|}
0.156 \\
\end{tabular} & 0.142 & 0.123 & 0.1 & 0.092 & 0.086 & 0.111 & 3.324 \\
\hline 112 & 0.012 & 0.014 & 0.016 & 0.017 & 0.018 & \begin{tabular}{|l|}
0.019 \\
\end{tabular} & 0.017 & 0.016 & 0.014 & 0.012 & 0.011 & \begin{tabular}{|l}
0.014 \\
\end{tabular} & 3.904 \\
\hline 113 & 0.337 & 0.355 & 0.436 & 0.463 & 0.510 & \begin{tabular}{|l|}
0.517 \\
\end{tabular} & 0.507 & & & 0.305 & 0.296 & 0.411 & 0.823 \\
\hline 114 & 0.331 & 0.352 & 0.421 & 0.456 & 0.507 & 0.515 & 0.500 & 0.439 & 0.389 & 0.303 & 0.293 & 0.400 & 0.921 \\
\hline 115 & 0.315 & 0.326 & 0.341 & 0.463 & 0.504 & 0.512 & 0.492 & 0.424 & 0.3 & 0.301 & 0.291 & \begin{tabular}{|l|}
0.389 \\
\end{tabular} & 0.940 \\
\hline 116 & 0.326 & 0.336 & 0.414 & 0.452 & 0.495 & \begin{tabular}{|l|}
0.501 \\
\end{tabular} & 0.476 & 0.416 & 0.376 & 0.293 & 0.284 & \begin{tabular}{|l|}
0.383 \\
\end{tabular} & 0.992 \\
\hline 117 & 0.277 & 0.284 & 0.341 & 0.374 & 0.420 & 0.425 & 0.417 & 0.375 & 0.341 & 0.291 & 0.272 & 0.330 & 1.075 \\
\hline 118 & 0.171 & 0.174 & 0.203 & 0.233 & 0.266 & 0.271 & 0.261 & 0.229 & & 0.169 & 0.155 & 0.205 & 1.452 \\
\hline 119 & 0.047 & 0.052 & 0.066 & 0.072 & 0.084 & \begin{tabular}{|l|}
0.086 \\
\end{tabular} & 0.086 & 0.067 & 0.053 & 0.049 & 0.044 & 0.061 & 1.866 \\
\hline 120 & 0.006 & 0.007 & 0.008 & 0.011 & 0.012 & \begin{tabular}{|l|}
0.013 \\
\end{tabular} & 0.011 & 0.009 & 0.008 & 0.007 & 0.005 & \begin{tabular}{|l|l|} 
\\
\end{tabular} & 2.206 \\
\hline 121 & 0.119 & 0.123 & 0.164 & 0.190 & 0.210 & 0.212 & 0.193 & 0.160 & 0.145 & 0.099 & 0.090 & 0.150 & 0.441 \\
\hline 122 & 0.113 & 0.121 & 0.161 & 0.180 & 0.203 & \begin{tabular}{|l|}
0.206 \\
\end{tabular} & 0.198 & 0.159 & 0.133 & 0.115 & 0.111 & \begin{tabular}{|l}
0.147 \\
\end{tabular} & 0.456 \\
\hline 123 & 0.114 & 0.117 & 0.157 & 0.167 & 0.195 & \begin{tabular}{|l|}
0.198 \\
\end{tabular} & 0.193 & 0.156 & 0.132 & 0.111 & 0.103 & \begin{tabular}{|l}
0.142 \\
\end{tabular} & 0.461 \\
\hline 124 & 0.103 & 0.112 & 0.148 & 0.165 & 0.187 & \begin{tabular}{|l|}
0.188 \\
\end{tabular} & 0.176 & 0.155 & 0.123 & 0.103 & 0.097 & 0.133 & 0.482 \\
\hline 125 & \begin{tabular}{|l|l|} 
\\
\end{tabular} & 0.091 & 0.127 & 0.141 & 0.154 & \begin{tabular}{|l|}
0.158 \\
\end{tabular} & 0.149 & 0.122 & 0.119 & 0.090 & 0.084 & 0.111 & 0.535 \\
\hline 126 & 0.080 & 0.090 & 0.110 & 0.118 & 0.128 & \begin{tabular}{|l|}
0.129 \\
\end{tabular} & 0.122 & 0.107 & 0.093 & 0.088 & 0.074 & 0.098 & 0.695 \\
\hline 127 & 0.023 & 0.027 & 0.034 & 0.037 & 0.041 & \begin{tabular}{|l|}
0.043 \\
\end{tabular} & 0.040 & 0.034 & 0.028 & 0.025 & 0.021 & 0.030 & 0.806 \\
\hline 128 & 0.002 & 0.003 & 0.004 & 0.004 & 0.005 & 0.006 & 0.005 & 0.004 & 0.003 & 0.003 & 0.002 & 0.003 & 1.015 \\
\hline 129 & 1.505 & 1.790 & 1.950 & 2.025 & 2.098 & 2.121 & 2.101 & 2.028 & 1.974 & 1.854 & 1.594 & 1.773 & 3.258 \\
\hline 130 & 1.416 & 1.444 & 1.732 & 1.934 & 2.060 & 2.060 & 2.043 & 1.842 & 1.702 & 1.645 & 1.422 & 1.661 & 3.331 \\
\hline 131 & 1.396 & 1.546 & 1.708 & 1.907 & 2.002 & 2.005 & 1.924 & 1.757 & 1.634 & 1.612 & 1.389 & 1.652 & 3.433 \\
\hline 132 & 1.322 & 1.475 & 1.606 & 1.805 & 1.872 & 1.896 & 1.817 & 1.665 & 1.536 & 1.521 & 1.322 & 1.552 & 3.69 \\
\hline
\end{tabular}




\begin{tabular}{|c|c|c|c|c|c|c|c|}
\hline Seq. & $\mathbf{X}_{\mathrm{w} / \mathbf{0}}$ & $\mathbf{X}_{\text {end }}$ & $\mathbf{X}_{\text {damper }}$ & $\log \left(X_{\text {damper }}\right)$ & $V_{\text {avg. }}$ & Re & Pipe Factor \\
\hline 89 & 2.1447 & 2.145 & 0.0000 & & 1792.71 & 240550.22 & 0.875 \\
\hline 90 & 2.1447 & 2.256 & 0.0985 & -1.006 & 1778.50 & 238642.73 & 0.882 \\
\hline 91 & 2.1447 & 2.347 & 0.1882 & -0.725 & 1754.14 & 235374.12 & 0.879 \\
\hline 92 & 2.1447 & 2.564 & 0.4036 & -0.394 & 1715.56 & 230197.75 & 0.879 \\
\hline 93 & 2.1447 & 3.249 & 1.0813 & 0.034 & 1608.14 & 215783.56 & 0.881 \\
\hline 94 & 2.1447 & 7.068 & 4.8764 & 0.688 & 1254.73 & 168361.73 & 0.868 \\
\hline 95 & 2.1447 & 21.042 & 18.8084 & 1.274 & 797.83 & 107055.08 & 0.870 \\
\hline 96 & 2.1447 & 262.550 & 260.2180 & 2.415 & 253.57 & 34024.38 & 0.786 \\
\hline 97 & 1.8945 & 1.895 & 0.0000 & & 4967.49 & 666547.65 & 0.902 \\
\hline 98 & 1.8945 & 2.061 & 0.1536 & -0.814 & 4854.99 & 651452.11 & 0.902 \\
\hline 99 & 1.8945 & 2.209 & 0.2999 & -0.523 & 4779.89 & 641375.29 & 0.902 \\
\hline 100 & 1.8945 & 2.425 & 0.5140 & -0.289 & 4668.06 & 626370.30 & 0.900 \\
\hline 101 & 1.8945 & 3.390 & 1.4700 & 0.167 & 4259.98 & 571613.15 & 0.904 \\
\hline 102 & 1.8945 & 6.805 & 4.8599 & 0.687 & 3304.04 & 443342.54 & 0.895 \\
\hline 103 & 1.8945 & 26.505 & 24.5048 & 1.389 & 1813.16 & 243293.36 & 0.880 \\
\hline 104 & 1.8945 & 441.066 & 438.9526 & 2.642 & 467.58 & 62740.86 & 0.857 \\
\hline 105 & 1.9927 & 1.993 & 0.0000 & & 3368.49 & 451990.72 & 0.894 \\
\hline 106 & 1.9927 & 2.176 & 0.1685 & -0.773 & 3287.08 & 441067.20 & 0.889 \\
\hline 107 & 1.9927 & 2.277 & 0.2684 & -0.571 & 3255.97 & 436892.66 & 0.890 \\
\hline 108 & 1.9927 & 2.582 & 0.5694 & -0.245 & 3148.97 & 422535.43 & 0.893 \\
\hline 109 & 1.9927 & 3.397 & 1.3773 & 0.139 & 2923.68 & 392306.13 & 0.889 \\
\hline 110 & 1.9927 & 7.455 & 5.4107 & 0.733 & 2250.14 & 301928.13 & 0.881 \\
\hline 111 & 1.9927 & 29.811 & 27.7141 & 1.443 & 1274.12 & 170963.96 & 0.847 \\
\hline 112 & 1.9927 & 279.553 & 277.3675 & 2.443 & 450.95 & 60508.99 & 0.881 \\
\hline 113 & 2.0049 & 2.005 & 0.0000 & & 2450.42 & 328802.03 & 0.881 \\
\hline 114 & 2.0049 & 2.301 & 0.2841 & -0.547 & 2418.93 & 324576.49 & 0.879 \\
\hline 115 & 2.0049 & 2.414 & 0.3961 & -0.402 & 2385.64 & 320109.50 & 0.872 \\
\hline 116 & 2.0049 & 2.589 & 0.5699 & -0.244 & 2366.80 & 317581.98 & 0.874 \\
\hline 117 & 2.0049 & 3.259 & 1.2323 & 0.091 & 2196.32 & 294706.16 & 0.885 \\
\hline 118 & 2.0049 & 7.081 & 5.0320 & 0.702 & 1731.46 & 232331.03 & 0.867 \\
\hline 119 & 2.0049 & 30.476 & 28.3707 & 1.453 & 946.12 & 126951.74 & 0.836 \\
\hline 120 & 2.0049 & 297.267 & 295.0711 & 2.470 & 329.37 & 44195.41 & 0.771 \\
\hline 121 & 2.9402 & 2.940 & 0.0000 & & 1480.17 & 198612.83 & 0.841 \\
\hline 122 & 2.9402 & 3.103 & 0.1358 & -0.867 & 1465.13 & 196594.06 & 0.849 \\
\hline 123 & 2.9402 & 3.261 & 0.2917 & -0.535 & 1437.76 & 192921.53 & 0.844 \\
\hline 124 & 2.9402 & 3.618 & 0.6456 & -0.190 & 1394.76 & 187151.58 & 0.842 \\
\hline 125 & 2.9402 & 4.832 & 1.8506 & 0.267 & 1272.04 & 170684.97 & 0.837 \\
\hline 126 & 2.9402 & 7.068 & 4.0809 & 0.611 & 1198.24 & 160781.93 & 0.868 \\
\hline 127 & 2.9402 & 27.228 & 24.1861 & 1.384 & 657.72 & 88253.75 & 0.835 \\
\hline 128 & 2.9402 & 340.691 & 337.5514 & 2.528 & 208.61 & 27991.74 & 0.737 \\
\hline 129 & 1.8372 & 1.837 & 0.0000 & & 5015.50 & 534229.31 & 0.917 \\
\hline 130 & 1.8372 & 2.005 & 0.1557 & -0.808 & 4854.82 & 517114.57 & 0.900 \\
\hline 131 & 1.8372 & 2.078 & 0.2289 & -0.640 & 4841.02 & 515644.87 & 0.907 \\
\hline 132 & 1.8372 & 2.379 & 0.5271 & -0.278 & 4692.31 & 499804.55 & 0.905 \\
\hline
\end{tabular}




\begin{tabular}{|c|c|c|c|c|c|c|c|c|c|c|c|c|}
\hline Seq. & Year & Month & Date & Time & $\mathbf{T}_{\text {act }}$ & $\mathbf{P}_{\text {bar }}$ & I & D & $\mathbf{V P}_{\text {CLopen }}$ & Orient & Edge & I/D \\
\hline 133 & 2005 & 11 & 25 & 11.00 & 10 & 30.00 & 1.2 & 3.85 & 2.103 & 0 & Con & 0.312 \\
\hline 134 & 2005 & 11 & 25 & 11.00 & 10 & 30.00 & 1.8 & 3.85 & 2.103 & 0 & Con & 0.468 \\
\hline 135 & 2005 & 11 & 25 & 11.00 & 10 & 30.00 & 2.5 & 3.85 & 2.103 & 0 & Con & 0.649 \\
\hline 136 & 2005 & 11 & 25 & 11.00 & 10 & 30.00 & 3.2 & 3.85 & 2.103 & 0 & Con & 0.831 \\
\hline 137 & 2005 & 11 & 24 & 15.50 & 19 & 29.78 & 0 & 3.85 & 1.010 & 0 & Con & 0.000 \\
\hline 138 & 2005 & 11 & 24 & 15.50 & 19 & 29.78 & 0.5 & 3.85 & 1.010 & 0 & Con & 0.130 \\
\hline 139 & 2005 & 11 & 24 & 15.50 & 19 & 29.78 & 0.7 & 3.85 & 1.010 & 0 & Con & 0.182 \\
\hline 140 & 2005 & 11 & 24 & 15.50 & 19 & 29.78 & 0.9 & 3.85 & 1.010 & 0 & Con & 0.234 \\
\hline 141 & 2005 & 11 & 24 & 15.50 & 19 & 29.78 & 1.2 & 3.85 & 1.010 & 0 & Con & 0.312 \\
\hline 142 & 2005 & 11 & 24 & 15.50 & 19 & 29.78 & 1.8 & 3.85 & 1.010 & 0 & Con & 0.468 \\
\hline 143 & 2005 & 11 & 24 & 15.50 & 19 & 29.78 & 2.5 & 3.85 & 1.010 & 0 & Con & 0.649 \\
\hline 144 & 2005 & 11 & 24 & 15.50 & 19 & 29.78 & 3.2 & 3.85 & 1.010 & 0 & Con & 0.831 \\
\hline 145 & 2005 & 11 & 24 & 14.25 & 19 & 29.78 & 0 & 3.85 & 0.510 & 0 & Con & 0.000 \\
\hline 146 & 2005 & 11 & 24 & 14.25 & 19 & 29.78 & 0.5 & 3.85 & 0.510 & 0 & Con & 0.130 \\
\hline 147 & 2005 & 11 & 24 & 14.25 & 19 & 29.78 & 0.7 & 3.85 & 0.510 & 0 & Con & 0.182 \\
\hline 148 & 2005 & 11 & 24 & 14.25 & 19 & 29.78 & 0.9 & 3.85 & 0.510 & 0 & Con & 0.234 \\
\hline 149 & 2005 & 11 & 24 & 14.25 & 19 & 29.78 & 1.2 & 3.85 & 0.510 & 0 & Con & 0.312 \\
\hline 150 & 2005 & 11 & 24 & 14.25 & 19 & 29.78 & 1.8 & 3.85 & 0.510 & 0 & Con & 0.468 \\
\hline 151 & 2005 & 11 & 24 & 14.25 & 19 & 29.78 & 2.5 & 3.85 & 0.510 & 0 & Con & 0.649 \\
\hline 152 & 2005 & 11 & 24 & 14.25 & 19 & 29.78 & 3.2 & 3.85 & 0.510 & 0 & Con & 0.831 \\
\hline 153 & 2005 & 11 & 25 & 12.25 & 13 & 30.00 & 0 & 3.85 & 0.255 & 0 & Con & 0.000 \\
\hline 154 & 2005 & 11 & 25 & 12.25 & 13 & 30.00 & 0.5 & 3.85 & 0.255 & 0 & Con & 0.130 \\
\hline 155 & 2005 & 11 & 25 & 12.25 & 13 & 30.00 & 0.7 & 3.85 & 0.255 & 0 & Con & 0.182 \\
\hline 156 & 2005 & 11 & 25 & 12.25 & 13 & 30.00 & 0.9 & 3.85 & 0.255 & 0 & Con & 0.234 \\
\hline 157 & 2005 & 11 & 25 & 12.25 & 13 & 30.00 & 1.2 & 3.85 & 0.255 & 0 & Con & 0.312 \\
\hline 158 & 2005 & 11 & 25 & 12.25 & 13 & 30.00 & 1.8 & 3.85 & 0.255 & 0 & Con & 0.468 \\
\hline 159 & 2005 & 11 & 25 & 12.25 & 13 & 30.00 & 2.5 & 3.85 & 0.255 & 0 & Con & 0.649 \\
\hline 160 & 2005 & 11 & 25 & 12.25 & 13 & 30.00 & 3.2 & 3.85 & 0.255 & 0 & Con & 0.831 \\
\hline 161 & 2005 & 12 & 30 & 14.50 & 28 & 30.00 & 0 & 3.85 & 2.103 & 1 & Con & 0.000 \\
\hline 162 & 2005 & 12 & 30 & 14.50 & 28 & 30.00 & 0.5 & 3.85 & 2.103 & 1 & Con & 0.130 \\
\hline 163 & 2005 & 12 & 30 & 14.50 & 28 & 30.00 & 0.7 & 3.85 & 2.103 & 1 & Con & 0.182 \\
\hline 164 & 2005 & 12 & 30 & 14.50 & 28 & 30.00 & 0.9 & 3.85 & 2.103 & 1 & Con & 0.234 \\
\hline 165 & 2005 & 12 & 30 & 14.50 & 28 & 30.00 & 1.2 & 3.85 & 2.103 & 1 & Con & 0.312 \\
\hline 166 & 2005 & 12 & 30 & 14.50 & 28 & 30.00 & 1.8 & 3.85 & 2.103 & 1 & Con & 0.468 \\
\hline 167 & 2005 & 12 & 30 & 14.50 & 28 & 30.00 & 2.5 & 3.85 & 2.103 & 1 & Con & 0.649 \\
\hline 168 & 2005 & 12 & 30 & 14.50 & 28 & 30.00 & 3.2 & 3.85 & 2.103 & 1 & Con & 0.831 \\
\hline 169 & 2005 & 12 & 30 & 15.50 & 25 & 29.78 & 0 & 3.85 & 1.010 & 1 & Con & 0.000 \\
\hline 170 & 2005 & 12 & 30 & 15.50 & 25 & 29.78 & 0.5 & 3.85 & 1.010 & 1 & Con & 0.130 \\
\hline 171 & 2005 & 12 & 30 & 15.50 & 25 & 29.78 & 0.7 & 3.85 & 1.010 & 1 & Con & 0.182 \\
\hline 172 & 2005 & 12 & 30 & 15.50 & 25 & 29.78 & 0.9 & 3.85 & 1.010 & 1 & Con & 0.234 \\
\hline 173 & 2005 & 12 & 30 & 15.50 & 25 & 29.78 & 1.2 & 3.85 & 1.010 & 1 & Con & 0.312 \\
\hline 174 & 2005 & 12 & 30 & 15.50 & 25 & 29.78 & 1.8 & 3.85 & 1.010 & 1 & Con & 0.468 \\
\hline 175 & 2005 & 12 & 30 & 15.50 & 25 & 29.78 & 2.5 & 3.85 & 1.010 & 1 & Con & 0.649 \\
\hline 176 & 2005 & 12 & 30 & 15.50 & 25 & 29.78 & 3.2 & 3.85 & 1.010 & 1 & Con & 0.831 \\
\hline 177 & 2005 & 12 & 30 & 14.25 & 25 & 29.78 & 0 & 3.85 & 0.510 & 1 & Con & 0.000 \\
\hline
\end{tabular}




\begin{tabular}{|c|c|c|c|c|c|c|c|c|c|c|c|c|c|}
\hline$q$. & end & Hood & $V P_{1}$ & $\mathbf{V P}_{2}$ & $\mathbf{V P}_{3}$ & $\mathrm{VP}_{4}$ & $\mathbf{V P}_{5}$ & $\mathbf{P}_{\text {CLa }}$ & $\mathrm{VP}_{6}$ & $\mathbf{V P}_{7}$ & $V P_{8}$ & $\mathrm{VP}_{9}$ & $V_{P_{10}}$ \\
\hline 33 & 212 & 428 & 0.931 & & 375 & 1.479 & 1.603 & 1.648 & 1.624 & 1.487 & 329 & 1.139 & \\
\hline 134 & 560 & 408 & 548 & & 0.809 & 0.866 & 0.965 & 983 & 939 & & 773 & & \\
\hline 35 & 860 & 357 & 130 & & 0.200 & 244 & 0.260 & 61 & & & & & -1 \\
\hline 136 & 674 & 66 & 22 & & 038 & 0.040 & 0.043 & 949 & & & 038 & & 022 \\
\hline 137 & 243 & 76 & 75 & & 0.841 & 0.934 & 0.959 & 07 & & & & & \\
\hline 138 & 270 & 46 & 516 & & 7 & 47 & 0.907 & 40 & 919 & 0.811 & 764 & & 631 \\
\hline 139 & 292 & 301 & 602 & & 0.798 & 0.846 & 0.905 & 910 & 398 & 0.803 & 0.746 & & 0.608 \\
\hline 140 & 345 & 21 & 575 & & 0.742 & 0.811 & \begin{tabular}{|l|}
0.858 \\
\end{tabular} & 370 & 48 & 0.761 & 704 & & 561 \\
\hline 141 & 498 & 58 & 92 & & 0.680 & 0.696 & 0.748 & 762 & & & 593 & & 482 \\
\hline 142 & 782 & 18 & 329 & & 0. & \begin{tabular}{|l|}
0.468 \\
\end{tabular} & 0.500 & & & & & & 0.334 \\
\hline 143 & 261 & & & & & & 0.211 & & & & 0.165 & & 100 \\
\hline 144 & 644 & 34 & 20 & & 0.026 & 0.030 & 0.031 & 33 & 029 & & 0.021 & & 019 \\
\hline 145 & 104 & & & & 0.407 & 0.456 & 0.462 & 03 & 77 & & 0.444 & & 350 \\
\hline 146 & 122 & & 10 & & 0.368 & 0.377 & 0.398 & 25 & 16 & 11 & \begin{tabular}{|l|}
0.372 \\
\end{tabular} & & 300 \\
\hline 147 & 165 & & & & 0.354 & 0. & 0.386 & 11 & 11 & & 0.366 & & + \\
\hline 148 & 220 & & & & 0.343 & 0.404 & 0.409 & & 10 & & 0.351 & & 287 \\
\hline 149 & 1.266 & 0.427 & 0.227 & & 0.326 & 0.331 & 0.346 & 59 & 41 & 19 & 0.303 & & 223 \\
\hline 150 & 459 & & & & 0. & 0.203 & 0.208 & & & & 0.190 & & 155 \\
\hline 151 & 745 & 0.054 & 28 & & 0.038 & 0.042 & 0.045 & & 46 & & 0.041 & & 029 \\
\hline 152 & 364 & & & & 0.009 & 0 & 0.010 & & & & 0.00 & & \\
\hline 153 & 618 & & & & 0.193 & 0.211 & 0.231 & & 29 & & 0.190 & & $t$ \\
\hline 154 & 616 & & & & 0. & & 0.216 & & & & 0.17 & & \\
\hline 155 & 595 & & & & 0.180 & 0.189 & 0.198 & 15 & 92 & & 0.173 & & 101 \\
\hline 156 & 609 & 69 & 091 & & 0. & 0.177 & 0.185 & & 79 & & 0.162 & & \\
\hline 157 & 696 & & & & 0. & 0. & 0.181 & & 67 & 30 & 0.153 & & 883 \\
\hline 158 & 788 & 43 & 1 & & 0.087 & 0.094 & 0.112 & & 09 & & 0.080 & & \\
\hline 159 & 001 & & & & & & 0 & & & & 0 & & \\
\hline 160 & 008 & 02 & 06 & & 0.009 & 0.011 & 0.013 & 14 & 08 & 0.005 & 0.004 & & 002 \\
\hline 161 & 981 & & & & 1.789 & 1.952 & 2.041 & & & & 1.677 & & \\
\hline 162 & 942 & 96 & & & 1.616 & 1.796 & 1.972 & 11 & 87 & 02 & 1.656 & 44 & +1 \\
\hline 163 & 5.035 & 2.930 & 1.106 & 1. & 1.597 & 1.736 & 1.925 & 33 & 952 & 1.801 & 1.668 & & \\
\hline 164 & 195 & & & & 1.480 & & 1.833 & & & & 1.617 & & \\
\hline 165 & 5.162 & 2.378 & 01 & 1.122 & 1.345 & 1.449 & 1.573 & 1.618 & 1.594 & 1.457 & 1.299 & 1.109 & 0.825 \\
\hline 166 & 5.510 & & 0.518 & & 0.779 & 0.836 & 0.935 & & & & \begin{tabular}{|l|} 
\\
\end{tabular} & & \\
\hline 167 & 5.810 & 07 & 00 & & 0.170 & 0.214 & 0.230 & 31 & 222 & 0.205 & 0.185 & 36 & 10 \\
\hline 168 & 6.624 & 0.016 & 0.019 & 0.020 & 0.035 & 0.037 & 0.040 & 0.046 & 42 & 0.036 & 0.035 & 0. & 0 \\
\hline 169 & 2.213 & & & & 0.801 & 0.894 & \begin{tabular}{|l|}
0.919 \\
\end{tabular} & & \begin{tabular}{|l|l|} 
\\
\end{tabular} & 0.862 & 0.786 & & \\
\hline 170 & 2.240 & 1.316 & 576 & 0.682 & 0.757 & 0.807 & 0.867 & 0.900 & 0.879 & 0.771 & 0.724 & 0.584 & 0.591 \\
\hline 171 & 2.262 & & 62 & & 0.758 & 0.806 & 0.865 & & 58 & & 0.706 & & \\
\hline 172 & 2.315 & 1.191 & 0.535 & & 0.702 & 0.771 & 0.818 & 0.830 & 0.808 & 0.721 & 0.664 & 0.526 & 0.52 \\
\hline 173 & 2.468 & 1.028 & 0.452 & 0.583 & 0.640 & 0.656 & 0.708 & 0.722 & 0.697 & 0.621 & 0.553 & 0.441 & 0. \\
\hline 174 & 2.152 & 0.088 & 0.289 & 0.362 & 0.395 & 0.428 & 0.460 & $0.4 / 3$ & 0.446 & 0.400 & $0.35 \%$ & 0.29 & \\
\hline 175 & 3.231 & 0.269 & \begin{tabular}{|l|}
0.075 \\
\end{tabular} & 0.112 & 0.136 & 0.157 & 0.171 & 0.181 & 0.170 & 0.145 & 0.125 & 0.09 & 0.06 \\
\hline 176 & 614 & & & & 0.0 & 0.026 & 0.027 & & $0.0<3$ & & 0.017 & & \\
\hline 177 & 084 & $5 / 1$ & 032 & & 0.3 & $T$ & 0.452 & 0.493 & 0.467 & & 0.43 & & 0.32 \\
\hline
\end{tabular}




\begin{tabular}{|c|c|c|c|c|c|c|c|c|c|c|c|c|c|}
\hline & & 12 & & $\mathbf{P}_{14}$ & $\mathbf{P}_{15}$ & $L_{L 1}$ & $\mathbf{P}_{16}$ & $\mathbf{P}_{17}$ & $V_{18}$ & $P_{19}$ & $\mathbf{P}_{20}$ & av & \\
\hline 33 & & & & & 601 & & & & & & & & \\
\hline & & & & & & & & & & & & 8 & \\
\hline 35 & & & & & & & & & & & & & \\
\hline & & & & & & & & & & & & & \\
\hline 37 & & & 343 & 0.889 & & & & 344 & & & & & \\
\hline & & & 352 & 871 & & & & & & & & & \\
\hline & & & & & & & & & & & & & \\
\hline 10 & & & & & & & & & & & & & \\
\hline & & & & & & & & & & & & & \\
\hline 42 & & & 1 & 0.482 & 02 & & & 473 & & 30 & & & \\
\hline & & & & ( & & & & & & & & & \\
\hline 44 & & & 7 & 031 & & & 31 & טסנת & & & & & \\
\hline 45 & & & & ( & & & & & & & & & \\
\hline & & & & & & & & & & & & & \\
\hline 17 & & & & ( & & & & & & & & & \\
\hline & & & & & & & & & & & & & \\
\hline 49 & & & 2 & 347 & & & 49 & 329 & & & & & \\
\hline & & & & & & & & & & & & & \\
\hline 1 & & & & ( & & & & 4 & & & & & \\
\hline 52 & & & & & & & & & & & & & \\
\hline & & & & & & & & & & & & & \\
\hline 54 & & & 1 & ( & & & & 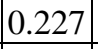 & & & & & \\
\hline & & & & & & & & & & & & & \\
\hline 56 & & & & ( & & & & & & & & & \\
\hline 15 & & & & & & & & & & & & & \\
\hline & & & & & & & & & & & & & \\
\hline 59 & & & & & & & & & & & & & \\
\hline 0 & & & & & & & & & & & & & \\
\hline 61 & & & & & & & & & & & & & \\
\hline & & & & & & & & & & & & & \\
\hline & & & & 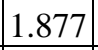 & & & & & & & & & \\
\hline 16 & & & & & & & & & & & & & \\
\hline & & & & 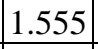 & & & & & & & & & \\
\hline- & & & & & & & & & & & & & \\
\hline 16 & & & & & & & & & & & & & \\
\hline 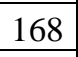 & & & & & & & & & & & & & \\
\hline 16 & & & & & & & & & & & & & \\
\hline & & & & + & & & & 55 & & & & & \\
\hline 171 & & & 의 & 4 & & & & & & 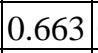 & & & \\
\hline 17 & & & & 0.11 & & & & . & & & & & \\
\hline 7 & & & & & & & & & & & & & \\
\hline & & & & & & & & & & & & & \\
\hline & & & & 0.1 & & & & 37 & & 27 & & & \\
\hline 17 & & 19 & 0. & + & .029 & & 27 & 0026 & & 01 & 0.01 & 21 & 3.59 \\
\hline 17 & & & & & & & & & & & & & \\
\hline
\end{tabular}




\begin{tabular}{|c|c|c|c|c|c|c|c|}
\hline Seq. & $\mathbf{X}_{\mathrm{w} / \mathbf{0}}$ & $\mathbf{X}_{\text {end }}$ & $\mathbf{X}_{\text {damper }}$ & $\log \left(X_{\text {damper }}\right)$ & $V_{\text {avg. }}$ & Re & Pipe Factor \\
\hline 133 & 1.8372 & 3.004 & 1.1429 & 0.058 & 4297.32 & 457732.14 & 0.889 \\
\hline 134 & 1.8372 & 6.337 & 4.4501 & 0.648 & 3278.75 & 349238.23 & 0.882 \\
\hline 135 & 1.8372 & 28.523 & 26.5745 & 1.424 & 1678.04 & 178737.41 & 0.870 \\
\hline 136 & 1.8372 & 191.722 & 189.6989 & 2.278 & 700.91 & 74657.75 & 0.849 \\
\hline 137 & 1.7312 & 1.731 & 0.0000 & & 3458.51 & 368385.95 & 0.904 \\
\hline 138 & 1.7312 & 1.940 & 0.1954 & -0.709 & 3353.46 & 357196.32 & 0.902 \\
\hline 139 & 1.7312 & 2.044 & 0.2984 & -0.525 & 3311.48 & 352724.02 & 0.911 \\
\hline 140 & 1.7312 & 2.330 & 0.5814 & -0.236 & 3202.38 & 341103.23 & 0.901 \\
\hline 141 & 1.7312 & 2.988 & 1.2331 & 0.091 & 3020.47 & 321727.62 & 0.907 \\
\hline 142 & 1.7312 & 5.580 & 3.8061 & 0.580 & 2481.54 & 264322.38 & 0.909 \\
\hline 143 & 1.7312 & 18.367 & 16.5501 & 1.219 & 1566.01 & 166804.75 & 0.875 \\
\hline 144 & 1.7312 & 145.780 & 143.8793 & 2.158 & 601.32 & 64050.22 & 0.861 \\
\hline 145 & 1.7109 & 1.711 & 0.0000 & & 2435.45 & 259413.21 & 0.897 \\
\hline 146 & 1.7109 & 1.998 & 0.2715 & -0.566 & 2334.80 & 248692.86 & 0.908 \\
\hline 147 & 1.7109 & 2.246 & 0.5174 & -0.286 & 2286.42 & 243539.61 & 0.930 \\
\hline 148 & 1.7109 & 2.559 & 0.8282 & -0.082 & 2234.51 & 238010.57 & 0.908 \\
\hline 149 & 1.7109 & 3.223 & 1.4863 & 0.172 & 2089.46 & 222560.55 & 0.908 \\
\hline 150 & 1.7109 & 6.780 & 5.0200 & 0.701 & 1652.71 & 176039.69 & 0.914 \\
\hline 151 & 1.7109 & 43.250 & 41.4190 & 1.617 & 757.86 & 80724.50 & 0.893 \\
\hline 152 & 1.7109 & 246.519 & 244.6185 & 2.388 & 331.18 & 35276.27 & 0.761 \\
\hline 153 & 2.3495 & 2.350 & 0.0000 & & 1623.00 & 172875.07 & 0.839 \\
\hline 154 & 2.3495 & 2.542 & 0.1732 & -0.761 & 1575.80 & 167847.25 & 0.840 \\
\hline 155 & 2.3495 & 2.650 & 0.2786 & -0.555 & 1525.50 & 162490.11 & 0.841 \\
\hline 156 & 2.3495 & 3.083 & 0.7068 & -0.151 & 1459.30 & 155438.28 & 0.816 \\
\hline 157 & 2.3495 & 3.997 & 1.6173 & 0.209 & 1410.21 & 150209.72 & 0.820 \\
\hline 158 & 2.3495 & 7.880 & 5.4796 & 0.739 & 1125.54 & 119887.49 & 0.836 \\
\hline 159 & 2.3495 & 27.930 & 25.4858 & 1.406 & 702.84 & 74863.26 & 0.824 \\
\hline 160 & 2.3495 & 135.258 & 132.7467 & 2.123 & 324.99 & 34616.04 & 0.703 \\
\hline 161 & 1.8578 & 1.858 & 0.0000 & & 5066.86 & 539700.31 & 0.916 \\
\hline 162 & 1.8578 & 2.030 & 0.1593 & -0.798 & 4901.71 & 522108.50 & 0.899 \\
\hline 163 & 1.8578 & 2.105 & 0.2338 & -0.631 & 4887.61 & 520607.40 & 0.905 \\
\hline 164 & 1.8578 & 2.414 & 0.5398 & -0.268 & 4734.60 & 504309.05 & 0.904 \\
\hline 165 & 1.8578 & 3.060 & 1.1775 & 0.071 & 4327.49 & 460945.37 & 0.887 \\
\hline 166 & 1.8578 & 6.574 & 4.6645 & 0.669 & 3273.47 & 348676.01 & 0.878 \\
\hline 167 & 1.8578 & 33.590 & 31.6136 & 1.500 & 1572.92 & 167540.84 & 0.851 \\
\hline 168 & 1.8578 & 208.743 & 206.6960 & 2.315 & 682.04 & 72648.13 & 0.838 \\
\hline 169 & 1.8333 & 1.833 & 0.0000 & & 3393.92 & 361505.97 & 0.899 \\
\hline 170 & 1.8333 & 2.060 & 0.2112 & -0.675 & 3285.37 & 349942.98 & 0.897 \\
\hline 171 & 1.8333 & 2.174 & 0.3233 & -0.490 & 3241.98 & 345321.68 & 0.906 \\
\hline 172 & 1.8333 & 2.487 & 0.6329 & -0.199 & 3129.01 & 333288.78 & 0.895 \\
\hline 173 & 1.8333 & 3.211 & 1.3504 & 0.130 & 2940.08 & 313164.20 & 0.901 \\
\hline 174 & 1.8333 & 6.193 & 4.3127 & 0.635 & 2375.27 & 253003.17 & 0.901 \\
\hline 175 & 1.8333 & 24.281 & 22.3497 & 1.349 & 1372.85 & 146230.33 & 0.843 \\
\hline 176 & 1.8333 & 173.007 & 170.9969 & 2.233 & 553.43 & 58949.28 & 0.839 \\
\hline 177 & 1.7291 & 1.729 & 0.0000 & & 2420.22 & 257791.63 & 0.895 \\
\hline
\end{tabular}




\begin{tabular}{|c|c|c|c|c|c|c|c|c|c|c|c|c|}
\hline Seq. & Year & Month & Date & Time & $\mathbf{T}_{\text {act }}$ & $\mathbf{P}_{\text {bar }}$ & $\mathrm{I}$ & D & $V_{P_{\text {CLopen }}}$ & Orient & Edge & I/D \\
\hline 178 & 2005 & 12 & 30 & 14.25 & 25 & 29.78 & 0.5 & 3.85 & 0.510 & 1 & Con & 0.130 \\
\hline 179 & 2005 & 12 & 30 & 14.25 & 25 & 29.78 & 0.7 & 3.85 & 0.510 & 1 & Con & 0.182 \\
\hline 180 & 2005 & 12 & 30 & 14.25 & 25 & 29.78 & 0.9 & 3.85 & 0.510 & 1 & Con & 0.234 \\
\hline 181 & 2005 & 12 & 30 & 14.25 & 25 & 29.78 & 1.2 & 3.85 & 0.510 & 1 & Con & 0.312 \\
\hline 182 & 2005 & 12 & 30 & 14.25 & 25 & 29.78 & 1.8 & 3.85 & 0.510 & 1 & Con & 0.468 \\
\hline 183 & 2005 & 12 & 30 & 14.25 & 25 & 29.78 & 2.5 & 3.85 & 0.510 & 1 & Con & 0.649 \\
\hline 184 & 2005 & 12 & 30 & 14.25 & 25 & 29.78 & 3.2 & 3.85 & 0.510 & 1 & Con & 0.831 \\
\hline 185 & 2005 & 11 & 25 & 14.00 & 18 & 30.00 & 0 & 3.85 & 0.255 & 1 & Con & 0.000 \\
\hline 186 & 2005 & 11 & 25 & 14.00 & 18 & 30.00 & 0.5 & 3.85 & 0.255 & 1 & Con & 0.130 \\
\hline 187 & 2005 & 11 & 25 & 14.00 & 18 & 30.00 & 0.7 & 3.85 & 0.255 & 1 & Con & 0.182 \\
\hline 188 & 2005 & 11 & 25 & 14.00 & 18 & 30.00 & 0.9 & 3.85 & 0.255 & 1 & Con & 0.234 \\
\hline 189 & 2005 & 11 & 25 & 14.00 & 18 & 30.00 & 1.2 & 3.85 & 0.255 & 1 & Con & 0.312 \\
\hline 190 & 2005 & 11 & 25 & 14.00 & 18 & 30.00 & 1.8 & 3.85 & 0.255 & 1 & Con & 0.468 \\
\hline 191 & 2005 & 11 & 25 & 14.00 & 18 & 30.00 & 2.5 & 3.85 & 0.255 & 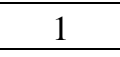 & Con & 0.649 \\
\hline 192 & 2005 & 11 & 25 & 14.00 & 18 & 30.00 & 3.2 & 3.85 & 0.255 & 1 & Con & 0.831 \\
\hline 193 & 2005 & 12 & 10 & 14.00 & 27 & 29.80 & 0 & 3.85 & 2.103 & 0 & Strt. & 0.000 \\
\hline 194 & 2005 & 12 & 10 & 14.00 & 27 & 29.80 & 0.5 & 3.85 & 2.103 & 0 & Strt. & 0.130 \\
\hline 195 & 2005 & 12 & 10 & 14.00 & 27 & 29.80 & 0.7 & 3.85 & 2.103 & 0 & Strt. & 0.182 \\
\hline 196 & 2005 & 12 & 10 & 14.00 & 27 & 29.80 & 0.9 & 3.85 & 2.103 & 0 & Strt. & 0.234 \\
\hline 197 & 2005 & 12 & 10 & 14.00 & 27 & 29.80 & 1.2 & 3.85 & 2.103 & 0 & Strt. & 0.312 \\
\hline 198 & 2005 & 12 & 10 & 14.00 & 27 & 29.80 & 1.8 & 3.85 & 2.103 & 0 & Strt. & 0.468 \\
\hline 199 & 2005 & 12 & 10 & 14.00 & 27 & 29.80 & 2.5 & 3.85 & 2.103 & 0 & Strt. & 0.649 \\
\hline 200 & 2005 & 12 & 10 & 14.00 & 27 & 29.80 & 3.2 & 3.85 & 2.103 & . & trt. & 0.831 \\
\hline 201 & 2005 & 12 & 10 & 15.25 & 26 & 29.80 & 0 & 3.85 & 1.010 & 0 & Strt. & 0.000 \\
\hline 202 & 2005 & 12 & 10 & 15.25 & 26 & 29.80 & 0.5 & 3.85 & 1.010 & 0 & Strt. & 0.130 \\
\hline 203 & 2005 & 12 & 10 & 15.25 & 26 & 29.80 & 0.7 & 3.85 & 1.010 & 0 & Strt. & 0.182 \\
\hline 204 & 2005 & 12 & 10 & 15.25 & 26 & 29.80 & 0.9 & 3.85 & 1.010 & 0 & Strt. & 0.234 \\
\hline 205 & 2005 & 12 & 10 & 15.25 & 26 & 29.80 & 1.2 & 3.85 & 1.010 & 0 & Strt. & 0.312 \\
\hline 206 & 2005 & 12 & 10 & 15.25 & 26 & 29.80 & 1.8 & 3.85 & 1.010 & 0 & Strt. & 0.468 \\
\hline 207 & 2005 & 12 & 10 & 15. & 26 & 29.80 & 2.5 & 3.85 & & 0 & Strt. & 0.649 \\
\hline 208 & 2005 & 12 & 10 & 15.25 & 26 & 29.80 & 3.2 & 3.85 & 1.010 & 0 & Strt. & 0.831 \\
\hline 209 & 2005 & 12 & 10 & 17.00 & 26 & 29.78 & 0 & 3.85 & 0.510 & 0 & Strt. & 0.000 \\
\hline 210 & 2005 & 12 & 10 & 17.00 & 26 & 29.78 & 0.5 & 3.85 & & 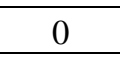 & Strt. & 0.130 \\
\hline 211 & 2005 & 12 & 10 & 17.00 & 26 & 29.78 & 0.7 & 3.85 & 0.510 & 0 & Strt. & 0.182 \\
\hline 212 & 2005 & 12 & 10 & 17.00 & 26 & 29.78 & 0.9 & 3.85 & 0.510 & 0 & Strt. & 0.234 \\
\hline 213 & 2005 & 12 & 10 & 17.00 & 26 & 29.78 & 1.2 & 3.85 & 0.510 & 0 & Strt. & 0.312 \\
\hline 214 & 2005 & 12 & 10 & 17.00 & 26 & 29.78 & 1.8 & 3.85 & 0.510 & 0 & Strt. & 0.468 \\
\hline 215 & 2005 & 12 & 10 & 17.00 & 26 & 29.78 & 2.5 & 3.85 & 0.510 & 0 & Strt. & 0.649 \\
\hline 216 & 2005 & 12 & 10 & 17.00 & 26 & 29.78 & 3.2 & 3.85 & 0.510 & 0 & Strt. & 0.831 \\
\hline 217 & 2005 & 12 & 10 & 18.50 & 24 & 29.78 & 0 & 3.85 & 0.255 & 0 & Strt. & 0.000 \\
\hline 218 & 2005 & 12 & 10 & 18.50 & 24 & 29.78 & 0.5 & 3.85 & 0.255 & 0 & Strt. & 0.130 \\
\hline 219 & 2005 & 12 & 10 & 18.50 & 24 & 29.78 & 0.7 & 3.85 & 0.255 & 0 & Strt. & 0.182 \\
\hline 220 & 2005 & 12 & 10 & 18.50 & 24 & 29.78 & 0.9 & 3.85 & 0.255 & 0 & Strt. & 0.234 \\
\hline 221 & 2005 & 12 & 10 & 18.50 & 24 & 29.78 & 1.2 & 3.85 & 0.255 & 0 & Strt. & 0.312 \\
\hline 222 & 2005 & 12 & 10 & 18.50 & 24 & 29.78 & 1.8 & 3.85 & 0.255 & 0 & Strt. & 0.468 \\
\hline
\end{tabular}




\begin{tabular}{|c|c|c|c|c|c|c|c|c|c|c|c|c|c|}
\hline & $P_{\text {end }}$ & Hood & $\mathbf{P}_{1}$ & $11_{2}$ & $\mathbf{V P}_{3}$ & $\mathrm{VP}_{4}$ & $\mathbf{V P}_{5}$ & $\mathbf{V P}_{\text {CLa }}$ & $\mathrm{VP}_{6}$ & $\mathbf{V P}_{7}$ & $\mathrm{VP}_{8}$ & $\mathrm{VP}_{9}$ & \\
\hline 178 & 102 & .546 & 0.300 & & 0.358 & 367 & 0.388 & 0.415 & 0.406 & 0.401 & 362 & 0.331 & \\
\hline 179 & 145 & 511 & 282 & & 0.344 & 0.355 & 0.376 & 401 & 401 & 0.381 & & & 287 \\
\hline 180 & 00 & 55 & 69 & 31 & 33 & 94 & 399 & 05 & 00 & 372 & 341 & 85 & 277 \\
\hline 181 & 246 & 407 & 17 & & 16 & 321 & 0.336 & 449 & 31 & 309 & 293 & 267 & 213 \\
\hline 182 & 139 & 29 & & & & 93 & 198 & & & & 180 & & 145 \\
\hline 183 & 725 & 334 & 018 & & 0.028 & 0.032 & 0.035 & 37 & 36 & $\sqrt{34}$ & 031 & 28 & 019 \\
\hline 184 & 344 & 06 & & & & 8 & 0.009 & & & & & & \\
\hline 185 & 880 & & & & & 209 & 0.229 & & & & 191 & & 126 \\
\hline 186 & 590 & 994 & 10 & & & 93 & 0.214 & & & & & & \\
\hline 187 & 598 & & & & & & 0.199 & & & & 172 & & 100 \\
\hline 188 & 612 & 72 & 92 & & 0.168 & 0.178 & 0.186 & 207 & 78 & 0.174 & 0.161 & & 098 \\
\hline 189 & 540 & 42 & & & & & 0.179 & & & & & & 4 \\
\hline 190 & 756 & 33 & & & & 92 & 0.110 & & & & 81 & & 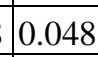 \\
\hline 191 & 878 & 54 & & & & 0.040 & 0.047 & & & & 30 & & 0.026 \\
\hline 192 & 66 & & & & & & 0.011 & & & & 005 & & 003 \\
\hline 193 & 545 & 442 & & & & 398 & 2.090 & & & & 1.725 & & 273 \\
\hline 194 & 992 & & & & & & 2.002 & & & & & & 35 \\
\hline 195 & 712 & 99 & & & & 02 & 1.880 & & & 721 & 555 & & 160 \\
\hline 196 & 348 & 52 & & & & 45 & 1.845 & & & & 85 & & 106 \\
\hline 197 & 049 & 21 & & & & 59 & 1.512 & & & 492 & 1.329 & & 055 \\
\hline 198 & 829 & 68 & 0 & & & 85 & 0.840 & & & & 15 & & 528 \\
\hline 199 & 345 & & & & & & 0.268 & & & & 212 & & \\
\hline 200 & 765 & 32 & & & & 30 & 0.032 & & & 0.032 & 0.029 & & 027 \\
\hline 201 & 243 & 76 & & & & & 0.959 & & & & & & \\
\hline 202 & 270 & 346 & & & & 347 & 0.907 & & 19 & 0.811 & 0.764 & & 631 \\
\hline 203 & 292 & 1.301 & & & & & 0.905 & & & & 0.746 & & \\
\hline 204 & 345 & & & & 0. & 1 & 0.858 & & & 0.761 & 04 & & \\
\hline 205 & 498 & 058 & & & 0. & 696 & 0.748 & & 37 & 0.661 & 593 & & ( \\
\hline 206 & 702 & 18 & & & & & 0.500 & & & & & & 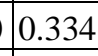 \\
\hline 207 & 633 & 234 & & & 0. & 115 & 0.126 & 46 & 34 & 125 & 0.114 & 98 & 0.095 \\
\hline 208 & 404 & 0.009 & & & & & 0.021 & & & & 0.019 & & \\
\hline 209 & 136 & 95 & & & 0.3 & 0.417 & 0.487 & 22 & 82 & 0.415 & 0.419 & 15 & 0.27 \\
\hline 210 & 156 & .569 & 249 & 0 & 0.359 & 0.401 & 0.478 & 0.506 & 0.471 & 0.389 & 0.403 & 78 & ( \\
\hline 211 & $1 / 0$ & & & & & & 0.458 & & & & 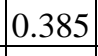 & & -1 \\
\hline 212 & 206 & 527 & 34 & & 0.325 & 0.368 & 0.425 & \begin{tabular}{|l|l|} 
\\
\end{tabular} & 0.432 & 0.349 & 0.350 & 259 & 0.242 \\
\hline 213 & 267 & 0.475 & & & & & 0.387 & & & & 0.308 & 49 & 0.227 \\
\hline 214 & 488 & 54 & & & 0.172 & 0.185 & 0.194 & 24 & 0.191 & 0.199 & 0.206 & 159 & 0.149 \\
\hline 215 & 722 & 0.084 & 0.048 & 0.0 & 0.072 & 0.079 & 0.082 & 0.091 & 0.078 & 0.070 & 0.071 & 0.058 & 0.0 \\
\hline 216 & .903 & 0.012 & 09 & & 0.012 & 12 & 0.013 & 15 & 0.014 & 0.011 & 0.011 & & 0.009 \\
\hline 217 & .577 & 0.299 & 115 & 0 & 0.190 & 0.208 & 0.228 & 0.261 & 0.231 & 0.211 & 0.192 & 155 & 0.127 \\
\hline 218 & 0.581 & 0.291 & & & & 0.192 & 0.213 & & 0.219 & 0.201 & 0.179 & 0.142 & 0 \\
\hline 219 & 0.595 & 0.283 & 0.104 & 0.119 & 0.180 & 0.189 & 0.198 & 0.215 & 0.192 & 0.188 & 0.173 & 0.121 & 0.101 \\
\hline 220 & .609 & 0.269 & 091 & 0 & 0.1 & 0.177 & 0.185 & 0.206 & 0.179 & 0.175 & 0.162 & 0.101 & 0.099 \\
\hline 221 & .637 & 0.239 & \begin{tabular}{|l|l|}
0.087 \\
\end{tabular} & & 0.14 & 0.165 & 0.178 & 0.190 & 0.169 & 0.10 & 0.155 & 0.09 & 0.0 \\
\hline 222 & .753 & 0.130 & 0.058 & 0.072 & 0.084 & 0.091 & 0.109 & 0.121 & 0.111 & 0.095 & 0.082 & 0.079 & 0.0 \\
\hline
\end{tabular}




\begin{tabular}{|c|c|c|c|c|c|c|c|c|c|c|c|c|c|}
\hline q. & $P_{11}$ & $\mathbf{P}_{12}$ & $\mathbf{P}_{13}$ & $\mathbf{P}_{14}$ & $\mathbf{P}_{15}$ & $\mathbf{P}_{\text {CLb }}$ & $\mathbf{P}_{16}$ & $\mathbf{P}_{17}$ & $\mathbf{P}_{18}$ & $\mathbf{P}_{19}$ & $\mathbf{P}_{20}$ & $\mathbf{P}_{\text {avg. }}$ & \\
\hline 78 & & & & & & & & & & & & & \\
\hline & & & & & & & & & & & & & \\
\hline & & & & & & & & & & & & & \\
\hline 31 & & 78 & 12 & & & & & & & & & & \\
\hline & & & & & & & & & & & & & \\
\hline & & & & & & & & & & & & & \\
\hline 34 & & 06 & 07 & 08 & & & & & & & & & 83 \\
\hline & & & & & & & & & & & & & \\
\hline & & & & & & & & & & & & & \\
\hline 37 & & & 203 & 05 & & & & & & & & & \\
\hline & & & & & & & & & & & & & \\
\hline & & & & & & & & & & & & & \\
\hline 90 & & & 07 & & & & & & & & & & $66 /$ \\
\hline & & & & & & & & & & & & & \\
\hline & & & & & & & & & & & & & \\
\hline & & 32 & 733 & 08 & & & & & & & & & .853 \\
\hline & & & & & & & & & & & & & \\
\hline & & & 41 & & & & & & & & & & \\
\hline 66 & & 98 & 504 & & & & & & & & & & .39 \\
\hline & & & & & & & & & & & & & 72 \\
\hline & & 2 & 3 & & & & & & & & & & 125 \\
\hline 99 & & 89 & 212 & & & & & & & & & & .13 \\
\hline & & & & & & & & & & & & & \\
\hline 1 & & 46 & 43 & & & & & & & & & & 422 \\
\hline 22 & & 88 & & & & & & & & & & & 498 \\
\hline & & & & & & & & & & & & & \\
\hline 4 & & 35 & 50 & & & & 1 & 23 & & & & & 41 \\
\hline 5 & & & 564 & & & & & & & & & & $3 / 2$ \\
\hline & & & & & & & & & & & & & .359 \\
\hline 77 & & & 14 & & & & & & & & & & 518 \\
\hline 8 & & & & & & & & & & & & 8 & .386 \\
\hline $0 S$ & 259 & 9 & 427 & 8 & & & & & & & & & .75 \\
\hline 210 & & 90 & & & & & & & & & & & \\
\hline 211 & & & 398 & & & & & 6 & & & & & .82 \\
\hline & & & & & & & & & & & & & .87 \\
\hline & & & & & & & & & & & & & \\
\hline 21 & & & 87 & & & & & & & & & & 30 \\
\hline & & & & & & & & & & & & & 65 \\
\hline & & & & & & & & & & & & & 094 \\
\hline 21 & & & 10 & & & & & & & & & 34 & .39 \\
\hline 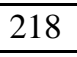 & & & & & & & & & & & & & . \\
\hline & & & & & & & & & & & & & .432 \\
\hline 220 & & & 37 & & & & & 36 & 81 & 32 & 4 & 49 & .46 \\
\hline & & & & & & & & & & & & & \\
\hline 22 & $00 J$ & 002 & 104 & 100 & & .126 & .1 & 0.1 & & $0.07 /$ & 0.05 & 0.089 & .00 \\
\hline
\end{tabular}




\begin{tabular}{|c|c|c|c|c|c|c|c|}
\hline Seq. & $\mathbf{X}_{\mathrm{w} / \mathbf{0}}$ & $\mathbf{X}_{\text {end }}$ & $\mathbf{X}_{\text {damper }}$ & $\log \left(X_{\text {damper }}\right)$ & $\mathbf{V}_{\text {avg. }}$ & $\operatorname{Re}$ & Pipe Factor \\
\hline 178 & 1.7291 & 2.026 & 0.2797 & -0.553 & 2317.63 & 246863.95 & 0.906 \\
\hline 179 & 1.7291 & 2.282 & 0.5338 & -0.273 & 2268.32 & 241611.38 & 928 \\
\hline 180 & \begin{tabular}{|l|}
1.7291 \\
\end{tabular} & 2.606 & 0.8558 & -0.068 & 2215.27 & 235960.99 & 0.906 \\
\hline 181 & 1.7291 & 3.301 & 1.5440 & 0.189 & 2066.93 & 220160.58 & 0.905 \\
\hline 182 & 1.7291 & 7.107 & 5.3265 & 0.726 & 1617.91 & 172332.48 & 0.910 \\
\hline 183 & \begin{tabular}{|l|}
1.7291 \\
\end{tabular} & 57.836 & 55.9734 & 1.748 & 657.55 & \begin{tabular}{|l|}
70039.32 \\
\end{tabular} & 0.862 \\
\hline 184 & 1.7291 & 282.246 & 280.3205 & 2.448 & 309.85 & \begin{tabular}{|l|}
33003.98 \\
\end{tabular} & 0.737 \\
\hline 185 & 2.1433 & 2.143 & 0.0000 & & 1631.49 & 173779.41 & 0.842 \\
\hline 186 & 2.1433 & 2.392 & 0.2297 & -0.639 & 1584.04 & 168725.35 & 0.843 \\
\hline 187 & 2.1433 & 2.663 & 0.4973 & -0.303 & 1534.67 & 163466.74 & 0.838 \\
\hline 188 & 2.1433 & 3.096 & 0.9259 & -0.033 & 1468.19 & 156385.68 & 0.813 \\
\hline 189 & \begin{tabular}{|l|}
2.1433 \\
\end{tabular} & 3.594 & 1.4207 & 0.153 & 1417.66 & 151002.58 & 0.823 \\
\hline 190 & 2.1433 & 7.518 & 5.3233 & 0.726 & 1131.52 & 120524.85 & 0.841 \\
\hline 191 & 2.1433 & 24.316 & 22.0775 & 1.344 & 707.34 & \begin{tabular}{|l|}
75342.51 \\
\end{tabular} & 0.837 \\
\hline 192 & 2.1433 & 163.341 & 161.0256 & 2.207 & 291.65 & 31065.57 & 0.662 \\
\hline 193 & 1.8833 & 1.687 & -0.1965 & & 5205.14 & 554429.10 & 0.896 \\
\hline 194 & 1.8833 & 2.005 & 0.1096 & -0.960 & 5158.51 & 549461.85 & 0.900 \\
\hline 195 & \begin{tabular}{|l|}
1.8833 \\
\end{tabular} & 2.106 & 0.2069 & $\begin{array}{l}-0.684 \\
\end{array}$ & 4928.97 & 525012.26 & 0.872 \\
\hline 196 & 1.8833 & 2.334 & 0.4319 & -0.365 & 4826.30 & 514076.87 & 0.874 \\
\hline 197 & 1.8833 & 2.820 & 0.9134 & -0.039 & 4601.24 & 490104.54 & 0.896 \\
\hline 198 & 1.8833 & 7.278 & 5.3414 & 0.728 & 3358.31 & 357712.68 & 0.898 \\
\hline 199 & 1.8833 & 29.118 & 27.1263 & 1.433 & 1836.90 & 195658.30 & 0.856 \\
\hline 200 & 1.8833 & 225.309 & 223.2345 & 2.349 & 691.94 & \begin{tabular}{|l|}
73702.22 \\
\end{tabular} & 0.905 \\
\hline 201 & 1.7312 & 1.731 & 0.0000 & & 3482.52 & 370943.40 & 0.904 \\
\hline 202 & $\mid 1.7312$ & 1.940 & 0.1954 & -0.709 & 3376.74 & 359676.09 & 0.902 \\
\hline 203 & 1.7312 & 2.044 & 0.2984 & -0.525 & 3334.46 & \begin{tabular}{|l|}
355172.74 \\
\end{tabular} & 0.911 \\
\hline 204 & 1.7312 & 2.330 & 0.5814 & -0.236 & 3224.61 & 343471.28 & 0.901 \\
\hline 205 & $\mid 1.7312$ & 2.988 & 1.2331 & 0.091 & 3041.44 & 323961.16 & 0.907 \\
\hline 206 & 1.7312 & 5.580 & 3.8061 & 0.580 & 2498.76 & 266157.39 & 0.909 \\
\hline 207 & 1.7312 & 39.312 & 37.4777 & 1.574 & 1302.78 & \begin{tabular}{|l|}
138766.21 \\
\end{tabular} & 0.873 \\
\hline 208 & 1.7312 & 297.428 & 295.5147 & 2.471 & 517.12 & 55081.63 & 0.878 \\
\hline 209 & 1.9729 & 1.973 & 0.0000 & & 2376.29 & 253112.61 & 0.856 \\
\hline 210 & 1.9729 & 2.147 & 0.1577 & -0.802 & 2329.92 & 248173.04 & 0.852 \\
\hline 211 & $\mid 1.9729$ & 2.374 & 0.3824 & -0.417 & 2268.48 & 241629.20 & 0.843 \\
\hline 212 & 1.9729 & 2.671 & 0.6765 & -0.170 & 2203.31 & \begin{tabular}{|l|}
234686.59 \\
\end{tabular} & 0.843 \\
\hline 213 & 1.9729 & 3.252 & 1.2521 & 0.098 & 2098.54 & \begin{tabular}{|l|}
223527.38 \\
\end{tabular} & 0.851 \\
\hline 214 & $\mid 1.9729$ & 7.296 & 5.2723 & 0.722 & 1628.05 & 173412.36 & 0.883 \\
\hline 215 & 1.9729 & 26.288 & 24.2163 & 1.384 & 965.67 & \begin{tabular}{|l|}
102858.99 \\
\end{tabular} & 0.865 \\
\hline 216 & 1.9729 & 199.594 & 197.4405 & 2.295 & 374.42 & \begin{tabular}{|l|}
39881.83 \\
\end{tabular} & 0.857 \\
\hline 217 & 2.1320 & 2.132 & 0.0000 & & 1646.58 & 175386.35 & 0.844 \\
\hline 218 & 2.1320 & 2.380 & 0.2292 & -0.640 & 1598.64 & 170280.23 & 0.846 \\
\hline 219 & 2.1320 & 2.650 & 0.4961 & -0.304 & 1548.83 & \begin{tabular}{|l|}
164974.69 \\
\end{tabular} & 0.841 \\
\hline 220 & 2.1320 & 3.083 & 0.9243 & -0.034 & 1481.61 & 157815.03 & 0.816 \\
\hline 221 & 2.1320 & 3.581 & 1.4190 & 0.152 & 1430.55 & 152375.94 & 0.826 \\
\hline 222 & 2.1320 & 7.507 & 5.3238 & 0.726 & 1141.32 & 121568.38 & 0.847 \\
\hline
\end{tabular}




\begin{tabular}{|c|c|c|c|c|c|c|c|c|c|c|c|c|}
\hline Seq. & Year & Month & Date & Time & $\mathbf{T}_{\text {act }}$ & $\mathbf{P}_{\text {bar }}$ & I & D & $\mathbf{V P}_{\text {CLopen }}$ & Orient & Edge & I/D \\
\hline 223 & 2005 & 12 & 10 & 18.50 & 24 & 29.78 & 2.5 & 3.85 & 0.255 & 0 & Strt. & 0.649 \\
\hline 224 & 2005 & 12 & 10 & 18.50 & 24 & 29.78 & 3.2 & 3.85 & 0.255 & 0 & Strt. & 0.831 \\
\hline 225 & 2005 & 12 & 31 & 11.00 & 27 & 29.80 & 0 & 3.85 & 2.103 & 1 & Strt. & 0.000 \\
\hline 226 & 2005 & 12 & 31 & 11.00 & 27 & 29.80 & 0.5 & 3.85 & 2.103 & 1 & Strt. & 0.130 \\
\hline 227 & 2005 & 12 & 31 & 11.00 & 27 & 29.80 & 0.7 & 3.85 & 2.103 & 1 & Strt. & 0.182 \\
\hline 228 & 2005 & 12 & 31 & 11.00 & 27 & 29.80 & 0.9 & 3.85 & 2.103 & 1 & Strt. & 0.234 \\
\hline 229 & 2005 & 12 & 31 & 11.00 & 27 & 29.80 & 1.2 & 3.85 & 2.103 & 1 & Strt. & 0.312 \\
\hline 230 & 2005 & 12 & 31 & 11.00 & 27 & 29.80 & 1.8 & 3.85 & 2.103 & 1 & Strt. & 0.468 \\
\hline 231 & 2005 & 12 & 31 & 11.00 & 27 & 29.80 & 2.5 & 3.85 & 2.103 & 1 & Strt. & 0.649 \\
\hline 232 & 2005 & 12 & 31 & 11.00 & 27 & 29.80 & 3.2 & 3.85 & 2.103 & 1 & Strt. & 0.831 \\
\hline 233 & 2005 & 12 & 31 & 13.00 & 26 & 29.80 & 0 & 3.85 & 1.010 & 1 & Strt. & 0.000 \\
\hline 234 & 2005 & 12 & 31 & 13.00 & 26 & 29.80 & 0.5 & 3.85 & 1.010 & 1 & Strt. & 0.130 \\
\hline 235 & 2005 & 12 & 31 & 13.00 & 26 & 29.80 & 0.7 & 3.85 & 1.010 & 1 & Strt. & 0.182 \\
\hline 236 & 2005 & 12 & 31 & 13.00 & 26 & 29.80 & 0.9 & 3.85 & 1.010 & 1 & Strt. & 0.234 \\
\hline 237 & 2005 & 12 & 31 & 13.00 & 26 & 29.80 & 1.2 & 3.85 & 1.010 & 1 & Strt. & 0.312 \\
\hline 238 & 2005 & 12 & 31 & 13.00 & 26 & 29.80 & 1.8 & 3.85 & 1.010 & 1 & Strt. & 0.468 \\
\hline 239 & 2005 & 12 & 31 & 13.00 & 26 & 29.80 & 2.5 & 3.85 & 1.010 & 1 & Strt. & 0.649 \\
\hline 240 & 2005 & 12 & 31 & 13.00 & 26 & 29.80 & 3.2 & 3.85 & 1.010 & 1 & Strt. & 0.831 \\
\hline 241 & 2005 & 12 & 31 & 16.00 & 26 & 29.78 & 0 & 3.85 & 0.510 & 1 & Strt. & 0.000 \\
\hline 242 & 2005 & 12 & 31 & 16.00 & 26 & 29.78 & 0.5 & 3.85 & 0.510 & 1 & Strt. & 0.130 \\
\hline 243 & 2005 & 12 & 31 & 16.00 & 26 & 29.78 & 0.7 & 3.85 & 0.510 & 1 & Strt. & 0.182 \\
\hline 244 & 2005 & 12 & 31 & 16.00 & 26 & 29.78 & 0.9 & 3.85 & 0.510 & 1 & Strt. & 0.234 \\
\hline 245 & 2005 & 12 & 31 & 16.00 & 26 & 29.78 & 1.2 & 3.85 & 0.510 & 1 & Strt. & 0.312 \\
\hline 246 & 2005 & 12 & 31 & 16.00 & 26 & 29.78 & 1.8 & 3.85 & 0.510 & 1 & Strt. & 0.468 \\
\hline 247 & 2005 & 12 & 31 & 16.00 & 26 & 29.78 & 2.5 & 3.85 & 0.510 & 1 & Strt. & 0.649 \\
\hline 248 & 2005 & 12 & 31 & 16.00 & 26 & 29.78 & 3.2 & 3.85 & 0.510 & 1 & Strt. & 0.831 \\
\hline 249 & 2005 & 12 & 31 & 18.50 & 24 & 29.78 & 0 & 3.85 & 0.255 & 1 & Strt. & 0.000 \\
\hline 250 & 2005 & 12 & 31 & 18.50 & 24 & 29.78 & 0.5 & 3.85 & 0.255 & 1 & Strt. & 0.130 \\
\hline 251 & 2005 & 12 & 31 & 18.50 & 24 & 29.78 & 0.7 & 3.85 & 0.255 & 1 & Strt. & 0.182 \\
\hline 252 & 2005 & 12 & 31 & 18.50 & 24 & 29.78 & 0.9 & 3.85 & 0.255 & 1 & Strt. & 0.234 \\
\hline 253 & 2005 & 12 & 31 & 18.50 & 24 & 29.78 & 1.2 & 3.85 & 0.255 & 1 & Strt. & 0.312 \\
\hline 254 & 2005 & 12 & 31 & 18.50 & 24 & 29.78 & 1.8 & 3.85 & 0.255 & 1 & Strt. & 0.468 \\
\hline 255 & 2005 & 12 & 31 & 18.50 & 24 & 29.78 & 2.5 & 3.85 & 0.255 & 1 & Strt. & 0.649 \\
\hline 256 & 2005 & 12 & 31 & 18.50 & 24 & 29.78 & 3.2 & 3.85 & 0.255 & 1 & Strt. & 0.831 \\
\hline
\end{tabular}




\begin{tabular}{|c|c|c|c|c|c|c|c|c|c|c|c|c|c|}
\hline eq. & end & Hood & $V_{P_{1}}$ & $\mathbf{V P}_{2}$ & $\mathbf{V P}_{3}$ & $\mathbf{V P}_{4}$ & $\mathbf{V P}_{5}$ & $V P_{\text {CLa }}$ & $\mathrm{VP}_{6}$ & $\mathbf{V P}_{7}$ & $\mathrm{VP}_{8}$ & $\mathrm{VP}_{9}$ & $\mathbf{V P}_{\mathbf{1 0}}$ \\
\hline 223 & 875 & 0.051 & 021 & & 0.032 & 0.039 & 0.046 & 0.047 & 0.042 & 0.037 & 031 & 0.022 & .027 \\
\hline 224 & 966 & 009 & .003 & 0.004 & 0.006 & 0.008 & 0.010 & 011 & .010 & 0.007 & 0.006 & 005 & .004 \\
\hline 225 & 485 & 382 & 245 & 1.487 & 1.683 & 1.858 & 2.050 & 667 & & & 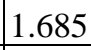 & & 233 \\
\hline 226 & 932 & 986 & 126 & & 606 & 1.786 & 1.962 & 001 & 977 & 1.792 & 1.646 & 434 & 095 \\
\hline 227 & 652 & 39 & 32 & & 1.480 & 1.562 & 1.840 & 940 & & 1.681 & 1.515 & & \\
\hline 228 & 788 & 92 & 078 & 1. & 54 & 1.505 & 1.805 & 343 & 90 & 1.651 & 1.445 & 38 & 066 \\
\hline 229 & 989 & 861 & 027 & & 315 & 1.419 & 1.472 & 585 & & 1.452 & 1.289 & & 1.015 \\
\hline 230 & 769 & 008 & 500 & & & 0.745 & 0.800 & 834 & 785 & .748 & 775 & & 400 \\
\hline 231 & 285 & 57 & 110 & 0 & 0.162 & 0.202 & 0.228 & 255 & 213 & 0.209 & 0.172 & & 098 \\
\hline 232 & 705 & 26 & 0.020 & & & 0.026 & 0.028 & 34 & & $0.0<8$ & 0.025 & & 0.020 \\
\hline 233 & 203 & & & & & 0.884 & 0.909 & & & 0.852 & 0.776 & & 0.634 \\
\hline 234 & 230 & 1.306 & 0.566 & 0.672 & 0. & 0.797 & 0.857 & 90 & & 0.761 & 0.714 & & 0.581 \\
\hline 235 & 252 & 61 & & & 0.148 & 96 & 0.855 & 360 & & 0.103 & 0.696 & & - \\
\hline 236 & 305 & 181 & 525 & 0 & 0.692 & \begin{tabular}{|l|}
0.761 \\
\end{tabular} & 0.808 & 820 & 98 & 0.711 & 0.654 & & .511 \\
\hline 237 & 458 & 18 & 42 & & 0 & 0.646 & 0.698 & 12 & & 0.611 & 0.543 & & $0.4 \mathrm{~J} 2$ \\
\hline 238 & 742 & 78 & & & 0.385 & 0.418 & 0.450 & 63 & & 0.393 & 0.347 & & 0.284 \\
\hline 239 & 593 & 0.194 & 0.044 & 0 & 51 & 0.065 & 0.076 & 96 & 34 & 0.075 & 0.064 & & 0.045 \\
\hline 240 & & & & & & & 0.016 & & & 0.016 & 0.014 & & 009 \\
\hline 241 & 116 & 0.575 & 0.237 & 0 & 333 & 0.387 & 0.457 & 0.492 & 452 & 0.385 & 0.389 & & .249 \\
\hline 242 & 36 & 49 & & & & 0. & 0.448 & & & 0.359 & 0.373 & & 235 \\
\hline 243 & 155 & 534 & 218 & 0 & 0.318 & 0.358 & 0.428 & 449 & 0.432 & 0.351 & 0.355 & 25 & 0.219 \\
\hline 244 & 186 & 0.507 & 0.204 & & 0. & 0.338 & 0.395 & 29 & 02 & 0.319 & 0.320 & & 0.212 \\
\hline 245 & 247 & 55 & 90 & 0 & 0.287 & 0.299 & 0.357 & 371 & 0.363 & 0.271 & 0.278 & 0. & 0.197 \\
\hline 246 & 468 & 0.234 & 0.108 & 0.1 & 0.142 & 0.155 & 0.164 & 0.194 & 0.161 & 0.169 & 0.176 & 0. & $0.11 \mathrm{c}$ \\
\hline 247 & 702 & & & & & & 0.052 & & & 0.040 & 0.041 & & 0.016 \\
\hline 248 & 1.883 & 0.010 & 0.006 & 0.007 & 0.009 & 0.009 & 0.010 & 0.012 & 0.011 & \begin{tabular}{|l|}
0.008 \\
\end{tabular} & 0.008 & 0.007 & 0.006 \\
\hline 249 & 0.547 & 0.269 & 0.095 & & 0.170 & 0.188 & 0.208 & 0.241 & 0.211 & 0.191 & 0.172 & & 0.107 \\
\hline 250 & 0.557 & 0.261 & 0.089 & 0.102 & 0.167 & 0.172 & 0.193 & 0.212 & 0.199 & 0.181 & 0.159 & 0.12 & .095 \\
\hline 251 & 0.565 & 0.253 & 0.084 & 0.099 & 0.160 & 0.169 & 0.178 & 0.195 & 0.172 & 0.168 & 0.153 & 0.101 & 0.081 \\
\hline 252 & $0.5 / 9$ & 0.259 & 0.071 & 0.081 & 0.141 & $0.15 /$ & 0.165 & 0.186 & 0.159 & 0.155 & 0.142 & 0.001 & $0.0 / 5$ \\
\hline 253 & 0.607 & 0.209 & 0.067 & 0.075 & 0.125 & 0.145 & 0.158 & 0.170 & 0.149 & 0.142 & 0.135 & 0.079 & 0.065 \\
\hline 254 & 0.723 & 0.100 & 0.038 & 0.052 & 0.064 & \begin{tabular}{|l|}
0.071 \\
\end{tabular} & 0.089 & 0.101 & 0.091 & 0.075 & 0.062 & & 0.029 \\
\hline 255 & 0.845 & 0.021 & 0.001 & 0.009 & 0.012 & 0.019 & 0.026 & 0.027 & 0.022 & 0.017 & 0.011 & 0.002 & 0.007 \\
\hline 256 & 0.936 & 0.006 & 0.001 & 0.002 & 0.004 & 0.006 & 0.008 & 0.009 & 0.008 & 0.005 & 0.004 & 0.003 & 0.002 \\
\hline
\end{tabular}




\begin{tabular}{|c|c|c|c|c|c|c|c|c|c|c|c|c|c|}
\hline & $P_{11}$ & $P_{12}$ & $\mathbf{P}_{13}$ & $P_{14}$ & $\mathbf{P}_{15}$ & $\mathbf{P}_{\text {CLb }}$ & $\mathbf{P}_{16}$ & 17 & 18 & $\overline{\mathbf{P}_{19}}$ & $\mathbf{P}_{20}$ & $\mathbf{P}_{\text {avg. }}$ & \\
\hline 3 & & & & & & & & & & & & & \\
\hline & & & & & & & & & & & & & \\
\hline 25 & & & & & & & & & & & & & \\
\hline & & & & & & & & & & & & & \\
\hline & & & & & & & & & & & & & \\
\hline 28 & 994 & 58 & 64 & & $\overline{9}$ & & & 48 & & & & & \\
\hline 2 & & & & & & & & & & & & & \\
\hline & & & & & & & & & & & & & \\
\hline 231 & 131 & & & & 21 & & & & & & & & .11 \\
\hline & & & & & & & & & & & & & \\
\hline 233 & & & & & & & & & & & & & \\
\hline 234 & 89 & 38 & 02 & & 97 & & & & & & & & 50 \\
\hline & & & & & & & & & & & & & \\
\hline 36 & & & & & & & & & & & & & \\
\hline 37 & 54 & & & & & & & & & & & & 382 \\
\hline $3 \varepsilon$ & & & & & & & & & & & & & \\
\hline 239 & & & & & & & & & & & & & \\
\hline 240 & & & & & & & & & & & & & כטי \\
\hline 4 & & & & & & & & & & & & & .85 \\
\hline 42 & & & & & & & & & & & & & .79 \\
\hline 24 & & & & & & & & & & & & & 03 \\
\hline 24 & & & & & & & & & & & & & .88 \\
\hline 45 & & & 07 & & & & & 62 & & & & & $\overline{97}$ \\
\hline 24 & & & & & & & & & & & & & 31 \\
\hline 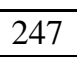 & & & & & & & & & & & & & .66 \\
\hline 248 & & 4 & 5 & & 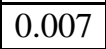 & & & & & & & & 87 \\
\hline 24 & & & D & & & & & 18 & & & & 4 & .38 \\
\hline 250 & & & & & & & & 11 & & & & & .40 \\
\hline 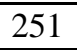 & & & & & & & & & & & & & 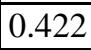 \\
\hline 252 & 32 & & & & & & & & & & & 19 & .45 \\
\hline 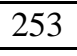 & & & & & & & & & & & & & .48 \\
\hline 25 & & & 84 & & & & & & & & & & 165 \\
\hline 255 & & & & & & & & & & & & & 83 \\
\hline 56 & 001 & & 2 & & & & & & & & & & .93 \\
\hline
\end{tabular}




\begin{tabular}{|c|c|c|c|c|c|c|c|}
\hline Seq. & $\mathbf{X}_{\mathrm{w} / \mathbf{0}}$ & $\mathbf{X}_{\text {end }}$ & $\mathbf{X}_{\text {damper }}$ & $\log \left(X_{\text {damper }}\right)$ & $\mathbf{V}_{\text {avg. }}$ & $\mathbf{R e}$ & Pipe Factor \\
\hline 223 & 2.1320 & 24.349 & 22.1217 & 1.345 & 712.74 & \begin{tabular}{|l|}
75917.87 \\
\end{tabular} & 0.852 \\
\hline 224 & 2.1320 & 166.571 & 164.2667 & 2.216 & 291.27 & 31024.72 & .708 \\
\hline 225 & 1.7161 & 1.716 & 0.0000 & & 4943.26 & 526534.66 & .894 \\
\hline 226 & 1.7161 & 2.042 & 0.3134 & -0.504 & 4897.89 & 521701.54 & .898 \\
\hline 227 & 1.7161 & 2.151 & 0.4170 & -0.380 & 4674.39 & 497895.99 & 0.869 \\
\hline 228 & 1.7161 & 2.386 & 0.6504 & -0.187 & 4574.33 & 487237.92 & .871 \\
\hline 229 & 1.7161 & 2.893 & 1.1522 & 0.062 & 4354.92 & 463867.66 & 0.893 \\
\hline 230 & 1.7161 & 7.690 & 5.9176 & 0.772 & 3134.38 & 333860.37 & 892 \\
\hline 231 & 1.7161 & 35.930 & 34.0959 & 1.533 & 1586.95 & 169035.45 & 0.829 \\
\hline 232 & 1.7161 & 258.044 & 256.1307 & 2.408 & 618.89 & 65921.60 & 893 \\
\hline 233 & 1.8572 & 1.857 & 0.0000 & & 3374.37 & 359423.07 & 898 \\
\hline 234 & 1.8572 & 2.089 & 0.2154 & -0.667 & 3264.99 & 347772.11 & 0.896 \\
\hline 235 & 1.8572 & 2.205 & 0.3298 & -0.482 & 3221.27 & 343 & 905 \\
\hline 236 & 1.8572 & 2.525 & 0.6466 & -0.189 & 3107.38 & 330984.70 & 894 \\
\hline 237 & 1.8572 & 3.267 & 1.3819 & 0.140 & 2916.74 & 310679.00 & 0.900 \\
\hline 238 & 1.8572 & 6.361 & 4.4550 & 0.649 & 2345.44 & 249826.18 & 898 \\
\hline 239 & 1.8572 & 70.095 & 68.1094 & 1.833 & 976.75 & 104039.29 & 800 \\
\hline 240 & 1.8572 & 409.380 & 407.3274 & 2.610 & 439.35 & 46797.24 & 0.841 \\
\hline 241 & 2.1737 & 2.174 & 0.0000 & & 2279.57 & 242809.40 & 0.845 \\
\hline 242 & 2.1737 & 2.373 & 0.1785 & -0.748 & 2231.01 & 237637.10 & 0.841 \\
\hline 243 & 2.1737 & 2.637 & 0.4395 & -0.357 & 2166.42 & 230757.78 & 0.831 \\
\hline 244 & 2.1737 & 2.981 & 0.7812 & -0.107 & 2098.09 & 223479.82 & 0.830 \\
\hline 245 & 2.1737 & 3.661 & 1.4560 & 0.163 & 1988.27 & 211781.67 & 0.837 \\
\hline 246 & 2.1737 & 8.846 & 6.6128 & 0.820 & 1484.33 & 158104.80 & 0.864 \\
\hline 247 & 2.1737 & 51.203 & 48.9013 & 1.689 & 694.11 & \begin{tabular}{|l|}
73934.09 \\
\end{tabular} & 0.775 \\
\hline 248 & 2.1737 & 291.777 & 289.4065 & 2.462 & 308.29 & 32837.62 & 0.806 \\
\hline 249 & 2.3386 & 2.339 & 0.0000 & & 1552.81 & 165398.70 & 0.829 \\
\hline 250 & 2.3386 & 2.636 & 0.2718 & -0.566 & 1501.59 & 159942.58 & 0.829 \\
\hline 251 & 2.3386 & 2.964 & 0.5964 & -0.224 & 1448.38 & 154275.61 & 0.823 \\
\hline 252 & 2.3386 & 3.502 & 1.1295 & 0.053 & 1375.80 & 146544.59 & 0.794 \\
\hline 253 & 2.3386 & 4.122 & 1.7455 & 0.242 & 1320.67 & 140672.09 & 0.803 \\
\hline 254 & 2.3386 & 9.624 & 7.2215 & 0.859 & 1000.76 & 106596.68 & 0.811 \\
\hline 255 & 2.3386 & 60.906 & 58.4311 & 1.767 & 448.20 & 47739.94 & 0.705 \\
\hline 256 & 2.3386 & 257.338 & 254.8079 & 2.406 & 230.91 & 24595.91 & 0.618 \\
\hline
\end{tabular}

